Final Report

FHWA/IN/JTRP-2003/26

\title{
USING PRECAST CONCRETE PANELS FOR PAVEMENT CONSTRUCTION IN INDIANA
}

\author{
By \\ Luh M. Chang \\ Associate Professor \\ Principal Investigator \\ and \\ Yu-Tzu Chen \\ Research Assistant \\ Sangwook Lee \\ Research Assistant \\ School of Civil Engineering \\ Purdue University
Joint Transportation Research Program
Project No. C-36-46X
File No. 5-11-24
SPR - 2779 \\ Prepared in Cooperation with the \\ Indiana Department of Transportation and \\ The U.S. Department of Transportation \\ Federal Highway Administration \\ Purdue University \\ West Lafayette, IN 47907 \\ June 2004
}




\begin{tabular}{|c|c|c|c|c|}
\hline $\begin{array}{l}\text { 1. Report No. } \\
\text { FHWA/IN/JTRP-2003/26 }\end{array}$ & \multicolumn{2}{|c|}{ 2. Government Accession No. } & \multicolumn{2}{|c|}{ 3. Recipient's Catalog No. } \\
\hline \multirow{2}{*}{\multicolumn{3}{|c|}{$\begin{array}{l}\text { 4. Title and Subtitle } \\
\text { Using Precast Concrete Panels for Pavement Construction in Indiana }\end{array}$}} & \multicolumn{2}{|l|}{$\begin{array}{l}\text { 5. } \quad \text { Report Date } \\
\text { June } 2004\end{array}$} \\
\hline & & & \multicolumn{2}{|c|}{ 6. Performing Organization Code } \\
\hline \multicolumn{3}{|c|}{$\begin{array}{l}\text { 9. Performing Organization Name and Address } \\
\text { Joint Transportation Research Program } \\
1284 \text { Civil Engineering Building } \\
\text { Purdue University } \\
\text { West Lafayette, IN 47907-1284 }\end{array}$} & \multicolumn{2}{|c|}{ 10. Work Unit No. } \\
\hline \multicolumn{3}{|c|}{$\begin{array}{l}\text { 12. Sponsoring Agency Name and Address } \\
\text { Indiana Department of Transportation } \\
\text { State Office Building } \\
100 \text { North Senate Avenue } \\
\text { Indianapolis, IN } 46204\end{array}$} & \multicolumn{2}{|c|}{$\begin{array}{l}\text { 13. Type of Report and Period Covered } \\
\text { Final Report }\end{array}$} \\
\hline \multicolumn{5}{|l|}{$\begin{array}{l}\text { 15. Supplementary Notes } \\
\text { Prepared in cooperation with } t\end{array}$} \\
\hline \multicolumn{5}{|c|}{$\begin{array}{l}\text { 16. Abstract } \\
\text { The closure of roadways for new pavement, overlays, or removal and replacement applications constantly causes } \\
\text { traffic congestions. To minimize the effects of traffic congestions, the study is intended to assess the feasibility of using } \\
\text { Precsat Concrete Pavement (PCP) method in INDOT pavement construction. } \\
\text { The research investigated the state-of-the-art of the PCP methods lately developed in United States. The } \\
\text { conventional concrete pavement methods such as Portland Cement Concrete Pavement (PCCP) including Jointed Plain } \\
\text { Concrete Pavement (JPCP), Jointed Reinforced Concrete Pavement (JRCP), and Continuously Reinforced Concrete } \\
\text { Pavement (CRCP) were reviewed and compared with PCP methods. With the speedy construction and lower user impact } \\
\text { cost of PCP, the PCP methods were further studied. It was found that Precast Prestressed Concrete Pavement (PPCP) is used } \\
\text { in Texas and California; Super-slab method in New York. Full Depth Repair method in Michigan; Stitch-in-Time method in } \\
\text { Colorado; the Four-by-Four method in California are repairing methods. Their design concepts, field installation procedures, } \\
\text { merits, pitfalls, costs and applications were evaluated. } \\
\text { With all the comparative advantages and disadvantages, it can be concluded that it is feasible to use PCP in INDOT } \\
\text { pavement construction. Based on the data collected and analyses on the PCP methods identified in this study, TxDOT's } \\
\text { PPCP method posses comparatively distinguishing merits. It is recommended to experiment PPCP method on INDOT } \\
\text { demonstration project as soon as it can. }\end{array}$} \\
\hline \multicolumn{2}{|c|}{$\begin{array}{l}\text { 17. Key Words } \\
\text { expansion joint, hot-mixed asphalt, portland cement concrete, } \\
\text { prestressed concrete, precast pavement, ride quality, } \\
\text { user cost }\end{array}$} & \multicolumn{3}{|c|}{$\begin{array}{l}\text { 18. Distribution Statement } \\
\text { No restrictions. This document is available to the public through the } \\
\text { National Technical Information Service, Springfield, VA } 22161\end{array}$} \\
\hline 19. Security Classif. (of this report) & 20. Security Classif. & is page) & 21. No. of Pages & 22. Price \\
\hline
\end{tabular}

Form DOT F 1700.7 (8-69) 


\section{TECHNICAL Summary}

INDOT Research

Technology Transfer and Project Implementation Information

\section{Using Precast Concrete Panels for Pavement Construction in Indiana}

\section{Introduction}

The increasing number of automobiles pushes many highways far beyond their designed capacity, and results in the deterioration of pavement at a faster rate. To cope with this increased deterioration, highways are often closed for construction of new pavements, overlays, or removal and replacement applications. To minimize the effects of such traffic delays during construction and to expedite the pavement construction, the purpose of this study is to assess the feasibility of using Precsat Concrete Pavement (PCP) in Indiana.

\section{Findings}

A comprehensive review was conducted on various state-of-the-art methods in PCP construction. The review first found the precast prestressed concrete panels method is used in Texas; Super-Slab method in New York. Full Depth Repair method in Michigan; Stitch-inTime method in Colorado; Four-by-Four Slab Replacement method in California are repairing methods. These methods were evaluated in terms of their design concepts, field installation procedures, merits, pitfalls, costs, and applications.

Texas' PPCP and New York's SuperSlab are developed for longer and continuous paving and the other three are for shorter and spot repairing. Therefore, the PPCP and the Super-Slab were selected for further in-depth study. They were compared with conventional cast-in-place concrete pavement. Although the PPCP and Super-Slab methods have a higher construction cost and the industry is not familiar with this new method, PPCP and Super-Slab methods possess the advantages of using precast concrete. The speedness of the laying precast panels not only results in less traffic congestion and delays, but can lower the user costs significantly. In addition, the precasting is under better controlled environment. It leads to a more durable concrete and requires less maintenance.

Comparing Texas' Precast Prestressed Concrete Panels (PPCP) method with New York's Precast Super-Slab (Super-Slab) method, precast Super-Slab is approximate half size of precast concrete panel. With its precision of Supergrader, Super-Slab has better subbase preparation for warped slabs. Nevertheless, due to the application of pre-tension and post-tension on PPCP's concrete, PPCP can have thinner slabs and a more durable concrete in the long run. Moreover, PCCP method is derived from near 20 years laboratory and roadway experiments on cast-in-place post-tensioned method in Texas. The theories are sound and empirically proved. This method holds no patents. The detailed information and experimental data are well documented and accessible. It can be reasonably predicted that the unit cost of PCP will be lowered if the constructed lane length is getting longer and the method can be repeatedly used. 


\section{Implementation}

The study concludes that it is feasible to use PCP in INDOT's pavement construction. Among the various PCP methods identified in this study, PPCP methods posses many comparative advantages. It is recommended that the PPCP method be experimented on an INDOT demonstration project. This is a demonstration project in Indiana for setting the stage for future full-scale implementation. To minimize effects of traffic congestion in this phase, the implementation site for this demonstration project is recommended to be on a non-priority roadway. Meanwhile, the implementation is suggested to be on short stretch of primary route at bridge/overpass, patch project or intersection replacement.

\section{Contacts}

For more information:

Prof. Luh-Maan Chang

Principal Investigator

School of Civil Engineering

Purdue University

West Lafayette IN 47907

Phone: (765) 494-2246

Fax: (765) 494-0644

E-mail: changlm@ecn.purdue.edu
Indiana Department of Transportation

Division of Research

1205 Montgomery Street

P.O. Box 2279

West Lafayette, IN 47906

Phone: (765) 463-1521

Fax: (765) 497-1665

\section{Purdue University}

Joint Transportation Research Program

School of Civil Engineering

West Lafayette, IN 47907-1284

Phone: (765) 494-9310

Fax: (765) 496-7996

jtrp@ecn.purdue.edu

http://www.purdue.edu/jtrp 


\section{TABLE OF CONTENTS}

$\underline{\text { Subject }}$

I. INTRODUCTION

1.1 Problem Statement ........................................................................ 1-2

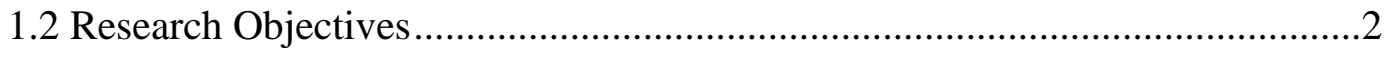

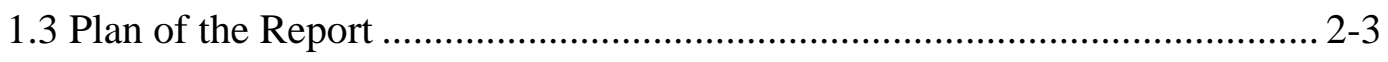

II. METHODOLOGY

2.1 Background and Literature Review ..........................................................4

2.2 Evaluation of Previous Projects .................................................................4

2.3 Conducting Cost Analysis.................................................................... 4-5

2.4 Investigation of Precast Production Capacity ...............................................5

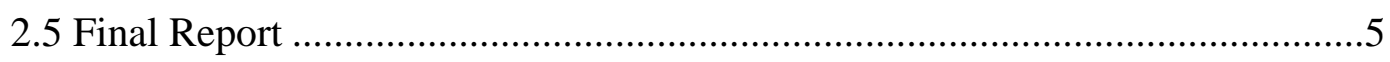

\section{BACKGROUND}

3. Pavement Profile. 6-7

3.1 Precast Prestressed Concrete Pavement................................................. 7-19

3.1.1 Overview of Precast Prestressed Concrete Pavement............................7

3.1.1.1 Precast Concrete............................................................. 7-8

3.1.1.2 Prestressed Concrete .........................................................8

3.1.1.3 Precast Prestressed Concrete Pavement Overview .................8

3.1.1.4 Design Factors and Variables ............................................9

3.1.1.4.1 Design Factors ........................................... 9-11

3.1.1.4.2 Design Variables ......................................... 11-13

3.1.2 Advantages \& Disadvantages .............................................. 14-19

3.1.2.1 Advantages........................................................... 14-17

3.1.2.2 Disadvantages ....................................................... 17-19

3.2 Portland Cement Concrete Pavement (PCCP) ....................................... 20-25

3.1 Overview of Portland Cement Materials and Pavement ................. 20-21

3.2 Advantages \& Disadvantages ................................................ 21-23

3.3 INDOT Experiences.......................................................... 23-25 


\section{PRECAST PRESTRESSED CONCRETE PANELS METHOD}

4.1 Types of Panels ................................................................................. 26-27

4.2 Assembly of Precast Prestressed Concrete Panels ...................................... 28-29

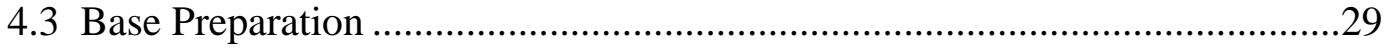

4.4 Georgetown, Texas Project................................................................... 29-30

4.4.1 Construction Procedures .............................................................. 31-39

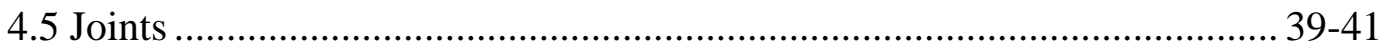

4.6 Advantages \& Disadvantages ............................................................... 41-44

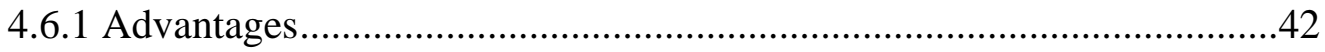

4.6.2 Disadvantages ............................................................................... 43-44

V. SUPER-SLAB

5.1 Precast Concrete Slab Design .............................................................. 45-47

5.2 Field Installation of Super slabs............................................................... 47-49

5.3 Case Study of Super-Slab System-Tappan Zee Bridge Toll

Plaza, Tarrytown, New York ................................................................ 49-50

5.4 Advantages and Concerns of Super-Slab System........................................ 50-51

VI. URETEK METHOD

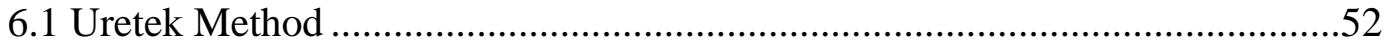

6.2 Stitch-in-Time Technology ……………………….................................. 52-53

6.3 Deep Injection Process................................................................................ 53-54

6.4 Case Study of Uretek Method- Colorado Pilot Project................................. 54-55

6.5 Advantages \& Disadvantages of Three Uretek Methods............................. 55-56

VII. FULL DEPTH REPAIR (FDR) METHOD

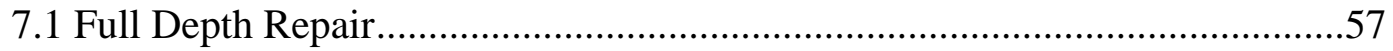

7.2 Construction Procedures ............................................................................... 57-61

7.2.1 Pre-cast Panel Mixture Design and Fabrication.............................. 57-58

7.2.2 Field Installation of Pre-cast Panels.................................................. 58-61

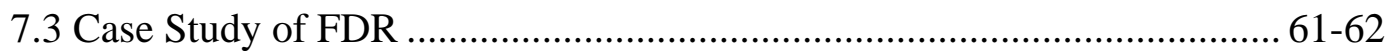

7.4 Advantages \& Disadvantages ......................................................................62 
VIII. FOUR-BY-FOUR METHOD

8.1 Caltrans Slab Replacement Method.......................................................63

8.2 Typical Pavement Section and Slab Replacement..................................63-64

8.3 Field Installation of Caltrans Slab Replacement Method ......................... 64-68

8.4 Caltrans Demonstration Project ............................................................. 69-71

8.5 Advantages \& Concerns of Caltrans Method ...................................... 71-72

IX. COMPARISON

9.1 Comparing PPCP with PCCP and HMA Pavement ............................... 73-79

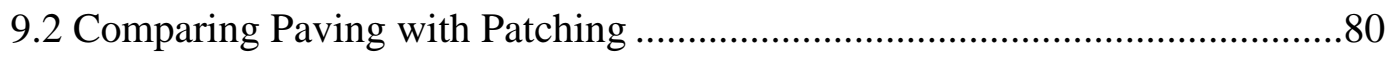

X. RECOMMENDATION AND CONCLUSION.................................... 81-82

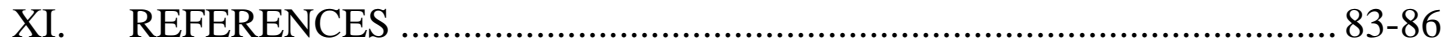




\section{TABLE OF FIGURES}

$\underline{\text { Figures }}$

Figure 3.1. Surface load Distribution of Flexible Pavement (left) and Rigid Pavement ...6

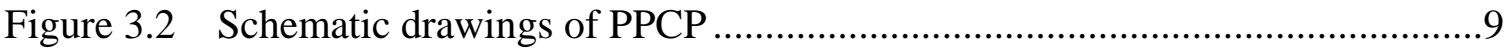

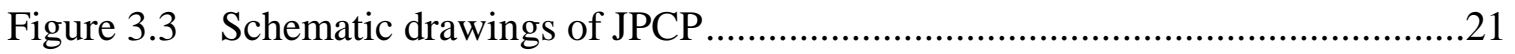

Figure 3.4 The schematic drawings of Portland Cement Concrete Pavement................21

Figure 3.5 The schematic drawing of PCCP with underdrains....................................24

Figure 4.1 Central stressing panel for PPCP .......................................................26

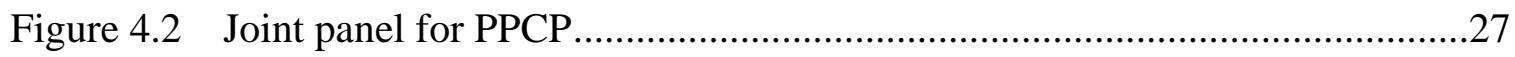

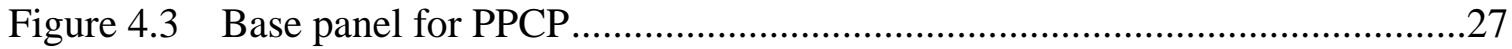

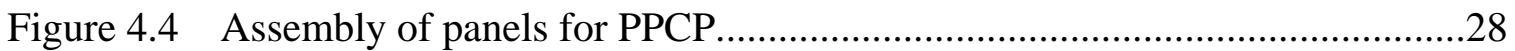

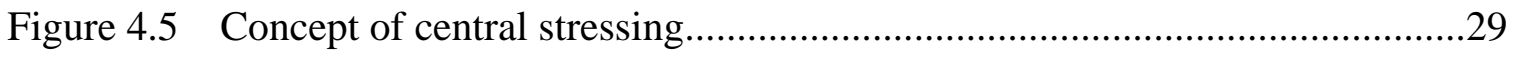

Figure 4.6 Location and layout of the Georgetown PPCP pilot project ........................30

Figure 4.7 The Precast Prestressed Concrete Panels Fabrication plant .........................31

Figure 4.8 Looking down the side (left) and from the top (right) of the casting bed .....31

Figure 4.9 Schematic Diagram of Base Panel ...........................................................32

Figure 4.10 "Boxes/inserts” are placed for preparing the stressing pockets of central stressing panel mold.........................................................................32

Figure 4.11 Schematic diagram of central stressing panel .........................................32

Figure 4.12 Small boxes/inserts are placed in for preparing access pockets of joint panel Mold

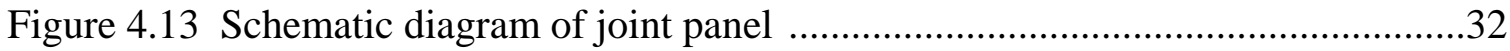

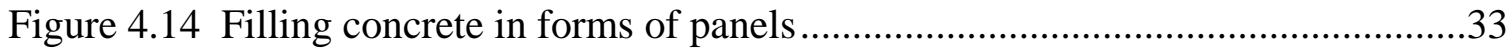

Figure 4.15 Leveling the surface of the concrete.......................................................33

Figure 4.16 Creating surface texture by a carpet drag finish ........................................33

Figure 4.17 Double-coat of curing compound was applied .........................................33

Figure 4.18 Finished set of base panel, central panel, joint panel (from left to right) in the

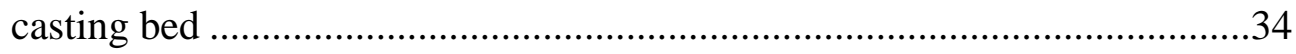

Figure 4.19 Move the finished panels to storage yard ................................................34

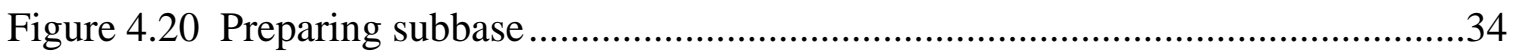


Figure 4.21 Place a 1"-2” thick asphalt leveling course on subbase .34

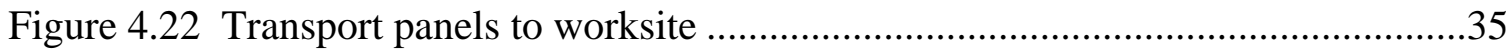

Figure 4.23 Place polyethylene sheet on asphalt course.............................................35

Figure 4.24 Place a full-width joint panel over the asphalt leveling course.....................35

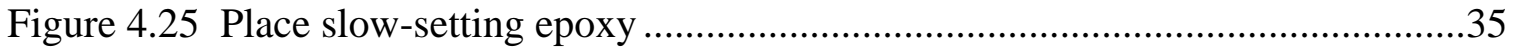

Figure 4.26 Place the base panel next to the joint panel and tie two panels together.......36

Figure 4.27 Place panels in the sequence of joint, base, and central panels ....................36

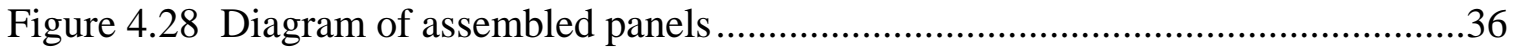

Figure 4.29 Strands will be threaded through the stressing pockets from the central

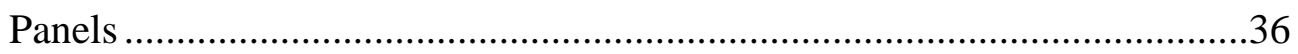

Figure 4.30 Strands from each end of the slab are coupled together (left) and tensioned in the central stressing pockets (right)

Figure 4.31 The schematic diagram of strand coupler used in the central stressing pockets 37

Figure 4.32 Finish the stressing pockets with fast-setting concrete. .37

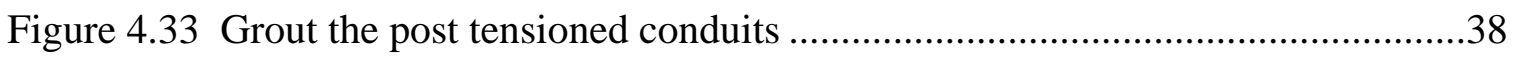

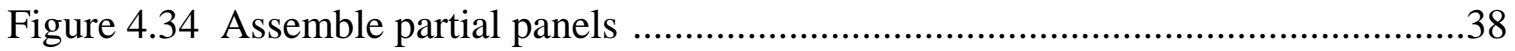

Figure 4.35 The strands will be threaded through the ducts in the panels.......................38

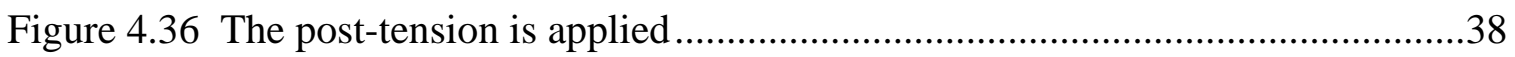

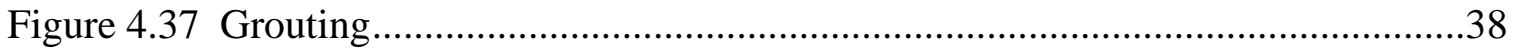

Figure 4.38 The finished precast pavement project in Georgetown, Texas.....................39

Figure 4.39 Expansion Joint Detail of the Joint Panel.................................................40

Figure 4.40 The detailed schematic diagram of spring-loaded post-tensioning anchor ...41

Figure 4.41 Fully encapsulated spring loaded post-tensioning anchor...........................41

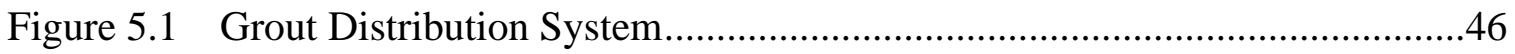

Figure 5.2 Precast Concrete Slab Form ..............................................................47

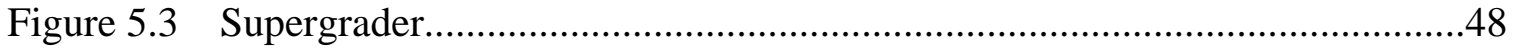

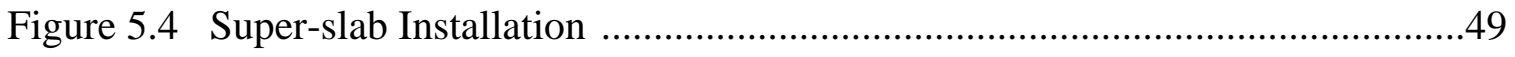

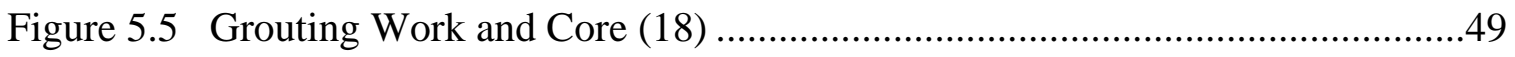

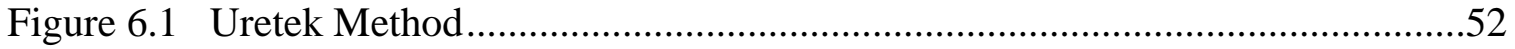

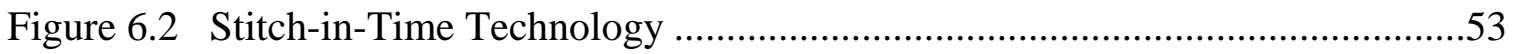




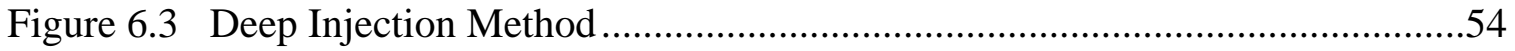

Figure 7.1 Pre-cast Concrete Panel Fabrication Process ...........................................58

Figure 7.2 Lift Hook Installation and Slab Removal ...............................................59

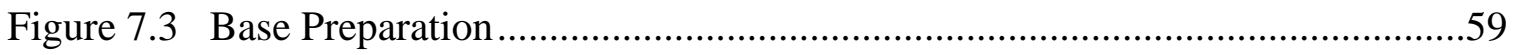

Figure 7.4 Cutting and Sandblasting of Dowel Slots...............................................60

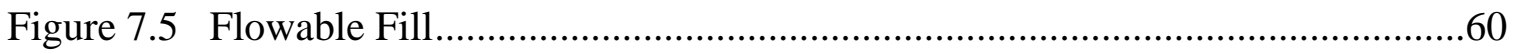

Figure 7.6 Precast Panel Installation..................................................................61

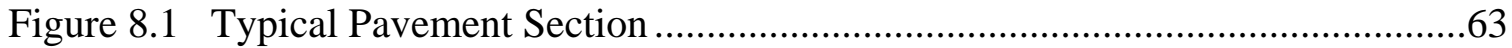

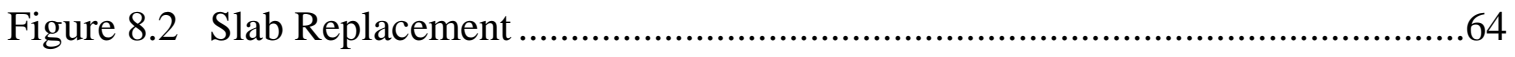

Figure 8.3 Concrete Removal with Lift Pin............................................................65

Figure 8.4 Bond Breaker Placement ...................................................................66

Figure 8.5 Drilling Dowel Slots.......................................................................67

Figure 8.6 Type A Dowel Bar Basket.................................................................67

Figure 8.7 Type U Dowel Bar Basket..................................................................67

Figure 8.8 Uniform Concrete Placement ...............................................................68

Figure 8.9 I-10 HOV Widening Project..............................................................69

Figure 8.10 Caltrans Demonstration Project................................................................70

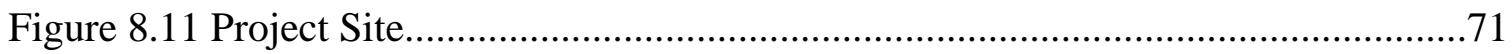




\section{TABLE OF TABLES}

\section{Tables}

Table 3.1 Pavement Smoothness Measurements ........................................................18

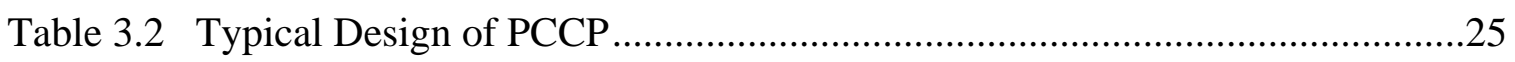

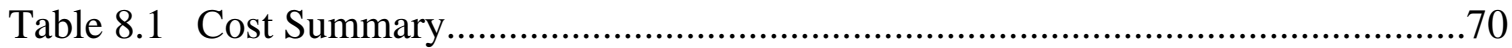

Table 9.1 Conventional V.S. Precast Pavements ..........................................................73

Table 9.2 Current Cost of Various Pavements in Indiana ............................................74

Table 9.3 Construction Cost for PCCP, PPCP, HMA pavement \& Super-Slab ..............74

Table 9.4 The User Cost Estimated through QUWEWZ ............................................76

Table 9.5 Total Cost including the user cost and construction cost..............................77

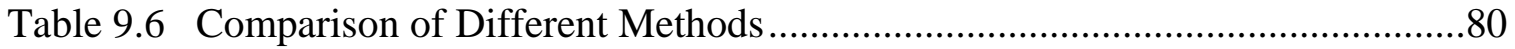




\section{INTRODUCTION}

\subsection{Problem Statement}

It is well known that the number of automobiles on highways has continued to grow in the United States. This increased number pushes many highways far beyond their originally designed capacity, resulting in the deterioration of pavement at a faster rate. To cope with this increased deterioration, highways are often closed for construction of new pavement, overlays, or removal and replacement applications. Increased traffic volumes on roads and highways create even greater traffic congestion during such projects. The significant increase in congestion, traffic delays and user costs as a result of construction delays are well documented $(27,28)$. This situation is more intensified in urban and densely populated areas. As a result, there is a need to develop repair and construction practices and processes that accelerate the time of construction, thereby reducing traffic delays, user costs and associated work time losses, fuel consumption increases, and other social and economic impacts.

To minimize the effects of such traffic delays and to expedite the pavement construction process, Federal Highway Administration (FHWA), Texas, California, Colorado, and Pennsylvania Departments Of Transportation (DOTs) have experimented with the use of precast concrete panels for expediting the construction of Portland Cement Concrete pavement.

The experimental results obtained from the Texas project were presented in the Transportation Research Board (TRB) 2001 annual meeting. Based on the Texas report (28), the

daily savings in construction time and user costs can be substantial. Although the initial costs for precast panels may at first be higher, the saving in user cost is far more than the first construction cost, due to the speed of construction. Texas Department of Transportation (TxDOT) is 
sufficiently satisfied with the precast concrete pavement construction process that they are proceeding with a larger scale project.

\section{2 $\quad$ Research Objectives}

Although Precast Concrete Pavement (PCP) has been tried in several states and has demonstrated some advantages over conventional concrete pavement construction in speed of construction and savings in user cost, a study is needed to examine the feasibility of PCP as an alternative to conventional cast in-place concrete pavement in Indiana.

Therefore, the purpose of this proposed study is to investigate this potential technology and to assess the feasibility of adopting this emerging technology in Indiana Department of Transportation (INDOT) pavement construction.

The general scope of this work is:

1) To conduct a comprehensive literature review on the state-of-the-art process for precast concrete panels for concrete pavement construction in the United States.

2) To investigate the feasibility of applying this potential new technology to INDOT for concrete pavement construction.

\section{$1.3 \quad$ Plan of the Report}

The report will begin with the methodology and describe the ways to achieve the objectives of the study. Then a brief review of various concrete paving and patching methods will be given. Among those methods, TxDOT’s precast prestressed concrete panels, Fort Miller's 
Precast Super Slab System, Michigan DOT’s Full Depth Repair Method, Ureteck’s Deep

Penetration and Stitch-in-Time method, and Caltran’s $4 \times 4$ method will be investigated in detail. 


\section{METHODOLOGY}

To achieve the objectives of the study, the following steps will be pursued:

\subsection{Background and Literature Review}

A thorough review of the available literature will be made to ascertain the current state of the arts of prestressed concrete pavement in the United States.

\subsection{Evaluation of Previous Projects}

A critical evaluation of the design, construction, and performance of FHWA sponsored projects that were lately constructed in Texas, Colorado, California, and Pennsylvania will be made. Herein, the characteristics of PPCP will be investigated and compared among reviewed states. The compared characteristics could include but not limited to: soil condition; typical pavement section; drainage; slab length; slab thickness, expansion and intermediate joints; base preparation; longitudinal post-tensioning; lifting, handling, and transporting; vertical and horizontal curves; grouting; tendon corrosion protection; maintenance ;and so on. A summary comparison matrix will be developed and provided.

\subsection{Conducting Cost Analysis}

To make proper project estimates and to control those estimated costs later, highway departments carefully track and compile the cost of highway construction. Thus, the costs of precast prestressed concrete pavement and conventional cast-in-place concrete pavement will be collected from each reviewed state. A thorough benefit /cost analysis on the collected cost data

will be conducted. At the same time, the costs of conventional concrete pavement in Indiana will 
be collected and compared with each reviewed state. Finally, a cost/benefit analysis of using PCP in Indiana will be performed.

\subsection{Investigation of Precast Production Capacity}

The success of a precast prestressed concrete pavement is heavily dependent on the precast contractors who fabricate and assemble the precast panels. The entire process consists of placing a HMA leveling course, a single sheet of friction-reducing polyethylene, precast panels, quick-setting concrete in stressing pockets, and grinding any uneven surface. What are the present ways to fabricate, lift, handle, transport and place in Indiana? What capacity do Indiana precast contractors have for supplying a large scale of PCP construction from plants or on job sites? These questions will be examined and answered in the following report.

\subsection{Final Report}

A final technical report will be prepared and submitted to INDOT for final approval. The report will include: methodology used, construction problems (advantages and disadvantages) including drainage concerns, references cited, the state-of-the-art of PCP in the United States, the results of critical evaluation and cost analysis, which will include future maintenance problems and costs associated with this type of construction, as well as the capacity of precast concrete contractors in Indiana. Based on the results of this proposed study and after Study Advisory Committee (SAC)'s recommendation on whether or not this type of pavement technology will work in Indiana, a decision on experimenting with PCP of this kind will be made. SAC will also decide whether the PCP demonstration projects will be tested on a new pavement, overlay, or removal and replacement application as well as selecting the location (urban or rural). 


\section{BACKGROUND}

\section{Pavement Profile}

Pavements provide a level, safe traveling surface for roadway users. Main components of a pavement structure are pavement and subgrade. Pavement may include surface, base/subbase, and subgrade. Subgrade may include compacted subgrade and natural subgrade. Pavements are typically categorized into flexible and rigid pavements by the distribution of the surface loads (shown in Figure 3.1). Surfaced with HMA, flexible pavements are usually composed with several layers to provide the support of the wheel loads. The load will be transferred from one layer to another. Surfaced by PCC, rigid pavements apply the wheel loads all over the slab $(1,2)$.
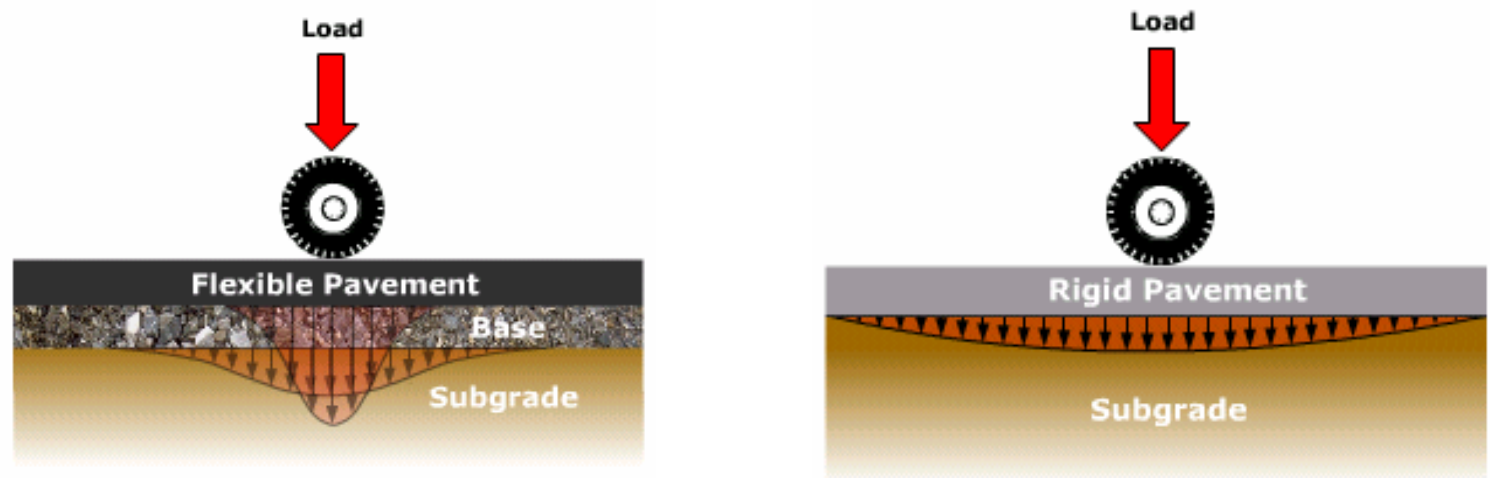

Figure 3.1. Surface load Distribution of Flexible Pavement (left) and Rigid Pavement (2)

With the growing number of automobiles on highways in the United States, the highway capacity has far exceeded its original design. Moreover, the overloaded traffic makes the deterioration of the pavement faster (3). On the other hand, the study from US Government's House Transportation and Infrastructure Committee suggested that in the next six years, the investment in the country’s highways should be increased to US\$ 375 billion. According to the committee, a majority $87 \%$ of the public are supportive of new highway projects. The same percentage would support an increase in fuel taxes if the money would be spent well (4). Finding the best way to build pavements, satisfying the public in quality and quantity within the shortest 
time and lowest budget, will be a critical task. In the conventional way of building pavements, highways need to be closed for further construction or renovation. This unquestionably results in greater traffic congestion. In order to minimize the potential problem, precast pavement may be a good solution.

In the United States, most pavements are surfaced by HMA or PCC (2). These popular choices are also the same as the pavements constructed in Indiana. Since the precast pavement is mainly use concrete as a raw material, the report will focus on analyzing the PCC technique. Additionally, the latest discussed "new" pavement (precast prestressed concrete pavement) will be discussed. The three pavements will be analyzed according to their profile, advantages and disadvantages, and cost.

\subsection{Precast Concrete}

\subsubsection{Overview of Precast Concrete pavement}

\subsubsection{Precast concrete}

According to the definition of precast concrete made in the $5^{\text {th }}$ edition of the PCI handbook, precast concrete is concrete cast elsewhere than its final position, including prestressed and non-prestressed components used in structural or nonstructural applications(5).

Precast concrete members can be assembled and fastened together on the jobsite. They may be non-reinforced, reinforced, or prestressed. The major advantages of the precast concrete are two-fold. First, it is the speed of construction. Precast members can be cast in precast plant yards or on the project site. They can be stockpiled and transported to the project site whenever they are needed. There is no on-site construction time for form building, concrete mixing, curing, or form removing. Second, it permits mass production of precast members on a casting- 
plant floor or on the ground near the construction site in protected locations where better quality control can be maintained (6).

\subsubsection{Prestressed Concrete}

Prestressed concrete is concrete that had been introduced to compressive stress before service live loads have been applied on the concrete. The usual procedure is to stretch highstrength steel tendons (generally wires or strands) and anchor them to the concrete, which resists the shortening of the stretched tendons after anchorage and results in the transfer of the compressive stress to the concrete. If the tendons are stretched to a predetermined tension before concrete has been placed, it is called pre-tensioning. If the tendons are tensioned after the concrete has been cast, it is called post-tensioning (7, pp. 1-30). Prestressed concrete includes pre-tensioning and/or post-tensioning.

\subsubsection{Precast Prestressed Concrete Pavement overview}

Precsat Prestressed Concrete Pavement (PPCP) is defined as "a pavement in which a permanent and essentially horizontal compressive stress has been introduced prior to the application of live load,” according to the AASHTO Subcommittee on Prestressed Concrete Pavement of the Committee on Rigid Pavement Design (6, page 5). PPCP may be constructed by the following steps: Panel fabrication in site or in factory nearby; AC Leveling course; full width/half width panel placement; thread in the tendons; and post-tensioning and grouting. The basic schematic drawing for the precast concrete pavement is shown in the Figure 3.2 below. 


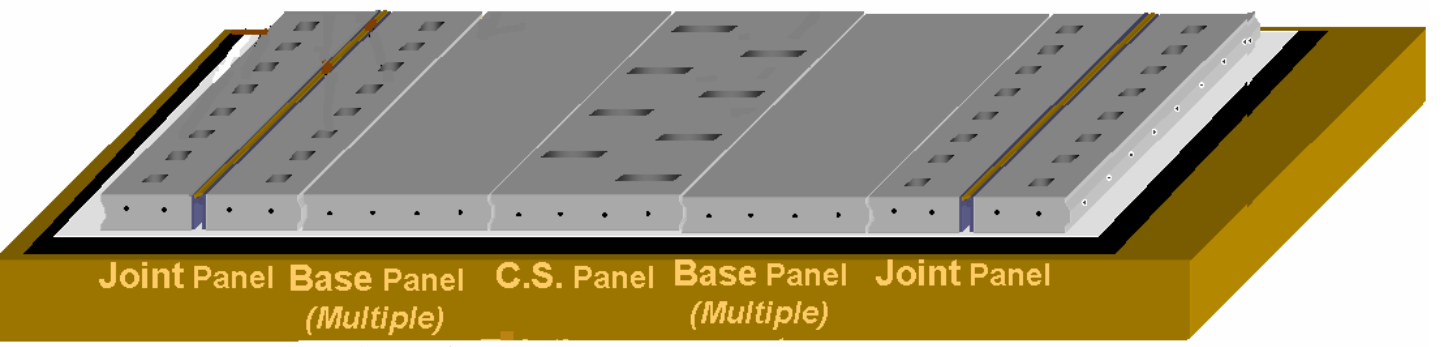

Figure 3.2 Schematic drawings of PPCP (9)

\subsubsection{Design Factors and Variables}

The design of PPCP involves many reasonable considerations. The important step is to determine the specific values of various independent variables. However, the determination has to be based on a thorough understanding of the factors affecting the design, thus allowing the PPCP to sustain the traffic loads and environmental influences within the service life.

The following sections briefly illustrate the design factors and variables. Each of the design factors and variables used in each of the test projects will be evaluated for applicability or establishment of proper values for use in Indiana. The reader can refer to the technical report entitled "New Concepts in Prestressed Concrete Pavement” by N.D. Cable, N.H. Burns, and F. McCullough for details (8, pp. 51-77). To preserve the authors’ original intent, the following sections are almost directly excerpted from the original texts.

\subsubsection{Design Factors}

The following design factors are to be reviewed:

\section{Elasto-Plastic Behavior Underloads}

The magnitude of the extreme fiber stress in the prestressed concrete members can be increased by an amount equal to the pre-stress. However, presently used design concepts are still 
conservative. They are restricted in the elastic ranges that neglect the movement redistribution partial plastic ranges in the prestressed concrete and the resulting potential increase in loadcarrying capacity.

\section{Load Repetition}

Prestressed concrete has a fatigue endurance level that is a function of applied stress level and number of repetitions. For a given load, these factors either increase the required prestressed level for a given pavement thickness or increase the thickness for a given pre-stress level.

\section{Subgrade Restraint}

Differential movement between a PPCP and the subgrade is resisted by friction, which induces restraint stress in the pavement. The magnitude of the restrained stress is a function of the co-efficient of subgrade friction and the dimensions of the slab and is at the maximum at the midlength and midwidth of the slab.

\section{Temperatures Curling}

The precast prestressed concrete slab will curl toward the side with the lower temperatures and this curling is resisted by the weight of the slab. Consequently, tensile stresses develop on the side that has the lower temperatures while compressive stresses develop on the other side.

\section{Moisture Warping}

Tensile stresses develop on the top surface of the precast prestressed concrete slab due to its relative dryness and compressive stresses develop on the substantially saturated bottom; Consequently, warping occurs. 


\section{Pre-stress Losses}

Approximately 15 to $20 \%$ of the applied pre-stress force is usually lost due to various factors such as elastic shortening, creep, shrinkage, relaxation of the stress tendons, slippage of the stressing tendons in the anchorage devices, friction between the stressing tendons and the enclosing conduits, and hydrothermal contraction of the PPCP.

\section{Buckling}

Precast prestressed concrete slab expands and contracts in response to hydrothermal changes within the concrete. There is the possibility of buckling during expansion.

\subsection{Design Variables}

The design variables to be reviewed include the following:

Foundation Strength

The stress in a PPCP for a given load is inversely proportional to the strength of the supporting foundation and the ability of the PPCP to withstand repetitive loads in proportion to the strength of the supporting foundation. Usually, PPCP has 200 psi or higher modulus of subgrade reaction.

\section{PCP Thickness}

Factors affecting the design of PPCP thickness include foundation strength, concrete strength, magnitude of prestress, and expected traffic loads. PPCP thickness has been determined more on the basis of providing the minimum allowable concrete cover on the prestressing tendons than on the basis of load-carrying consideration. This procedure has resulted in thickness of PPCP on the order of 4 to 6 inches. 


\section{Slab Length}

The two main factors that must be balanced when selecting the optimal slab length for PPCP are:

a) The prestress force required to overcome the frictional restraint between the subgrade and the slab, and to provide the desired minimum compressive stress at the midlength of the slab, is proportional to the slab length. The cost associated with providing this prestress force is, in turn, proportional to the magnitude of the required force.

b) The number of and total cost for transverse joints is inversely proportional to the slab length. (Total cost should include initial cost and maintenance cost over the life of the facility, since transverse joints are the largest maintenance item for a pavement.)

\section{Slab Width}

Slab width refers to the distance between the two exterior longitudinal free edges of the completed pavement and does not refer to the distance between intermediate inactive longitudinal construction joints.

In many instances it is not feasible to construct the full width of either a new pavement or an overlay on an existing pavement in a single operation and, as a result, the pavement must be constructed in two or more successive, contiguous longitudinal strips. Construction joints must be provided between adjacent pavement strips with this type of construction. This type of construction is necessary due to equipment limitation and to accommodate the public and the construction traffic.

\section{Magnitude of Prestress}

Many factors must be taken into account to assure that the desired prestress level is obtained, including: magnitude of frictional restraint between slab and subgrade, slab thickness, 
slab length, maximum diurnal temperatures fluctuation anticipated during the life of the pavement, pavement curling and warping, foundation conditions, magnitude of expected traffic loads, and number of traffic load repetitions. The problem is further complicated by the fact that many of these factors are interdependent. Recent PPCP projects have used prestress levels ranging from 150 to 300 psi longitudinally and from 0 to 200 psi transversely.

\section{Tendon Spacing}

The main factors governing tendon spacing are tendon size, magnitude of design prestress, allowable concrete bearing stress at the tendon anchorages, and permissible tensile stress in the tendons. Typically, spacing of two to four times and three to six times the slab thickness has been utilized for the longitudinal and transverse tendons, respectively.

\section{Transverse Joints}

The ideal transverse joint would: (a) accommodate the movement of the slab ends; (b) allow compressive forces to be transmitted from slab to slab; (c) carry traffic load without undesirable deflections or stresses at either the joint or slab ends; (d) be composed of materials that are resistant to wear, fatigue, and corrosion caused by traffic, environment, or deicer chemicals; (e) be sealed against infiltration of water and incompressible material that can contribute to pumping, spalling, and blowups; (f) be drained and self-cleaning (if not sealed), so

that little maintenance is required; (g) have components that can be easily removed and replaced if damaged; (h) have details that are compatible with the prestressing method employed; and (i) be low in cost.

System variables to be reviewed include the following (to help illustrate the PPCP system variable and components that will be reviewed and evaluated, the TxDOT test project is highlighted in the following paragraphs): 


\subsubsection{Advantages and Disadvantages of Using PPCP}

There is not much PPCP is built in the United States. When studying one of the constructed precast concrete pavements built in Texas, Bill Garbade, District Engineer for the Austin District of TxDOT, said “There were a lot more pros than cons. It’s certainly well worth the time and money to carry the experiment the next step.” Mark Herber, graduate engineer at the project site for the TxDOT Georgetown Area Office, agreed, "Everything turned out as expected.” The advantages and disadvantages summarized below are almost directly excerpted from the original project reports of the precast prestressed concrete pavement pilot project near Georgetown, Texas. $(10,11)$.

\subsubsection{Advantages}

First, the advantages are discussed as below:

1) Expedited Construction (Ref 10 P.6)

a) Expedited construction (almost immediate exposure to traffic after placement)

With the rapidly increasing number of automobiles on roadways, the need to repair or construct pavement is greater than ever. Since extra time is not required for the concrete to reach sufficient strength before opening to traffic, as with conventional concrete pavement, PPCP may be another good option in the market.

b) Possibility for overnight or weekend construction

The panels can be precast in the factory or some place near the field and then transported to the building site. It allows construction to proceed all year round by doing this. In other words, it can be constructed "unseen" (casting and curing the slab in site or 
at the factory) and in all kinds of weather. Overnight or weekend construction is possible for precast concrete.

c) Roadway user cost savings

User costs are the costs incurred by the users of the roadway due to the presence of construction activities, such as increased fuel consumption and lost work time. Shortening the period of time roadways are closed for construction will lead to roadway user cost savings.

\section{2) Long-term Usage}

a) Longer use time

Much greater control in the casting and curing segments of fabrication of precast prestressed pavement panels leads to a consistent concrete mix and ensures that the panels are properly cured. This minimizes problems commonly encountered with conventional concrete paving: built-in curl/wrap (due to temperatures and moisture gradients), surface strength loss (due to insufficient curing), and inadequate airentrainment. Eliminating these problems will lengthen the pavement life. Consequently, a decrease in long-term operational costs and work zone congestion can be expected. (Ref.10, P.1)

\section{b) More durable}

Applying post-tensioning reduces the required pavement thickness and cracking (or even prevents the cracking). This results in increasing the life of the pavement, selecting an effective thickness of the pavement, and significantly reducing maintenance costs.(Ref.10 P.6) 
3) Economic concerns.

a) More efficient usage of materials

Material will be saved by using post-tensioned method which reduces

pavement thickness. The PCCP thickness of $200 \mathrm{~mm}$ was chosen by the project managers to reach the expected $80 \mathrm{kN}$ (18 kip) ESAL (Equivalent Single Axle Load) that are applied to a 355 mm Continuously Reinforced Concrete Pavement (CRCP). Precast pavement utilizes a thinner prestressed slab than conventional concrete, while providing equivalent durability and high-performance. Material will be saved by reduced pavement thickness. Also, fewer tendons are needed for precast pavement. (Ref.10 P.2)

b) Less manpower

PPCP projects may adapt to the needs of the contractor/builder, such as a shortage of skilled or normal labor, or the concentration of manpower in fewer design centers, if the method can be repeated continuously.

c) Better quality

Better quality is possible because of thermal and acoustical control for PPCP's plant-fabrication. This may lead to less required maintenance and longer pavement life than conventional pavements. (Ref 10, P.7)

d) Popular material

Concrete has been utilized in pavement for decades. The use of concrete in PPCP could make the newly developed method less challenging. The chance to a successful implementation of PPCP is reasonably high. 
Therefore, PPCP will posses the benefits of using concrete that stabilize the structure under wind loads, thermal changes, acoustical vibration, and fire resistance.(Ref.5 P.1-3)

e) Maximum economy can be achieved with maximum repetition.

As more and more precast pavement projects are accomplished, contractors will be much more familiar with the techniques and equipments. This will lower the initial high cost problem. As long as there is a standard size of panels and a standard repetition of fabrication and construction procedures, lower construction costs should be anticipated. (Ref. 5 P.1-3)

\subsubsection{Disadvantages}

PPCP has been barely used in roadway construction in the United States. The Georgetown pilot project is experimental in nature. The lack of a proven and easily used design procedure has been a major obstacle to its application. The disadvantages found by the Center for Transportation Research- The University of Texas at Austin (CTR, UT-Austin) will be shown below: $(10,11)$

1) Ride Quality

A high-speed inertial profilometer was used to evaluate the ride quality of the finished pavement. Table 3.1 shows the results from the pavement smoothness measurements. The average International Roughness Index (IRI) was $2.61 \mathrm{~m} / \mathrm{km}$ (165.5 in/mile) for the partialwidth panels and $2.32 \mathrm{~m} / \mathrm{km}$ (147.1 in/mile) for the full-width panels. The values are higher than normally required correction for conventional concrete pavement. However, TxDOT felt that the ride quality did not warrant diamond grinding or any other corrective measure. Also 
no irregularities that could lead to dynamic loading and premature pavement failure were observed in any of the panels (Ref 11 P.6).

CTR, UT recommended that a ride quality standard be established to PPCP that will determine whether the finished pavement is smooth enough for immediate traffic use. Smoothness incentives and penalties would help ensure a high quality finished product from the contractor (Ref 11 P.5).

Table 3.1 Pavement Smoothness Measurements

\begin{tabular}{|c|r|r|r|r|r|r|r|r|}
\hline & \multicolumn{3}{|c|}{ Partial Width Panels } & \multicolumn{3}{c|}{ Full Width Panels } \\
\cline { 2 - 8 } & \multicolumn{2}{|c|}{ Inside Lane } & \multicolumn{2}{l|}{ Outside Lane } & \multicolumn{2}{l|}{ Inside Lane } & \multicolumn{2}{l|}{ Outside Lane } \\
\cline { 2 - 8 } & LWP & RWP & LWP & RWP & LWP & RWP & LWP & RWP \\
\hline IRI & 2.68 & 2.67 & 2.58 & 2.52 & 2.50 & 2.41 & 2.14 & 2.24 \\
$(\mathrm{~m} / \mathrm{km})$ & & & & & & & & \\
$(\mathrm{in} / \mathrm{mi})$ & 170.0 & 168.9 & 163.6 & 159.6 & 158.6 & 152.5 & 135.5 & 141.7 \\
\hline
\end{tabular}

LWP=Left Wheel Patch RWP=Right Wheel Path

Source from: Ref.11

2) Cost

The total cost of the Georgetown PPCP, including the panels’ fabrication, base preparation, and construction, was approximately $\$ 203 / \mathrm{m}^{2}\left(\$ 19 / \mathrm{ft}^{2}\right)$. The cost is significantly higher than expected for an equivalent 355 mm CRCP \$36-\$48/ $\mathrm{m}^{2}\left(\$ 3.34-4.59 / \mathrm{ft}^{2}\right)$. However, it may be understandable for the following reasons. First, the Georgetown precast pavement was a relatively small $(0.7 \mathrm{~km})$ project. This is only a tentative pavement that is not the economies of scale. A much larger project would have had a significantly lower unit cost. Secondly, again the Georgetown precast pavement project was tentative project. Neither the 
contractor nor the precast supplier were familiar with precast paving techniques and therefore likely submitted higher bids. The initial costs will be higher until constructors and transportation agencies become familiar with the techniques (Ref 11 P.5, 6).

3) Complexity

PPCP requires the same components as conventional concrete pavement. The PPCP also requires a system for imposing and maintaining permanent horizontal compressive stresses. One or more of the following items will be required: 1. friction-reducing layers or media; 2. sleeper slabs; 3. placement of tendons or conduits. ; 4. abutments. ; 5. grouting. ; and 6. jacking for preliminary and final stressing. (Ref.8 P.8)

Additionally, the distance traveled from the casting site may only be a few meters, where on-site recasting methods are used to avoid expensive haulage. When the precast pavement can be thousands of kilometers from the manufacturing site, the expensive haulage can be avoided. The arrangement of transportation and traffic may be an issue to address.

4) Construction Equipment

New construction equipment may be necessary for precast concrete construction projects. (Ref.8 P.11)

5) Unfamiliarity and the main body weakness

a) Most paving contractors are currently unfamiliar with precast concrete, which makes education programs for contractors necessary. (Ref.8 P.11)

b) Fire-resistance for PPCP is lower than for reinforced concrete. This is because of the high temperatures used to build high tensile tendon, which make it lose part of the stress.

c) The expensive anchor instrument needs to be used at the precast site. (Ref.8 P.11) 


\subsection{Portland Cement Concrete Pavement (PCCP):}

\subsubsection{Properties of Portland cement materials and pavement}

Portland cement concrete is composed of aggregate, water, and Portland cement ( a cement agent that may consist of lime (CaO), silica $\left(\mathrm{SiO}_{2}\right)$, alumina $\left(\mathrm{Al}_{2} \mathrm{O}_{3}\right)$, iron oxide $\left(\mathrm{Fe}_{2} \mathrm{O}_{3}\right)$ and so forth). Many types of supplementary cementing materials (SCM) or additives are used to replace a portion of Portland cement because of its high cost. (2)

There are three main kinds of rigid pavement including: Jointed Plain Concrete Pavement (JPCP), Jointed Reinforced Concrete Pavement (JRCP), and Continuously Reinforced Concrete Pavement (CRCP). The only difference between them is the jointing system used to control crack development due to expansion and contraction of the concrete. According to INDOT certified technician program training manual for Concrete paving, JRCP built with steel mesh and 40-feet transverse joint spacing was the main type of concrete pavement built by INDOT until just a few years ago; CRCP built with only a large amount of longitudinal steel (No.5 bars, 6 inches on center and with no transverse joints) was no longer utilized in INDOT. (40) A majority of DOTs use JPCP as shown in Figure 3.3 and Figure 3.4) because of its simplicity and proven performance. It is also one of the main pavements constructed in Indiana recently. (15) In American Concrete Pavement Association (ACPA) website (35) has the following description for JCPC:

Jointed plain concrete pavements (JPCP) contain enough joints to control the location all of the expected natural cracks. The concrete cracks at the joints and not elsewhere in the slabs. Jointed plain pavements do not contain any steel reinforcement. However, there may be smooth steel bars at transverse joints and deformed steel bars at longitudinal joints. The spacing between transverse joints is typically about 15 feet for slabs 7-12 inches thick. Today, a majority of the U.S. state agencies build jointed plain pavements. 


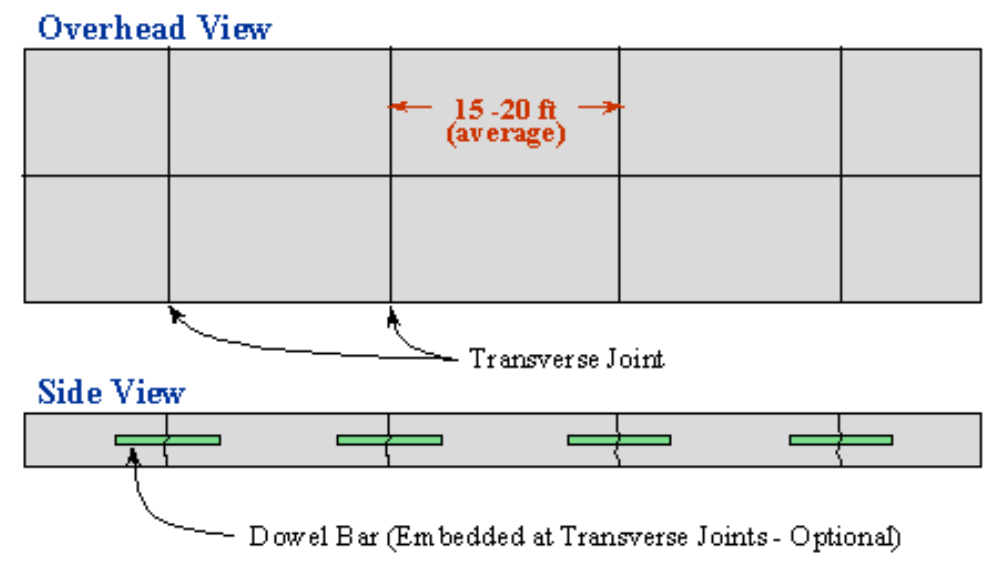

Figure 3.3. Schematic drawings of JPCP (Source: ACPA(35))

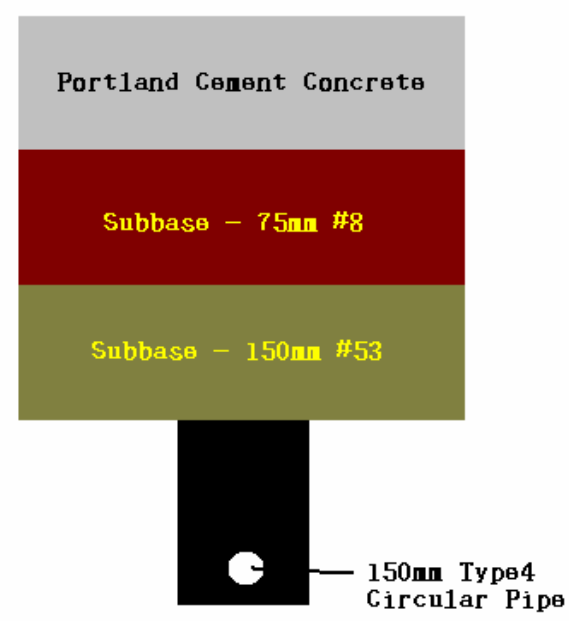

Figure 3.4 The schematic drawings of Portland Cement Concrete Pavement

\subsubsection{Advantages and Disadvantages}

A high proportion of pavements are built by concrete pavement. The advantages of PCCP focused in JPCP are discussed in the following. (30, 36, 37, 38) 


\section{1) Longer service life than flexible pavement}

Concrete pavements generally have longer service life than asphalt pavement. Without major repairing, concrete commonly serves 20-30 years. On the other hand, asphalt pavement typically lasts only 8-12 years before resurfacing or significant repair is required.

2) Support heavy loads

JPCP provides good performance even for heavy loads such as truck. Also, it is broadly used in airport projects for providing the substantial pavement strength required to withstand the impact of airplanes such as the Boeing 747 (weighing more than 850,000 pounds when fully loaded).

\section{3) Less Maintenance than flexible pavement}

As experienced, it requires less maintenance cost than asphalt pavement.

4) Ability to reflect light and heat

For pavement in city, the light color of concrete reflects from 33\% to 50\% more light than HMA pavement. This helps cities achieve the street lighting standard, satisfying the American National Standards Institute criteria with less initial investment in lighting fixtures and equipment and long-term energy costs.

Conversely, the disadvantages of using PCCP are discussed as follows:

1) Roughness

It may be noticed that it is rougher on PCCP than AC pavement. This may be caused by poor construction techniques, an unstable subgrade, or deterioration of the riding surface. Many researches also indicate that faulting (transverse joints and cracks) has a great influence on the roughness of the PCC pavements. 
2) Traffic disruption

The construction period is longer compared to HMA method, leading to traffic disruption and affecting the time and money of the users. However, there are several new techniques that can be utilized to shorten the working period of time, such as using precast concrete.

3) Initial cost

Initial construction cost is higher than HMA pavement, depending on local markets. 4) Surface distress

Based on INDOT experiences, the possible surface distresses are alkali-silica reactivity, blowups, corner breaks, cracking, longitudinal/transverse cracking, faulting, joint failure, joint seal failure, polishing, pop outs, punch outs, scaling, spalling, structural failure, and so forth. Most of them can be treated with replacement, or repairs. (15)

\subsection{INDOT Experiences}

Plain jointed Portland cement concrete pavement used by INDOT is depicted in Figure 3.5. It consists of concrete materials on a subbase and a prepared subgrade. The concrete on a subbase is composed of Portland cement, pozzolans, coarse and fine aggregates, water, and chemical admixture. Subbase is a granular layer placed under PCCP to minimize the problem of erodable subgrade and to provide support for the pavement. Subbase used in Indiana can be categorized into two kinds- drainable or dense graded. Subbase for cement concrete pavement (drainable) consists of an aggregate drainage layer over a compacted aggregate separation layer. This provides a conduit to remove water entering the pavement system and is used whenever under drains are required. Subbase (dense graded) consists of compacted aggregate. It provides 
not only a stable-working platform but also support for the pavement without drainage layers. The typical design of PCCP is shown in Table 3.2 and the standard drawing with under-drains of PCCP in Indiana is depicted in Figure 3.4 (15).

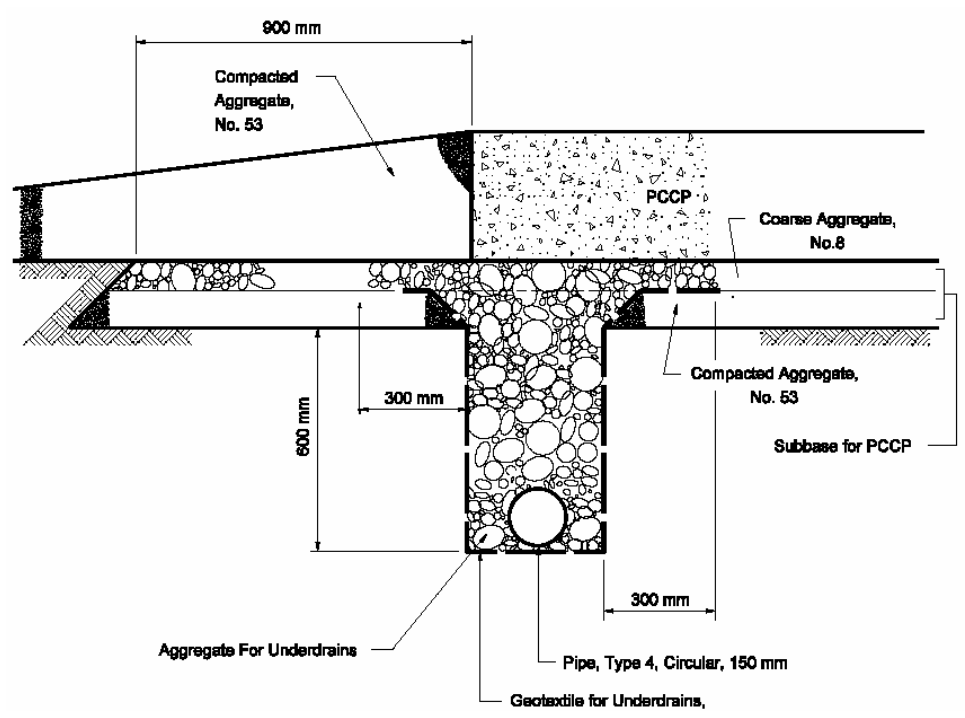

Figure 3.5. The schematic drawing of PCCP with under drains (INDOT (15)) 
Table 3.2. Typical Design of PCCP (generated from INDOT(15))

\begin{tabular}{|l|l|l|l|}
\hline & \multicolumn{2}{|c|}{ PCCP } & PCCP with \\
Concrete Curb
\end{tabular}




\section{IV.PRECAST PRESTRESSED CONCRETE PANELS METHOD}

\subsection{Types of Panels}

In the aforementioned report “New Concepts in Prestressed Concrete Pavement,” N. Cable presents some ideas for precast pavements that were utilized in the Texas test project. The project used full-depth; precast jointed panels, central stressing panels, and base panels.

Figures1, 2, and 3 show these panels. All the panels are pretensioned in the transverse direction. They have ducts cast into the slabs in both the transverse and longitudinal directions for posttensioning. They are adjacent slabs after they are set in place (Reference 12, Page 51-66).

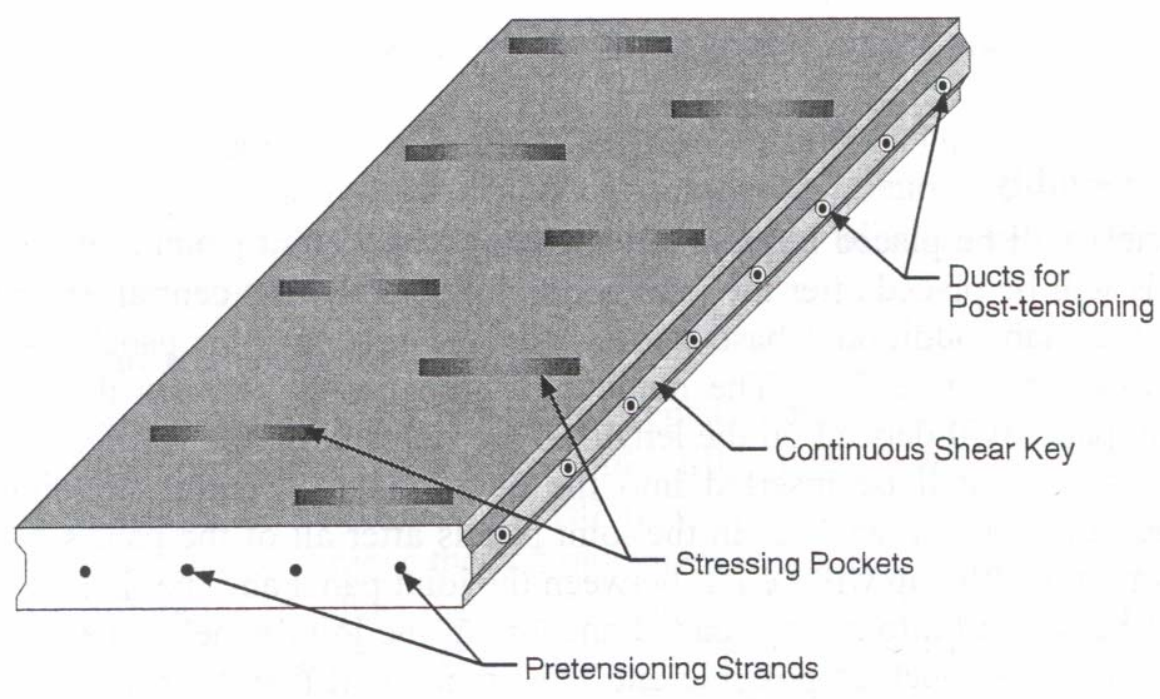

Figure 4.1. Central stressing panel for PPCP

(Excerpted from Reference 12, Page 53) 


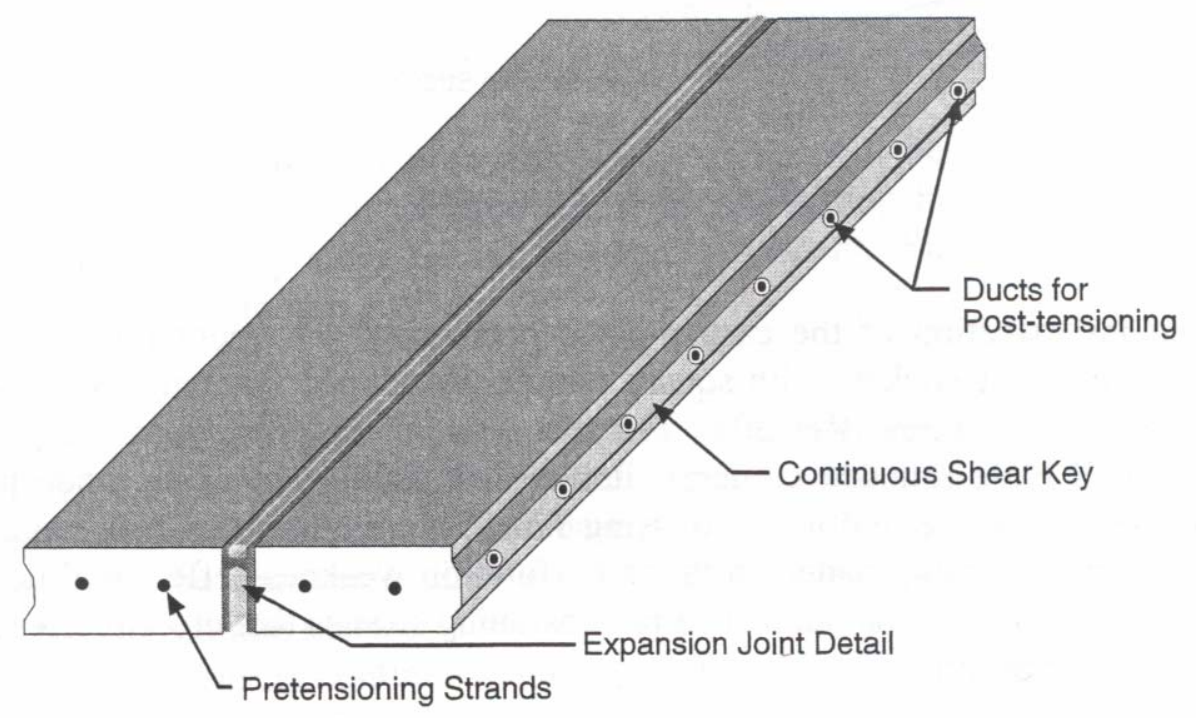

Figure 4.2. Joint panel for PPCP

(Excerpted from Reference 12, Page 53)

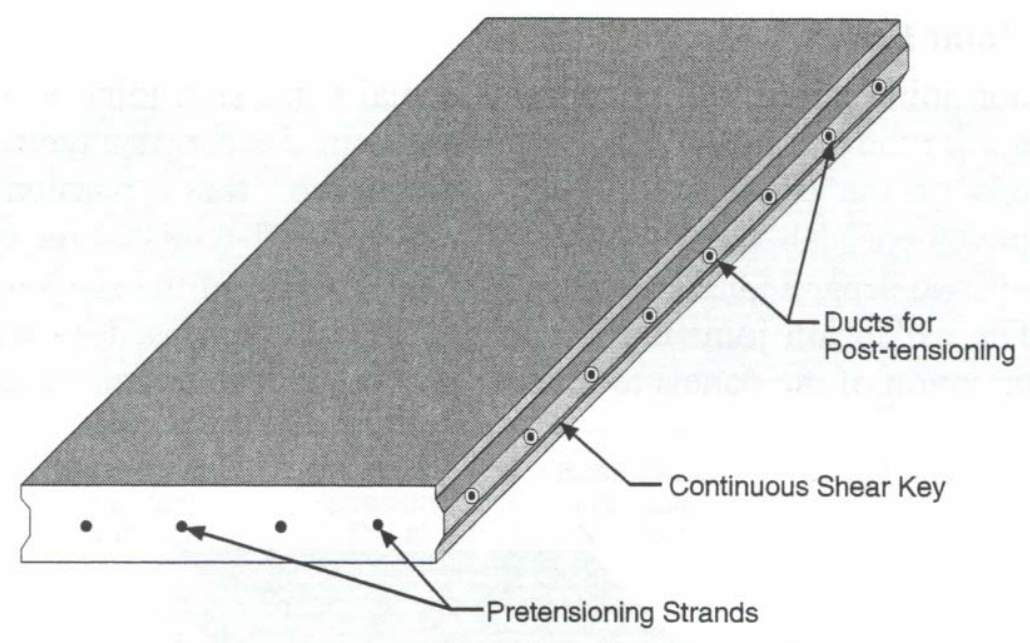

Figure4.3. Base panel for PPCP

(Excerpted from Reference 12, Page 54) 


\subsection{Assembly of Precast Prestressed Concrete Panels (Reference 12, Page 51-64)}

The assembly of the above precast prestressed concrete panels starts with a joint panel at the end of the slab. The base panels will be placed followed by the central stressing panel. Figure 4.4 shows the typical assembled panels. Many base panels can be added between the joint panel and the central stressing panel. The post-tensioning strands of tendons are inserted into the ducts through central stressing pockets and they are pushed/pulled through the ducts to spring-loaded and self-locked anchors in the joint panels. The strands are then post tensioned from the stressing pockets of the central stressed panel as shown in Figure 4.5.

After post-tensioning, the strands of tendons are grouted in the ducts, and the stressing pockets are filled with a fast-setting concrete. Meanwhile, sealants are injected into the joints between each of the panels.

If necessary, any uneven surfaces can be diamond-ground to assure the smooth ride of travelers.

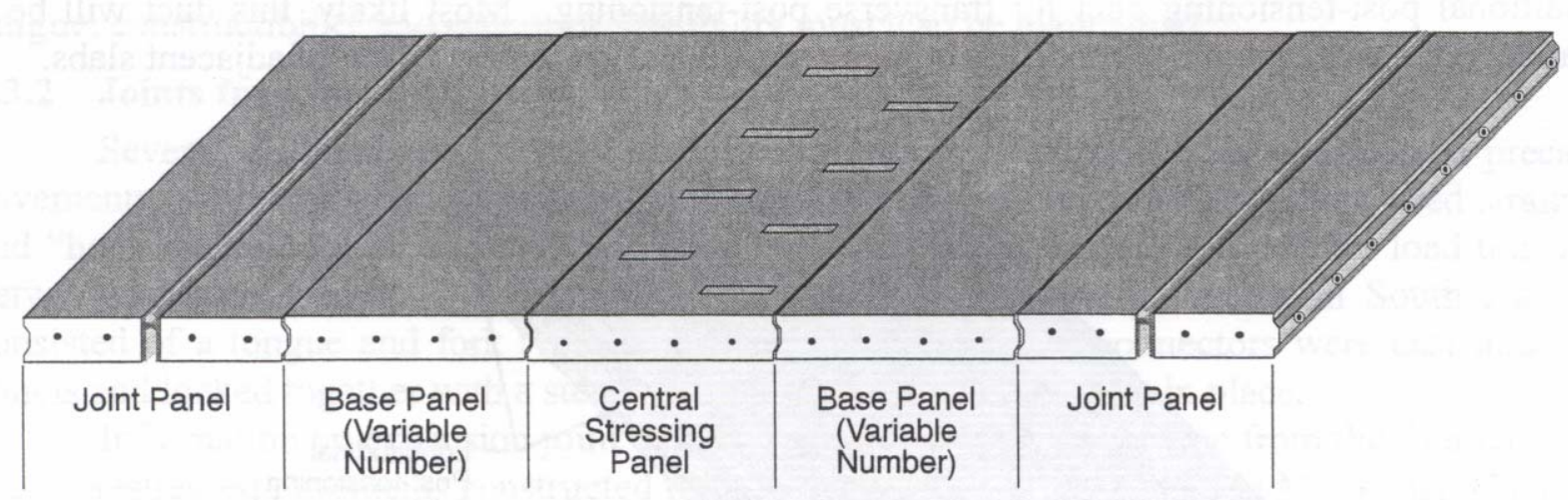

Figure 4.4. Assembly of panels for PPCP

(Excerpted from Reference 12, page 55) 


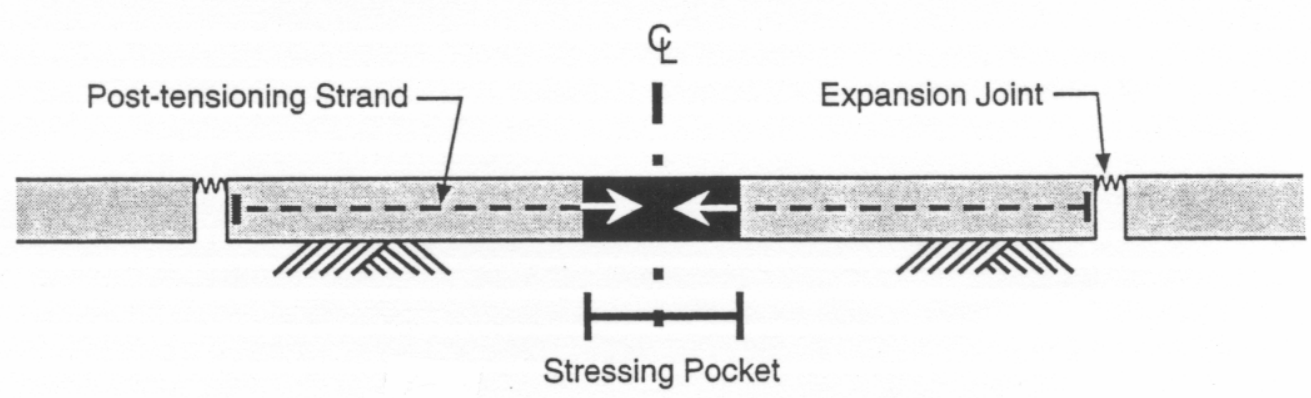

Figure 4.5. Concept of central stressing ((Excerpted from Reference 12, page 10)

\subsection{Base Preparation}

A thin (1-2 inches) HMA leveling course is placed in advance of the PPCP panels' placement over the existing pavement in the case of overlay application; or on the subgrade in case of a new pavement. The HMA course supports and levels the PPCP panels. In addition, traffic can be allowed onto the leveling course for up to a week after it is placed.

Before the PPCP panels, a single layer of polyethylene sheet is laid to reduce the prestress losses and the tensile stress generated in the PPCP panels. The polyethylene reduced the frictional resistance between the PPCP slab and the supporting leveling layer. The base preparation used in other states, test projects will also be reviewed for applicability to INDOT Standards.

\subsection{Georgetown Project, Texas}

The precast pavement pilot project near Georgetown, TX was constructed on the northbound frontage road of Interstate 35. The project focused on a simple geometric layout to test and fine-tune basic precast paving techniques, so the site contained neither horizontal curves nor super elevations. The total length of the precast pavment is 2300 feet (700 meters) on both 
sides of a new bridge. The precast prestressed concrete panels are placed transverse to the flow of traffic, including a full 11-meter (36-foot) roadway width of two 3.7-meter (12-foot) lanes, a 2.4-meter (7.9-foot) outside shoulder, and a 1.2-meter (4-foot) inside shoulder. Although not necessary, both full-width (11-meter/36-foot) and partial-width panels (5-or 6-meter/16-or 20foot) are used to test the applications. The full-width panels utilized on the north side of the bridge are approximately 68 meters (225 ft) long and the partial-sidth panels utilized on the south side are approximately 100 meters (325 ft) long as shown in the Figure 4.6. The panels were fabricated on a 22-meter (400-foot) casting bed, capable of producing 10 full-width panels and up to 20 partial-width panels at one time. The detail of fabrication panels, AC leveling course, panels placement, post-tensioning and grouting is illustrated in the following Figures provided by Center of Transportation Research (CTR), University of Texas-Austin. $(11,13,14)$ PPCP may be constructed by steps: panel fabrication on site or in a factory nearby, AC leveling course, full width/half width panel placement, thread in the tendons, post-tensioning and grouting.

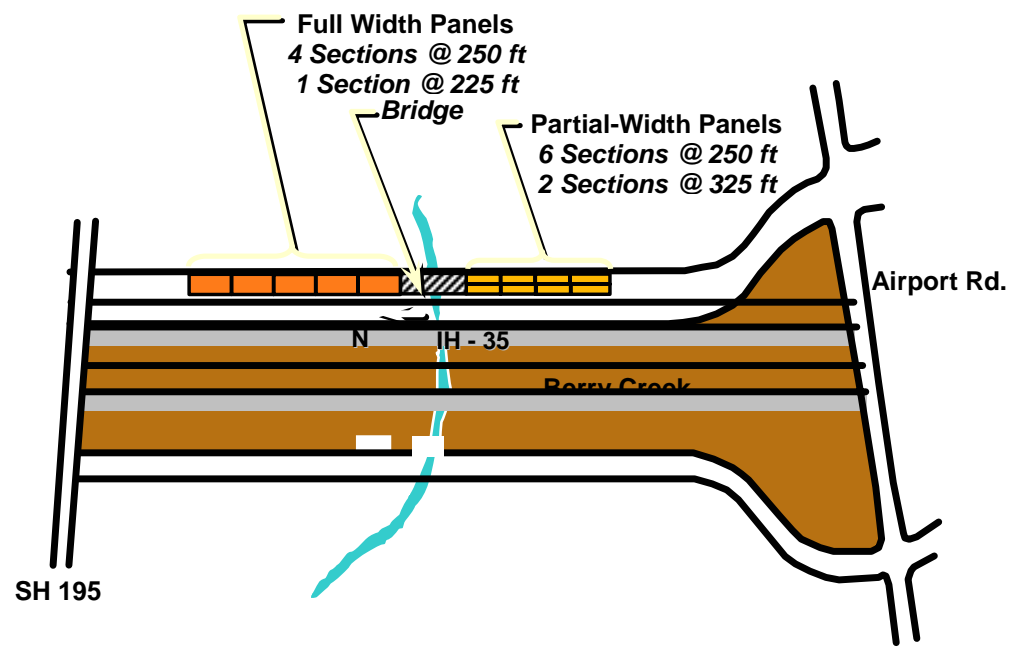

Figure 4.6 Location and layout of the Georgetown PPCP pilot project 


\subsubsection{Construction Procedures}

The following Figures provided by CTR, UT-Austin from Figures 4.7 to 4.38 illustrate the construcion, fabrication, and installation procedure.

\section{$\underline{\text { Panel Fabrication }}$}

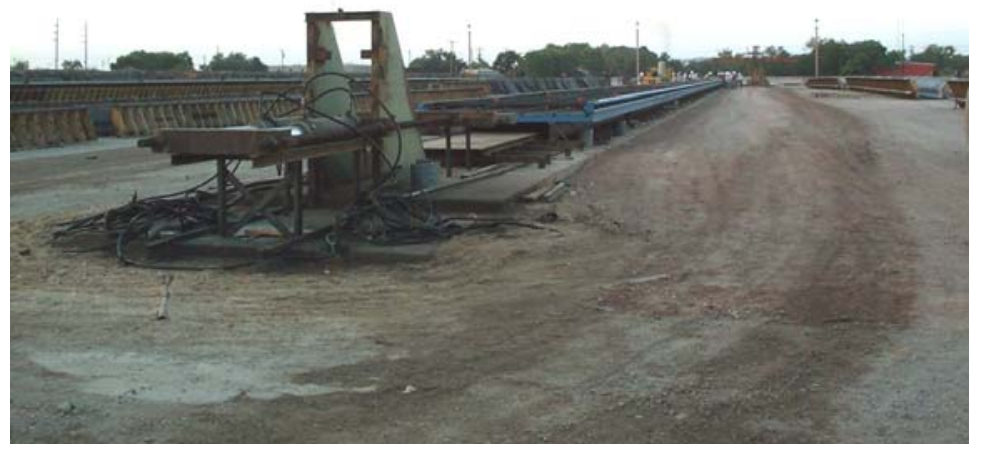

Figure4.7. The Precast Prestressed Concrete Panels Fabrication plant
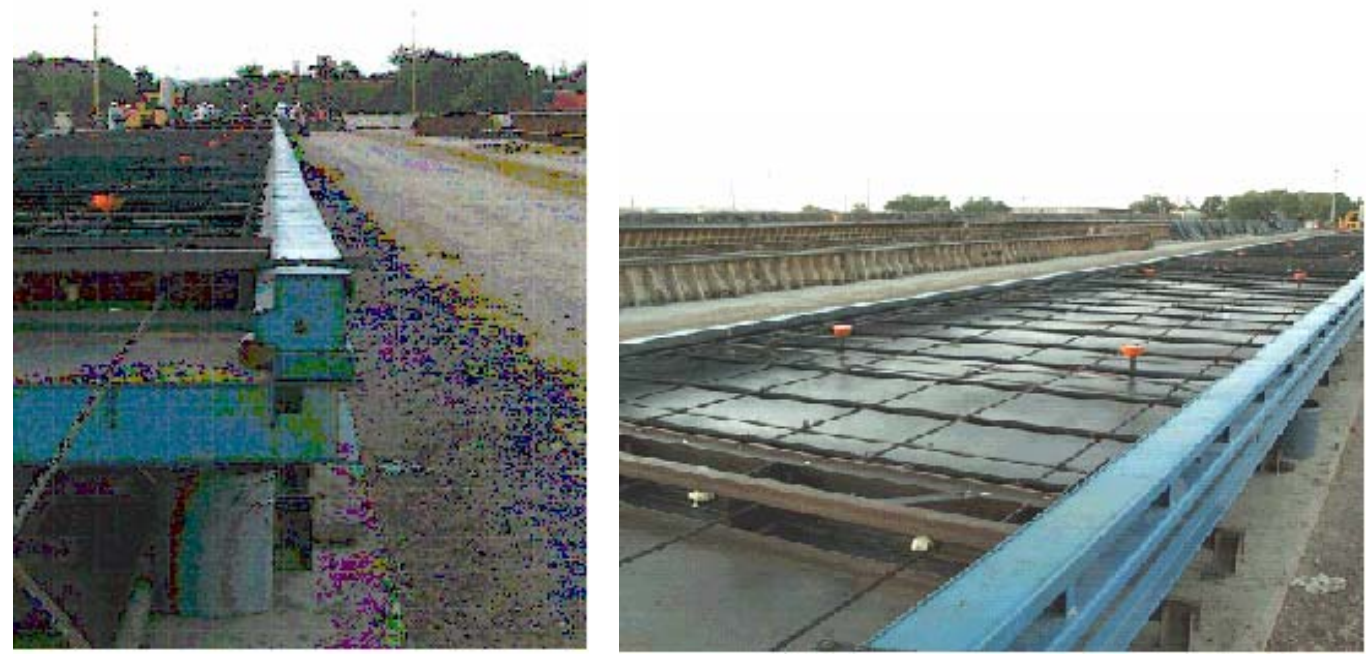

Figure 4.8 Looking down the side (left) and from the top (right) of the casting bed 


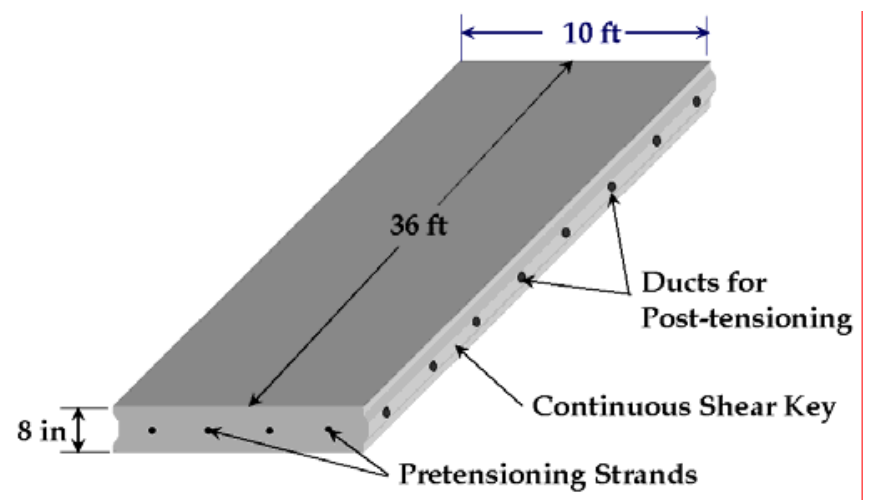

Figure 4.9 Schematic Diagram of Base Panel

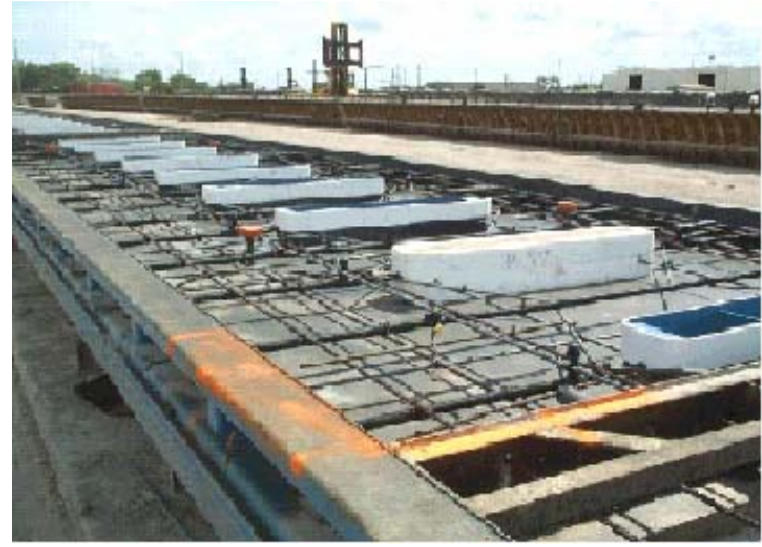

Figure 4.10. "Boxes/inserts" are placed for preparing the stressing pockets of central stressing panel mold

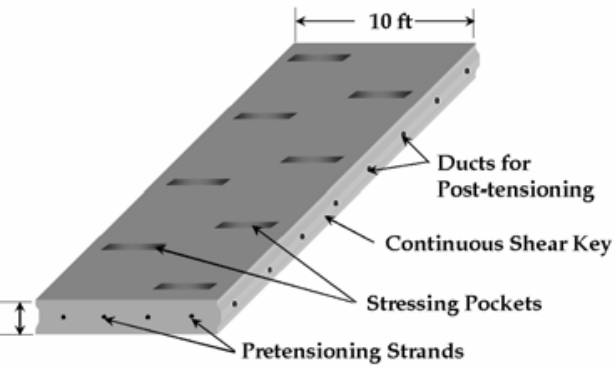

Figure 4.11. Schematic diagram of central stressing panel

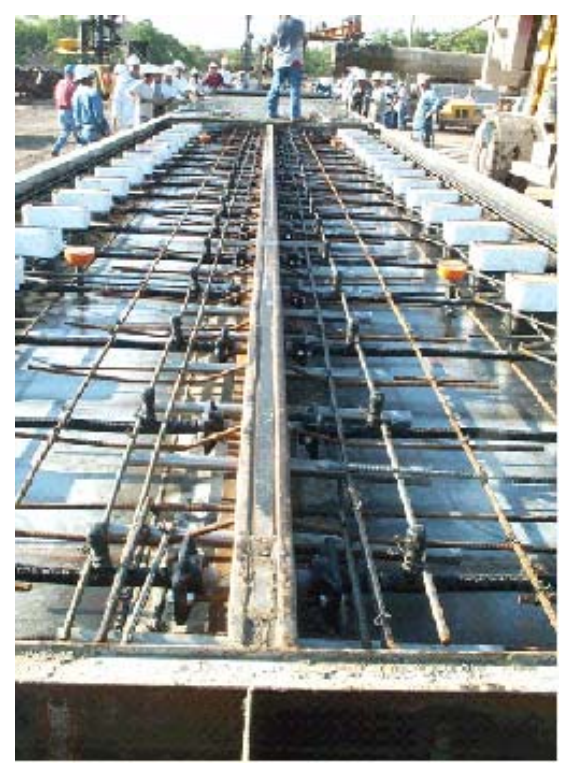

Figure 4.12. Small boxes/inserts are placed in for preparing access pockets of joint panel mold

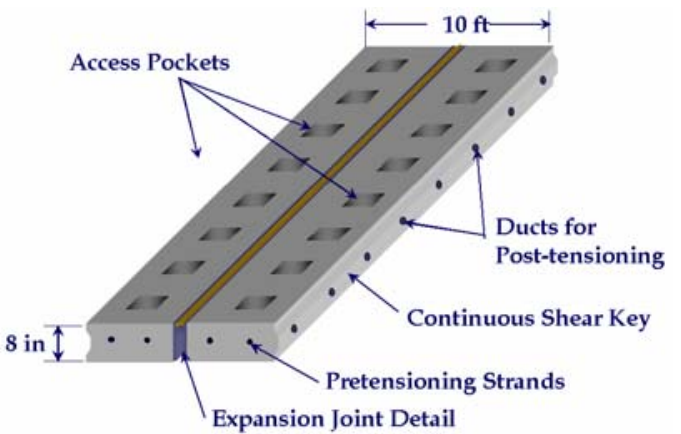

Figure 4.13 Schematic diagram of joint panel 


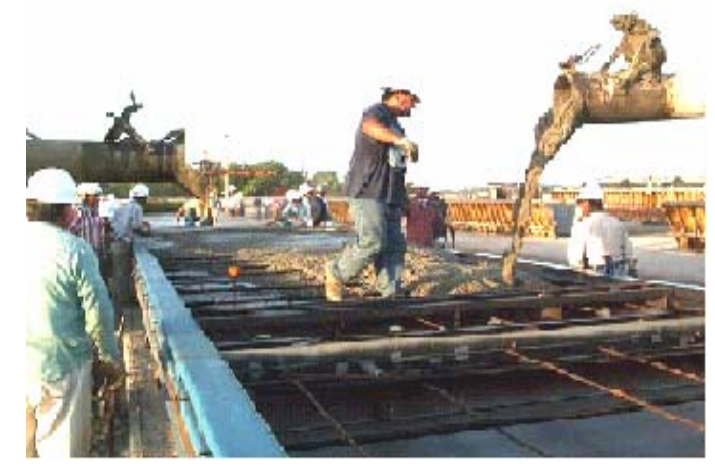

Figure 4.14. Filling concrete in forms of panels

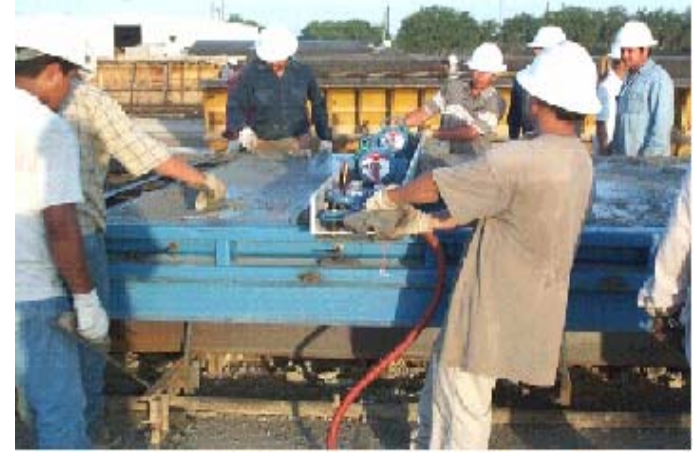

Figure 4.15. Leveling the surface of the concrete
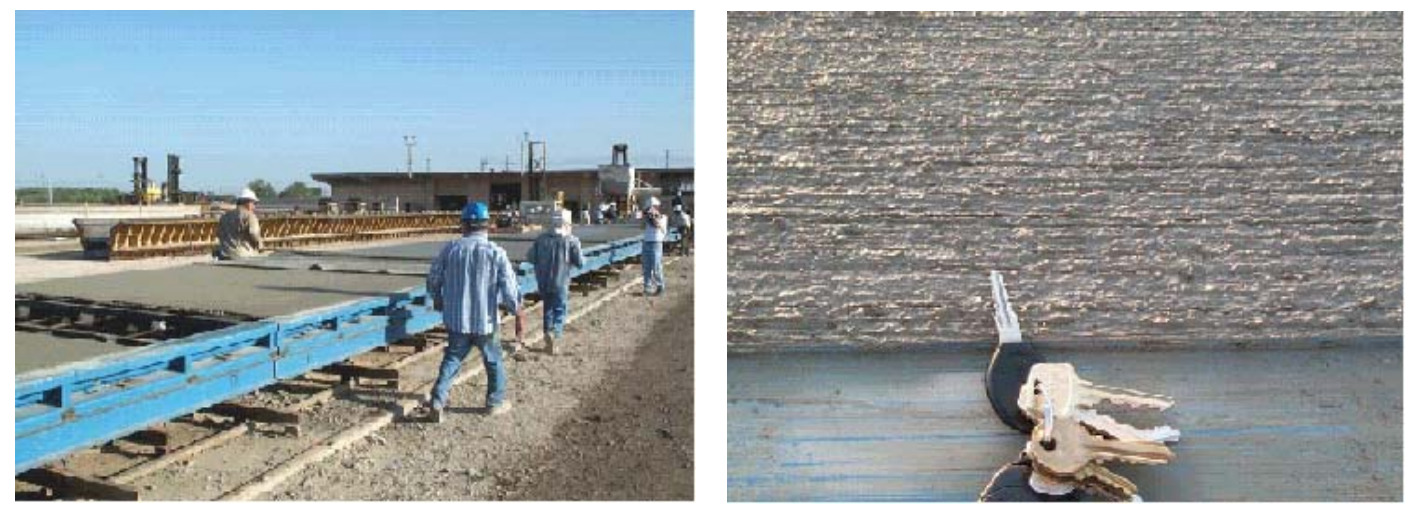

Figure 4.16 Creating surface textures by a carpet drag finish

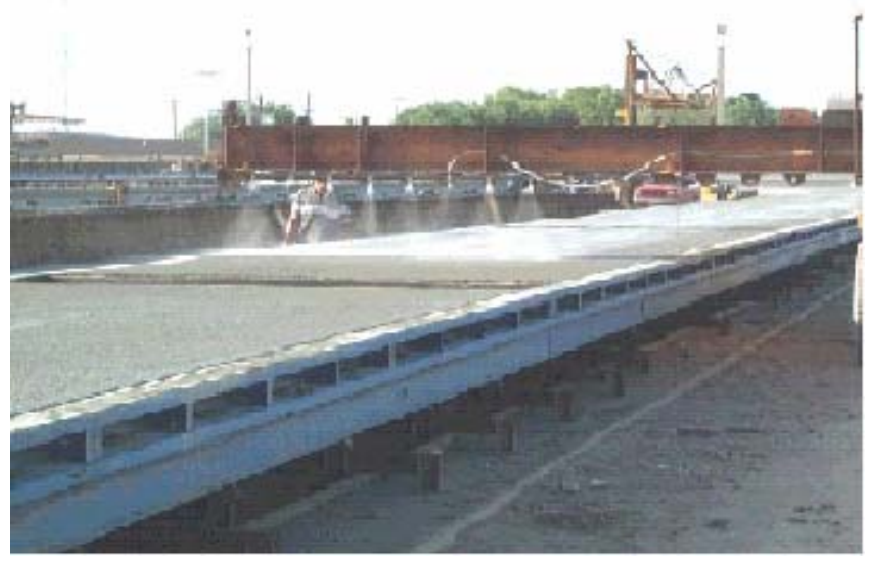

Figure 4.17 Double-coat of curing compound was applied 

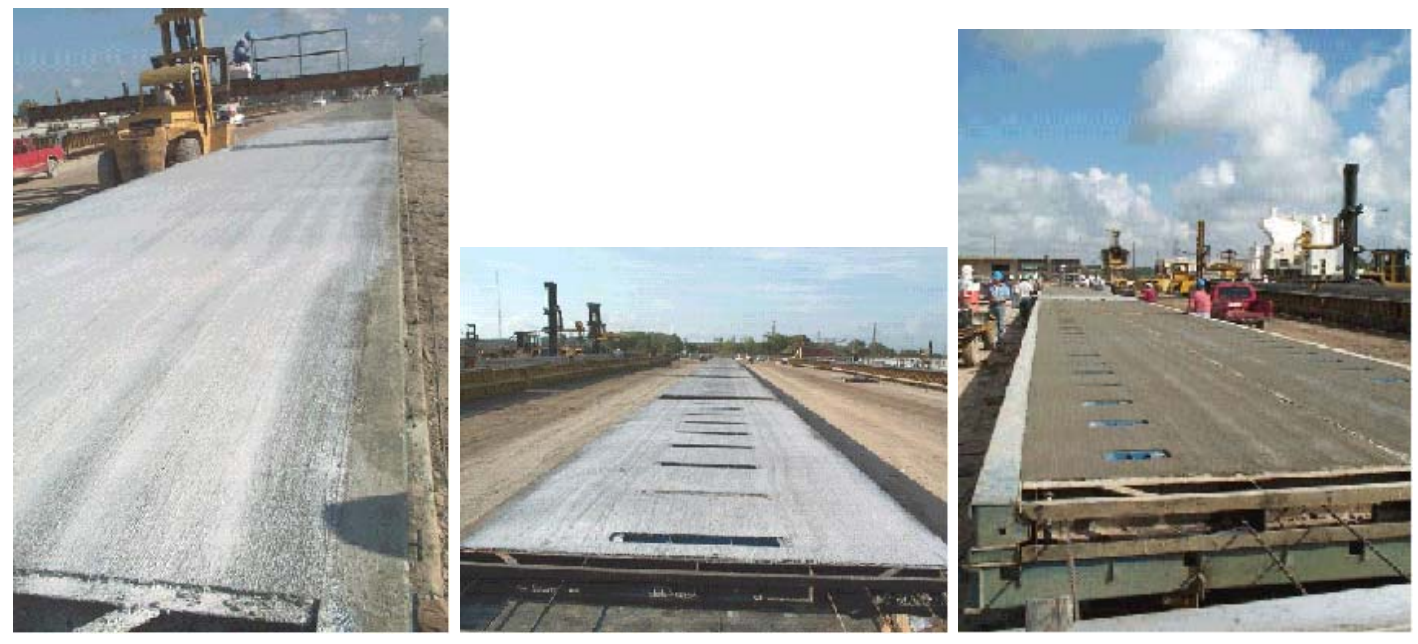

Figure 4.18. Finished set of base panel, central panel, joint panel (from left to right) in the casting bed
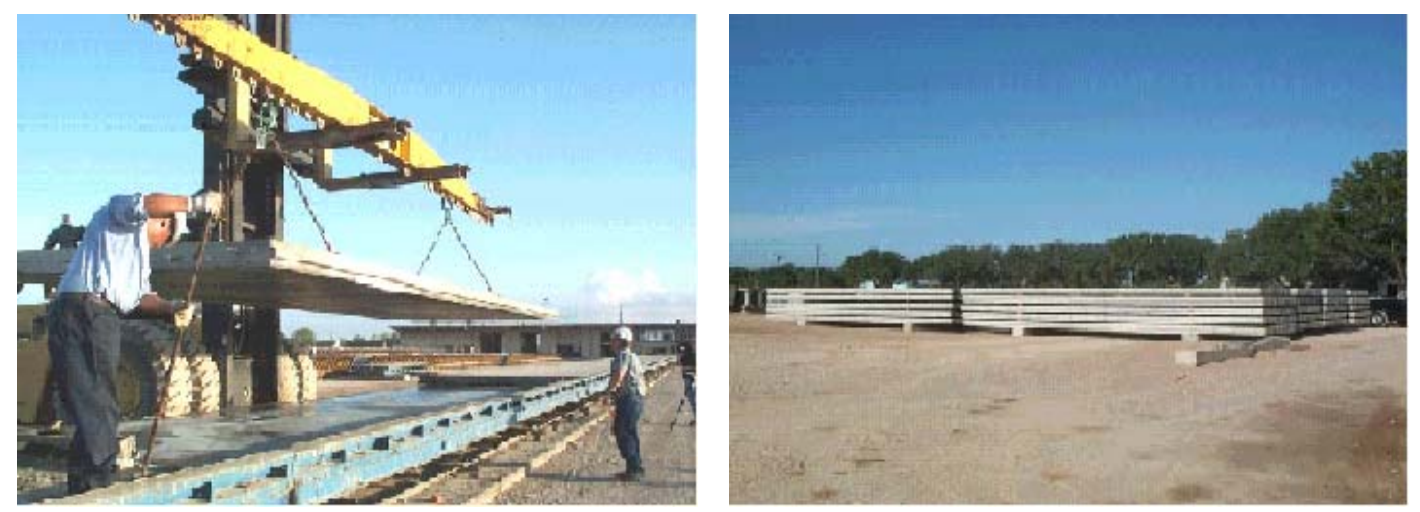

Figure 4.19. Move the finished panels to storage yard

\section{$\underline{\text { AC Leveling Course }}$}

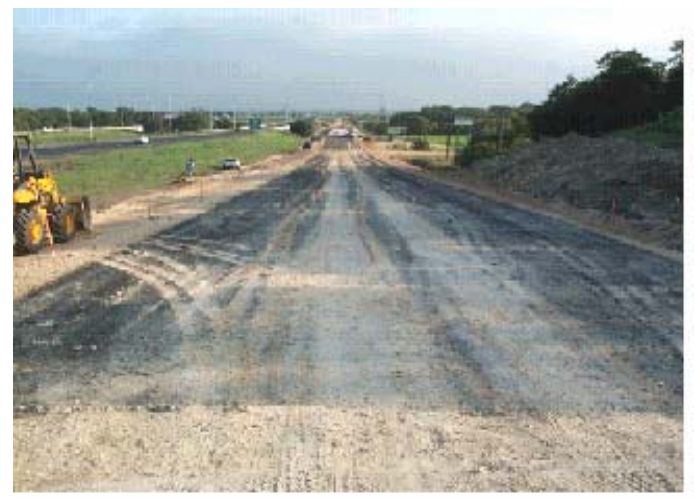

Figure 4.20 Preparing subbase

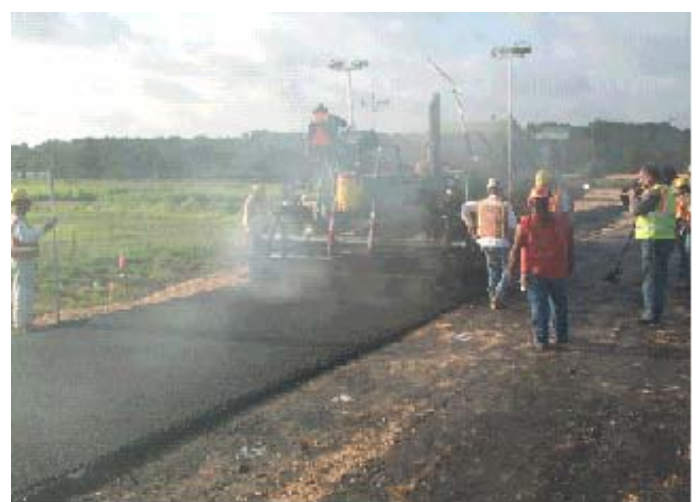

Figure 4.21 Place a 1”-2” thick asphalt leveling course on subbase 

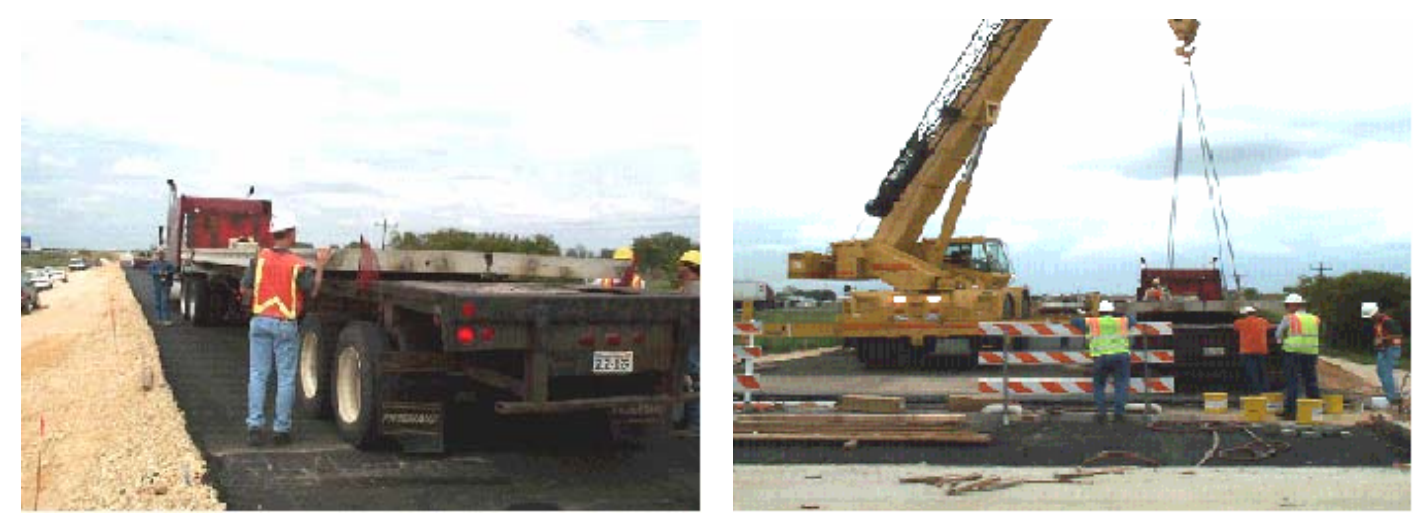

Figure 4.22 Transport panels to worksite

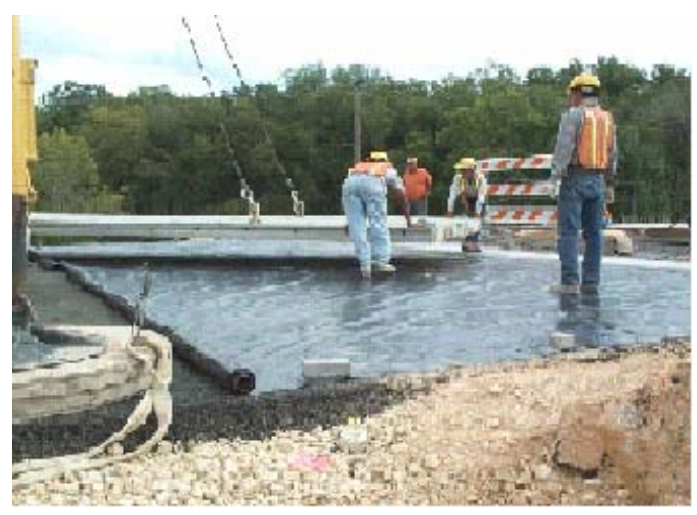

Figure 4.23 Place 1/8” polyethylene sheet on asphalt course

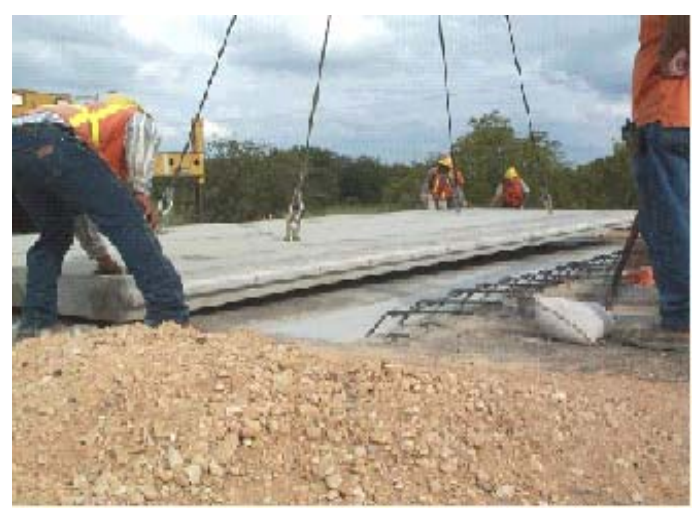

Figure 4.24 Place a full-width joint panel over the asphalt leveling course.

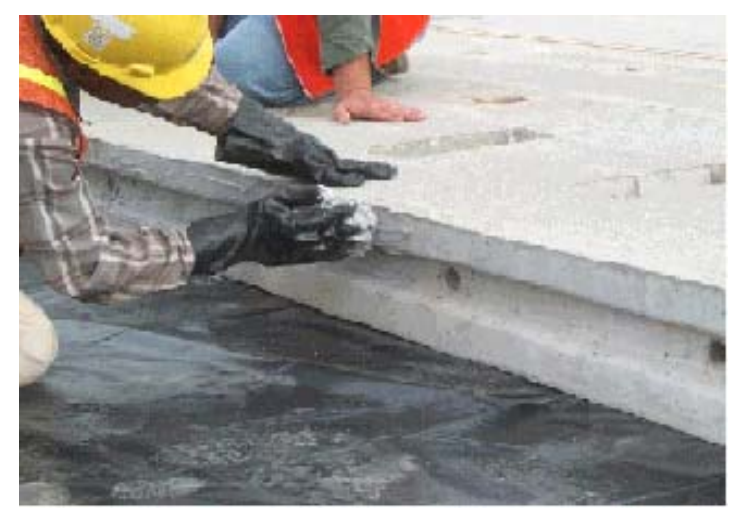

Figure 4.25 Place slow-setting epoxy 

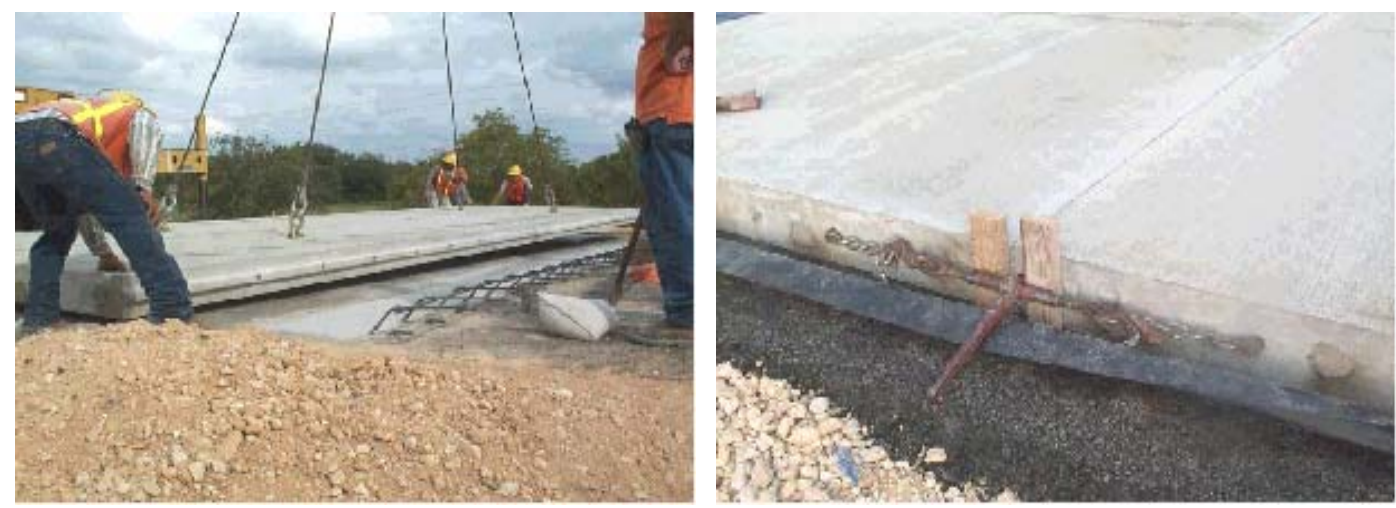

Figure 4.26 Place the base panel next to the joint panel and tie two panels together

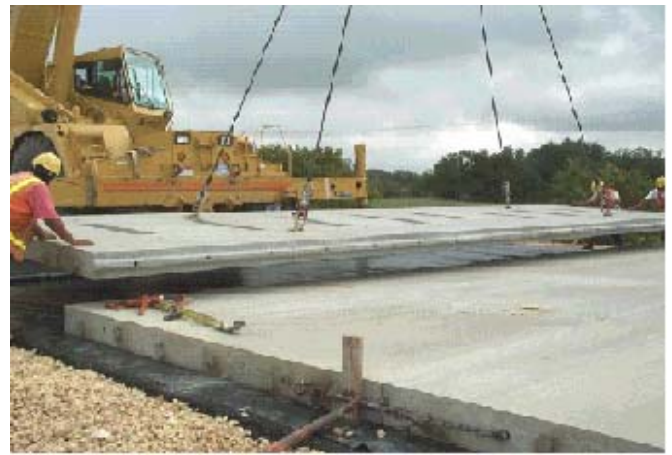

Figure 4.27 Place panels in the sequence of joint, base, and central panels

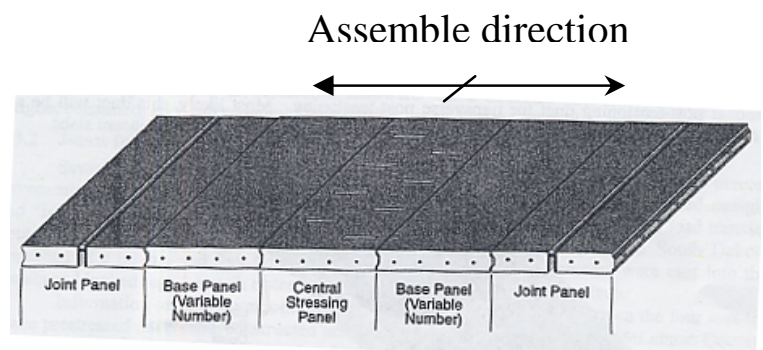

Figure 4.28 Diagram of assembled panels

\section{Post-tensioning and grouting}

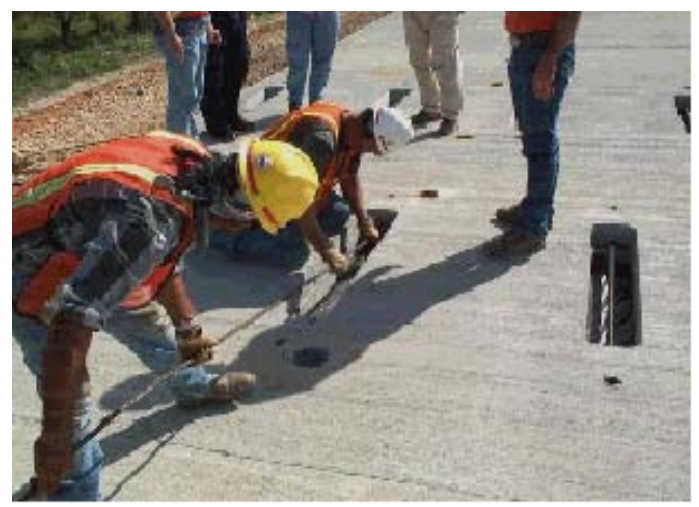

Figure 4.29 Strands will be threaded through the stressing pockets from the central panels 

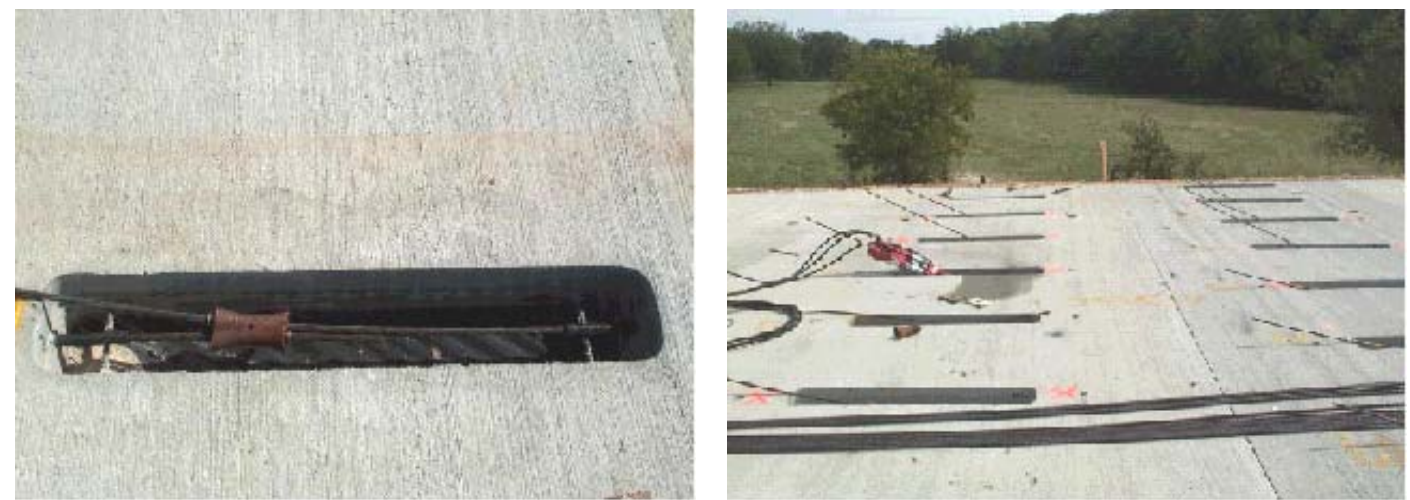

Figure 4.30 Strands from each end of the slab are coupled together (left) and tensioned in the central stressing pockets (right)

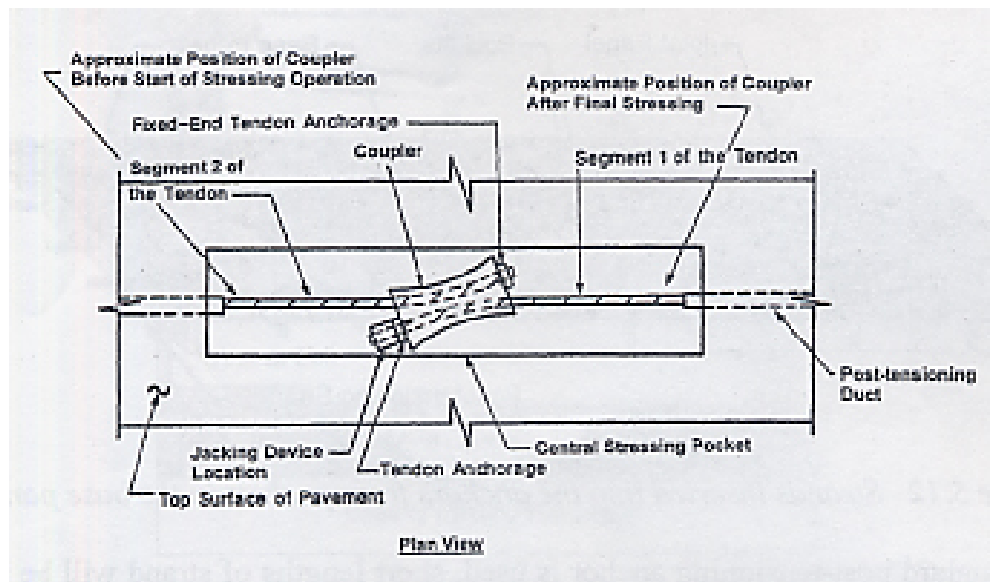

Figure 4.31 The schematic diagram of strand coupler used in the central stressing pockets

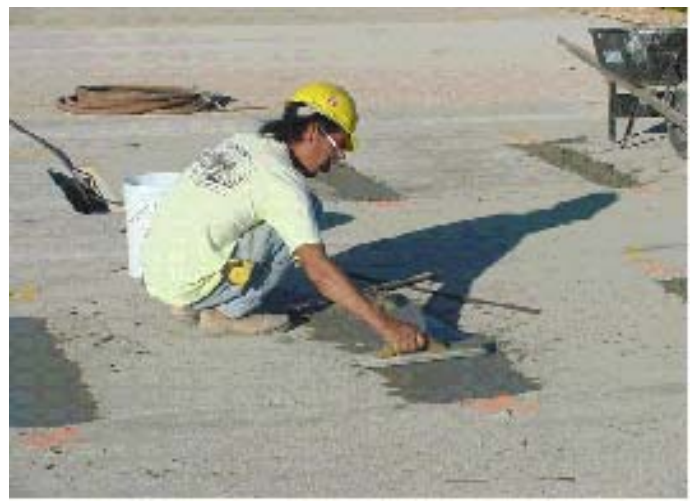

Figure 4.32 Finish the stressing pockets with fast-setting concrete 

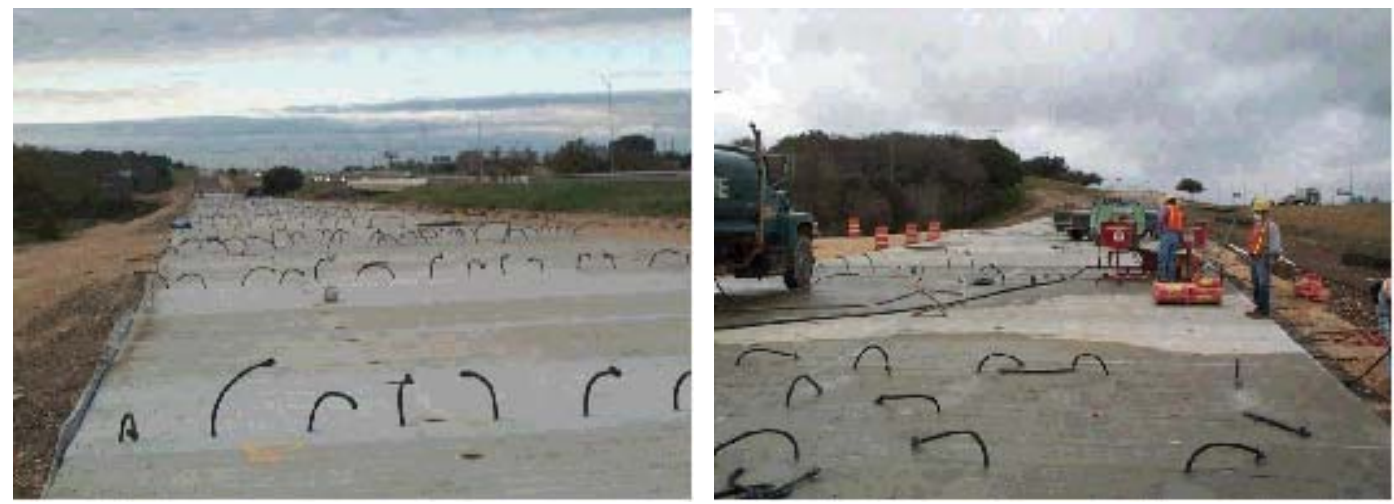

Figure 4.33 Grout the post tensioned conduits

\section{Partial-Panel Placement}

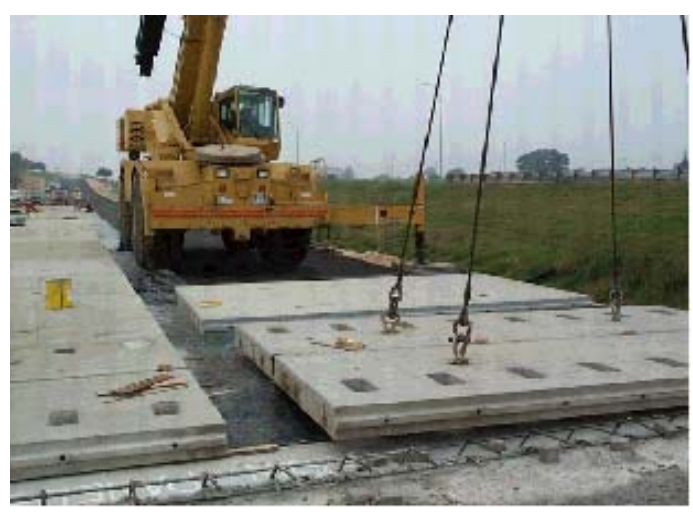

Figure 4.34 Assemble partial panels

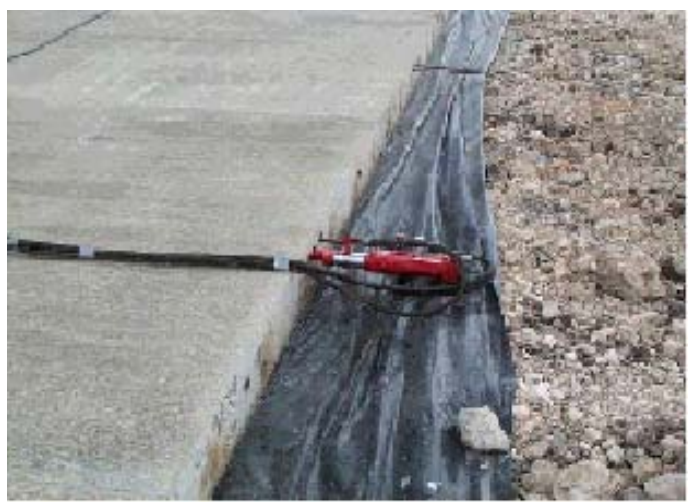

Figure 4.36 The post-tension is applied

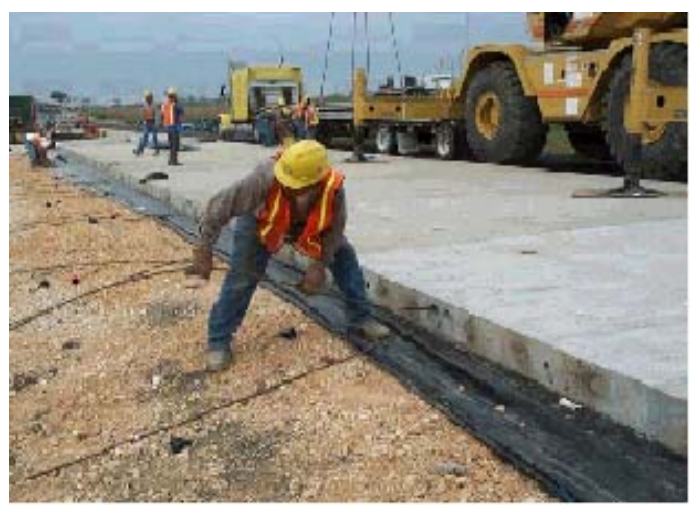

Figure 4.35 The strands will be threaded through the ducts in the panels

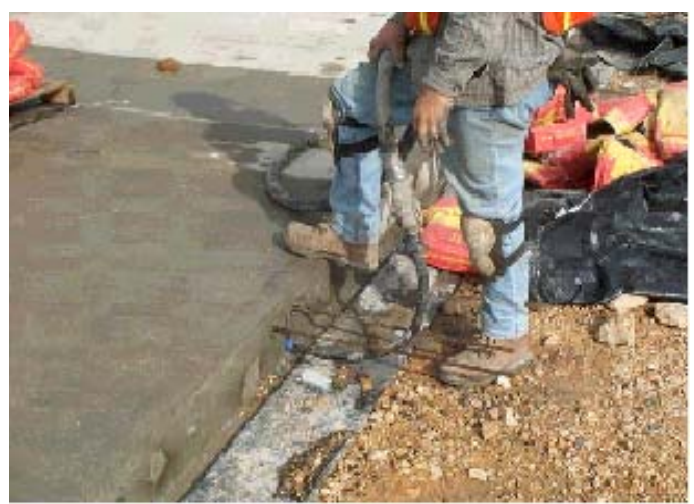

Figure 4.37 Grouting 


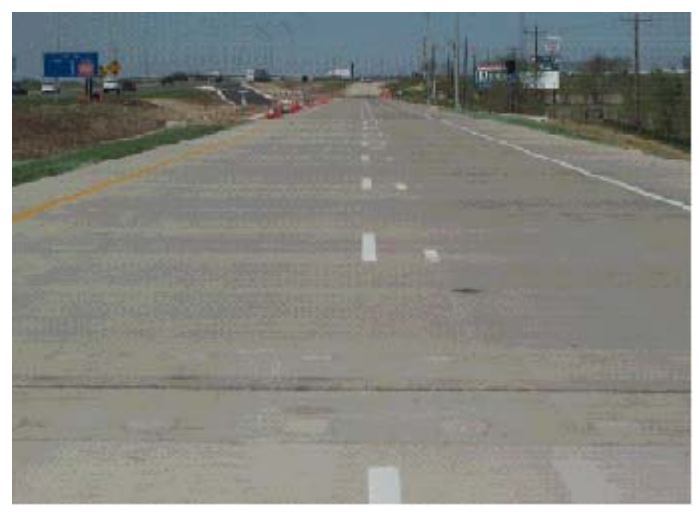

Figure 4.38 The finished precast pavement project in Georgetown, Texas

The project utilized three different panels: base panel, central stressing panel, and joint panel. Each of them has its own special function. For examples, base panels are described as “filler” panels between the central stressing panels and joint panels by CTR, University of Texas-Austin. Central stressing panels are similar to the base panels besides the addition pockets for stressing the post-tensioning tendons. The joint panel seems to be a more complex panel, which will be illustrated later on (15).

\section{$\underline{4.5 \text { Joints }}$}

Joints are integral parts of the PPCP. The two types of joints being concerned and used in precast concrete pavement in TxDOT are intermediate joints and the expansion joints. The intermediate joints which are used between the individual panels utilized the thin liquid sealant between panels to ensure that assembled precast panels act as a continuous pavement between expansion joints and provide complete load transfer between panels. The expansion joints which are used at the end of the slab are designed not only to accommodate the expansion and contraction movements of the pavement, but also to provide adequate load transfer between the slabs on either side of the joint (16). 
The expansion joint used in McLennan County cast-in-place prestressed pavement shown in Figure 4.39 has been proven to perform well under heavy traffic loading (high truck volume) after 18 years in service. Therefore, the Georgetown project utilized the same techniques. Before casting the joint panels, the joint detail was prefabricated. During fabrication, joint detail was cast into the joint panel. To make sure the joint remains parallel during fabrication of the joint panel, the steel flanges at the top of the joint are tack-welded together before casting the concrete for the joint panel. The welds were removed before applying posttensioning and after the panels are set in place. The anchors shown in Figure 4.40 were positioned in the joint panel so as not to interfere with the dowels or bar from the joint detail. Bolted to the joint structure, the anchors shown in Figure 4.41 are used to ensure that they accommodate not only the expected expansion and contraction movements of the pavement slabs but also withstand repeated wheel loading. According to the past experience, the joint width design should never exceed 31/2-4 in for providing good ride quality (16).

\section{$\underline{\text { Joint Panel Detail }}$}

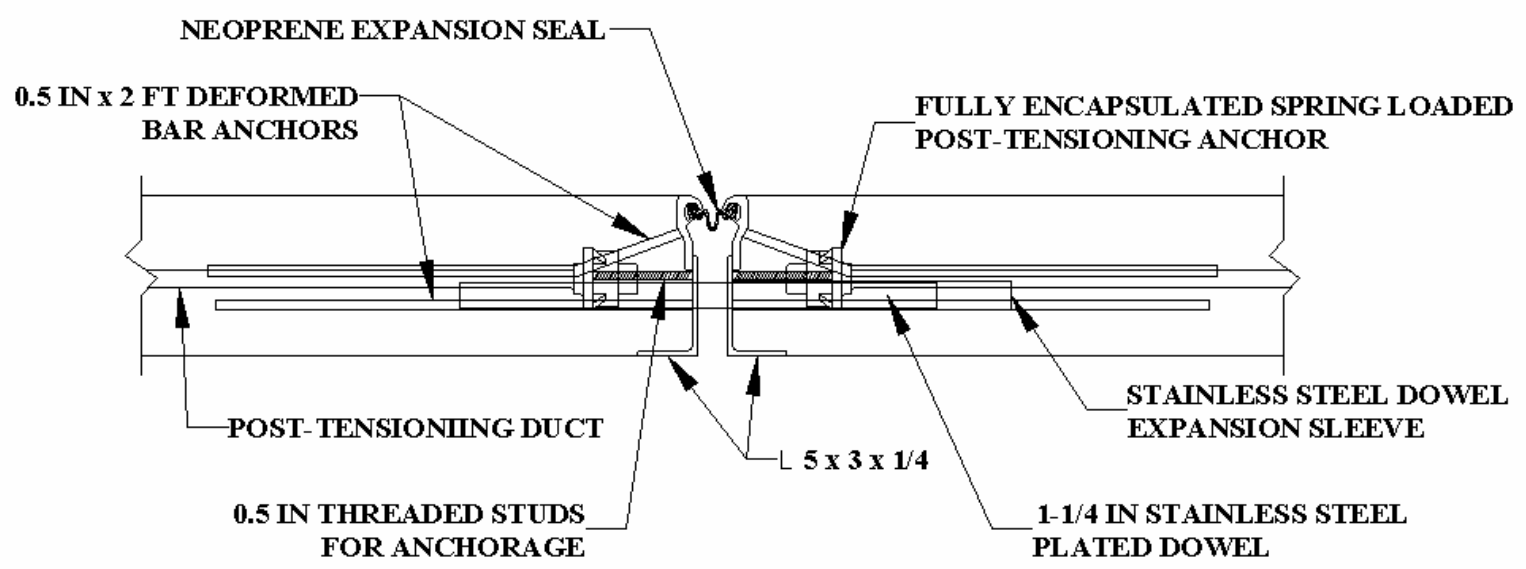

Figure 4.39 Expansion Joint Detail of the Joint Panel (17) 

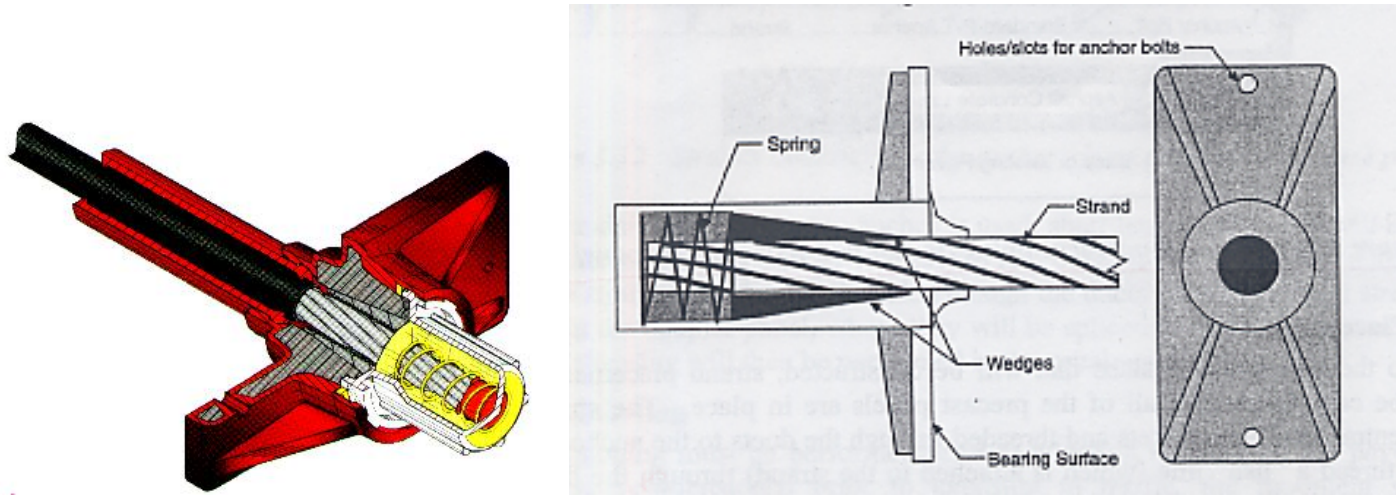

Figure 4.40 The detailed schematic diagram of spring-loaded post-tensioning anchor (17)

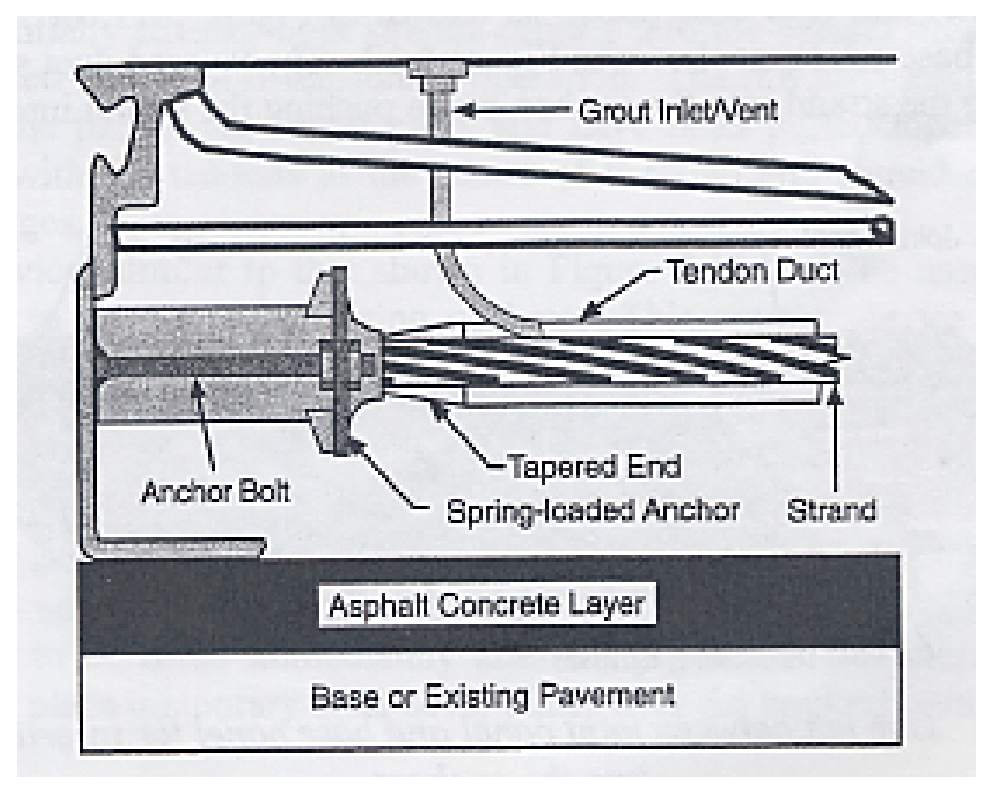

Figure 4.41. Fully encapsulated spring loaded post-tensioning anchor (17)

\subsection{Advantages and Disadvantages}

There is little PPCP built in the United States. The following advantages and disadvantages summarized are based on the project report of the precast prestressed concrete pavement pilot project near Georgetown, Texas. $(10,11)$ 


\subsubsection{Advantages}

First, the advantages are discussed as follows:

1) Expedited Construction

a) Expedited construction with almost immediate exposure to traffic after placement

Since extra time is not required for the concrete to reach sufficient strength before opening to traffic, as with conventional concrete pavement, the pace of PPCP construction is expedited.

b) Possibility for all year round construction

The panels can be precast in the factory or some place near the field and then transported to the placing site. It allows construction to proceed all year round. In other words, it can be “unseen” construction (cast and cure the slab in site or factory) under all kinds of weather. Overnight or weekend construction is possible for precast concrete.

c) Low user cost

User costs are the costs incurred by the users of the roadway due to the presence of construction activities, such as increased fuel consumption and lost work time. Shortening the closing period for the roadway for the construction will lead to roadway user cost savings. Since the PPCP project can be opened during construction and also can be immediately open to traffic after construction, it can be said that it has a low user cost during construction. 


\subsubsection{Disadvantages}

PPCP has been little used in the roadway construction in the United States. The Georgetown pilot project is the first experiment. The lack of a proven and easily used design procedure had been a major obstacle to its first application. The disadvantages found by the CTR, UT-Austin will be shown below:

1) Ride Quality

A high-speed inertial profilometer was used to evaluate the ride quality of the finished pavement. The average International Roughness Index (IRI) was $2.61 \mathrm{~m} / \mathrm{km}$ (165.5 in/mile) for the partial-width panels and $2.32 \mathrm{~m} / \mathrm{km}$ (147.1 in/mile) for the full-width panels. The values are higher than the normally required correction for conventional concrete pavement. However, TxDOT felt that the ride quality did not warrant diamond grinding or any other corrective measure. Also no irregularities that could lead to dynamic loading and premature pavement failure were observed in any of the panels. (11)

The recommendations from CTR, UT suggest that for future applications a ride quality standard should be established to precast pavement that will determine whether the finished pavement is smooth enough for immediate traffic use. Smoothness incentives and penalties would help to ensure a high quality finished product from the contractor. (11)

2) Cost

The total cost of the Georgetown PPCP, including the panels’ fabrication, base preparation, and construction, was approximately $\$ 203 / \mathrm{m}^{2}\left(\$ 19 / \mathrm{ft}^{2}\right)$. The cost is significantly higher than expected for an equivalent 355 mm CRCP $\$ 36-\$ 48 / \mathrm{m}^{2}\left(\$ 3.34-4.46 / \mathrm{ft}^{2}\right)$. However, it may be understandable for the following reasons: First, the Georgetown precast pavement was a relatively small $(0.7 \mathrm{~km})$ project. This is only a tentative pavement that is not 
the economies of scale. A much larger project would have had a significantly lower unit cost. Secondly, again the Georgetown PPCP project was tentative project. Neither the contractor nor the precast supplier was familiar with precast paving techniques and therefore likely submitted higher bids. The initial costs will be higher until constructors and transportation agencies become familiar with the techniques. (11) 


\section{V.SUPER-SLAB SYSTEM}

The Super-Slab system is the precast concrete pavement method that places precast slabs on the sub-grade. Fort Miller Co, Inc. designed it in 2001 as a jointed concrete pavement. Several patents on the system are currently pending (18).

Super-Slab was developed to be employed in heavy traffic areas, including highways, ramps, taxiways, and where user costs are high and long-term staging is nearly impossible. The general construction procedures for the Super-Slab system are addressed as follows, followed by the benefits and concerns of the system and a case study.

\section{$\underline{5.1}$ Precast Super-Slab Design}

Precast pavement panels typically include dowel bars to provide load distributions and to provide a secure interlock between slabs and two kinds of grouting ports, bedding grout ports, and dowel grout ports as shown in Figure 5.1. Bedding grout ports are used to pump a grouting material to the undersides of the slabs to fill any voids between the slabs and the prepared subgrade. Dowel grout ports are required for adjacent panels to be securely interconnected by pumping a high-strength material into the ports after the panels are placed on the sub-grade. Figure 5.2 shows the precast concrete form setup before pouring concrete, where rebar setting, grout ports, and dowel bars are shown.

Precast concrete slab design involves thickness and strength of concrete, the size and spacing of reinforcing and dowels, subgrade details, and the finish of top surface. In general, precast concrete slabs for the Super-Slab system features (18):

- High performance concrete is cured under factory-controlled environments

- Slabs are cast under very tight tolerances of $+/-4 \mathrm{~mm}$ 
- Dowels and tie bars are embedded

- There are inverted dove tail slots to match the embedded dowels and tie bars for grounding.

- Width is from 4' min. to 12' max.

- Length is up to 25'

- Thickness can be designed as required.

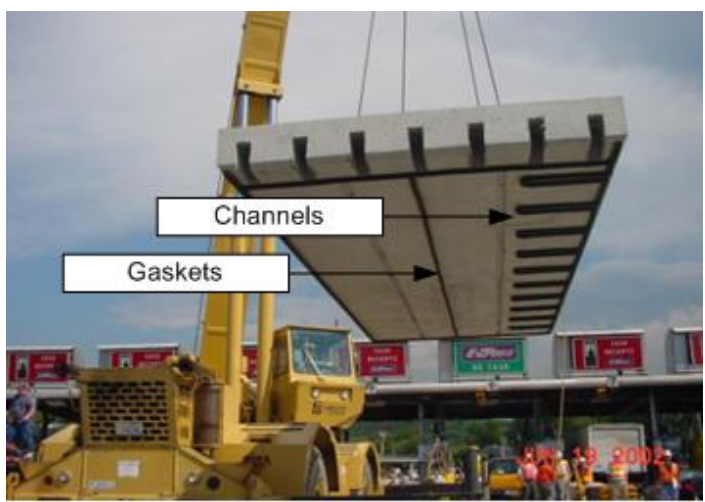

[a] Channels and Gaskets

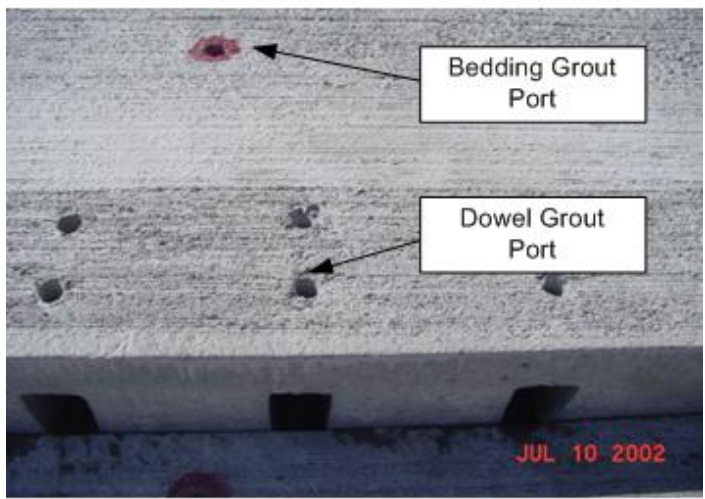

[b] Grout Ports

Figure 5.1 Grout Distribution System (18) 


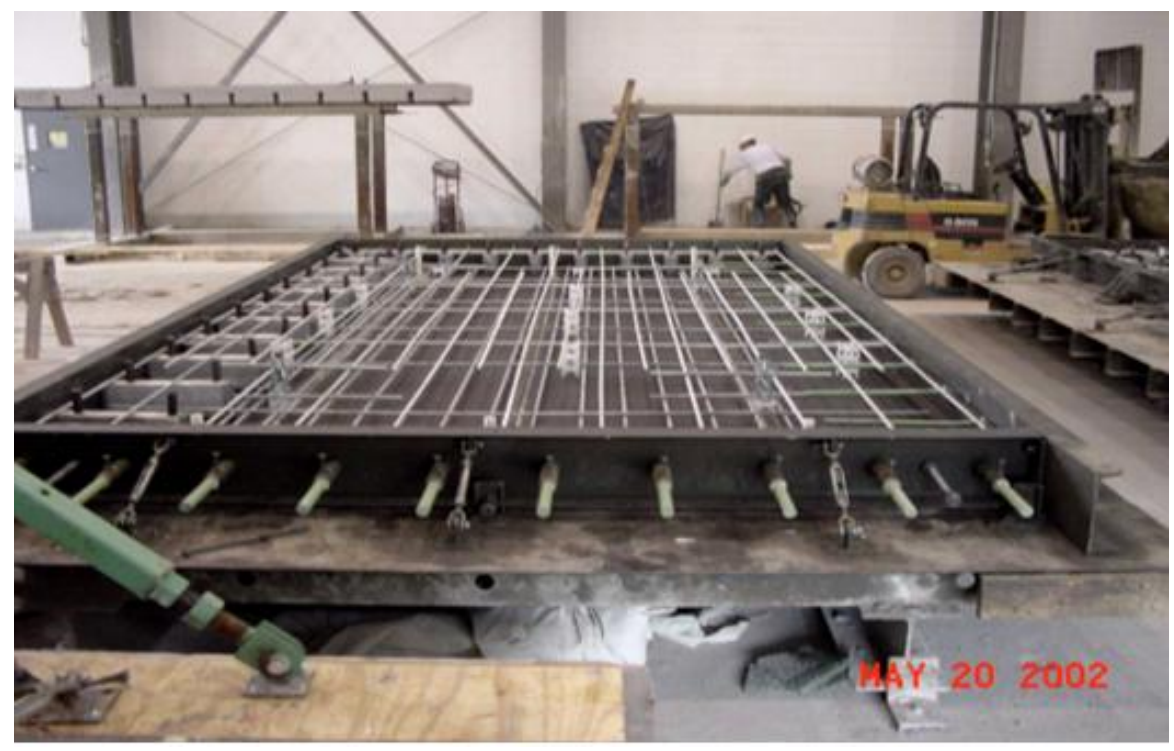

Figure 5.2 Precast Concrete Slab Form (18)

\section{$\underline{5.2} \underline{\text { Field Installation of Super-Slab }}$}

The field installation of slabs can be broken into 4 major steps:

- Step 1-Removal of existing slabs: The deteriorated existing pavement boundaries are identified and marked. The damaged pavement areas are removed by saw-cutting and excavating the areas of pavement.

- Step 2 - Preparation of sub-grade: Once the existing pavement is removed, remaining deteriorated concrete is dislodged. Sub-grade is compacted to the specified density and then is covered with the bedding material, a finely graded stone dust. The sub-grade topping is screeded with a specially designed sub-grade finisher known as Supergrading. Laser-controlled screeding minimizes the amount of grouting needed for bedding the slab (19). The sub-grade can be finished within +/- 1/8” of the required plane with the laser-controlled screed (18). Figure 5.3 shows the Supergrading system. 


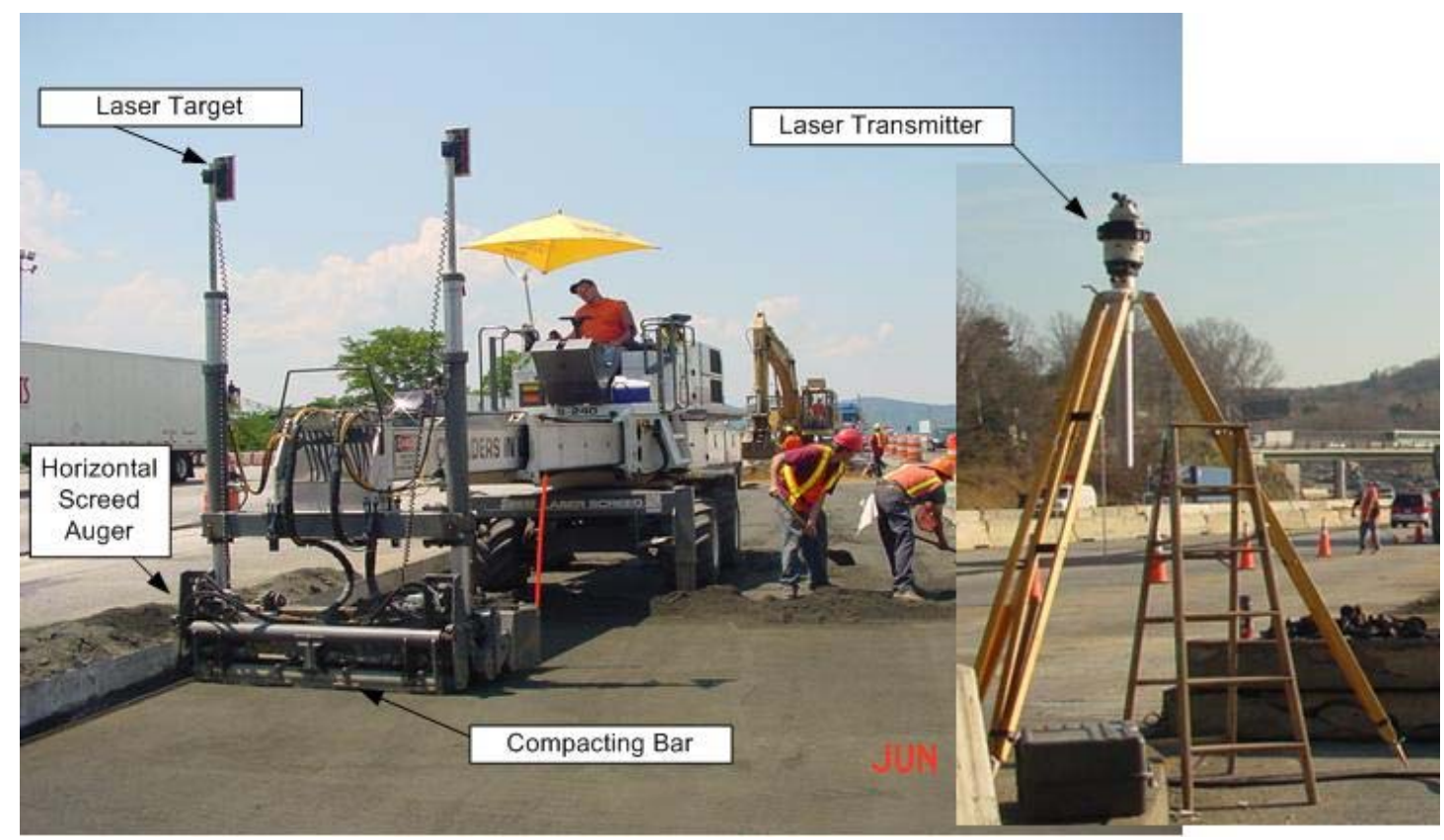

Figure 5.3. Supergrader (18)

- Step 3 - Placement of slabs: After fully compacted sub-grade is prepared, each precast concrete slab is placed on the stone dust bed. Each panel has dowels and tie bars on two sides and matching slots on the remaining two sides. The slots allow adjacent panels to be placed over the dowels or tie bars without causing any damage to dowels or slabs. Figure 5.4 shows the SuperSlab placement. The Super-Slabs can be placed at a rate of 8 to 10 slabs per hour (18).

- Step 4 - Placement of grouting: With the precast concrete slabs in place, grouting begins to ensure secure connection between slabs or to fill any voids of the slab undersides. As mentioned earlier, grouting work is performed through the two kinds of ports: dowel grout port and bedding grout port. One of the two dowel grout ports is pumped with a non-shrink grout until the grout oozes from the other port to make sure the dowel is completely covered with grout. The next step is to pump a grout into the bedding grout port and into the grout channels on the underside of the panels to fill any remaining voids between the precast concrete slabs and stone dust bed (20). Figure 5 shows the dowel grouting work and core taken through transverse dowel. 

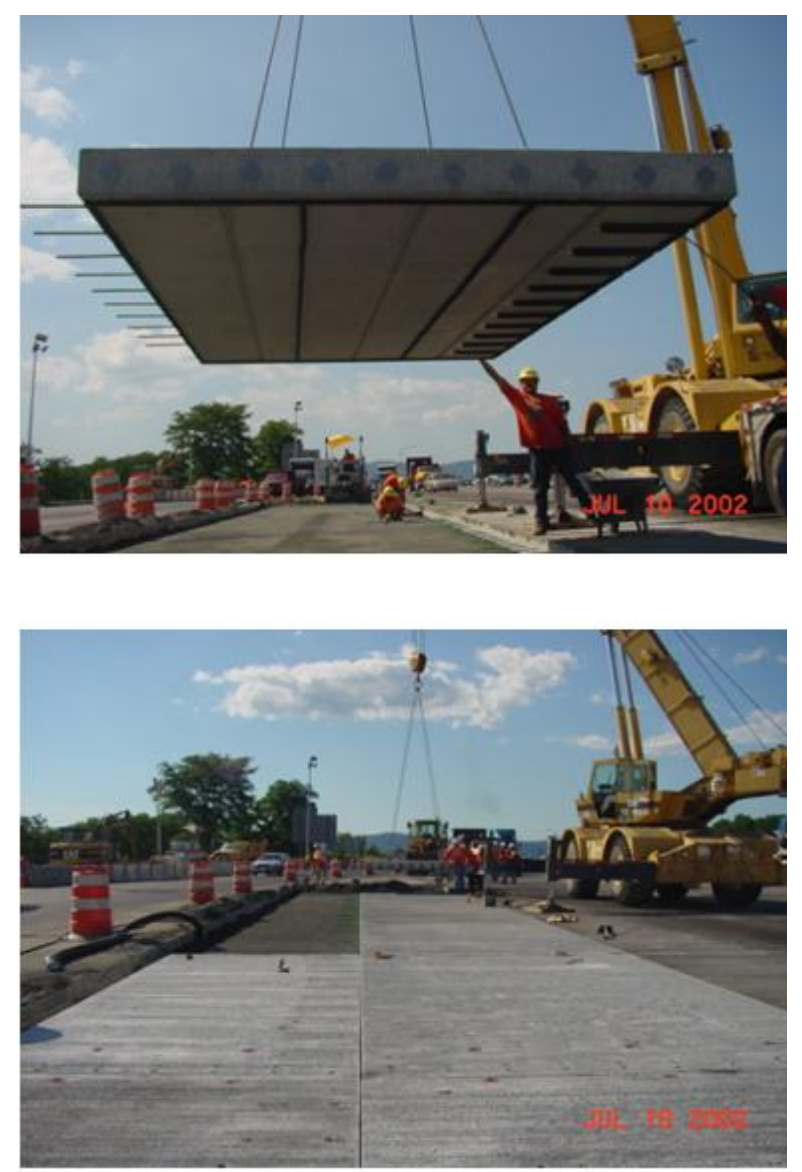

Figure 5.4. Super-Slab Installation (18)
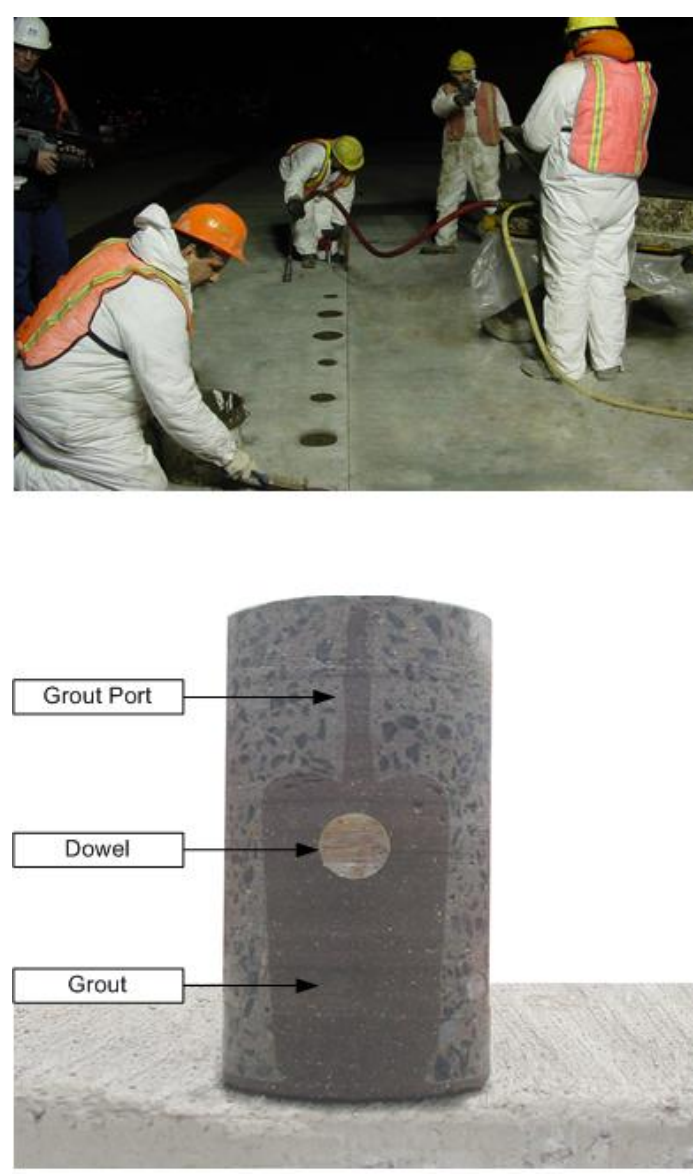

Figure 5.5. Grouting Work and Core (18)

\section{$\underline{5.3}$ Case Study of Super-Slab System - Tappan Zee Bridge Toll Plaza, Tarrytown, New York}

$\underline{(20)}$

The New York State Thruway Authority, the owner of the Tappan Zee project, wanted to replace the badly deteriorated pavement of the Tappan Zee Bridge Toll Plaza. However, the biggest problem was that all 13 lanes of the plaza needed to remain open during the morning rush hour for the whole project duration. On average, 135,000 vehicles use the toll plaza per day (18). This demand implied that a conventional cast-in-place pavement method could not be acceptable for this project. Therefore, the Thruway Authority selected the Super-Slab system 
after several brainstorming sessions with the people from the Fort Miller Co., the Federal Highway Administration, and the New York State Department of Transportation.

The project, begun in October 2001 and completed in July 2002, requested that the approach pavement on each side of the toll booths $\left(85,000 \mathrm{ft}^{2}\right.$ on the east side and $75,000 \mathrm{ft}^{2}$ on the west side) be excavated and replaced with precast concrete slabs. Since the work was limited to off-peak hours, it was performed Mondays through Thursdays between 10 am and 6 am on the following days. Each section had to be completed and open to traffic by 6 am to avoid a liquidated damage of $\$ 1,300$ per minute for every minute after 6 am, up to a maximum penalty of $\$ 250,000$ per day (19).

The project used a total of 1,064 precast concrete slabs that were single plane slabs with the thickness of 10”. The length of the slabs was 18 feet and the width was 7, 10, or 12 feet.

The Thruway Authority is pleased with the construction results, especially ride quality and appearance. Even if using the Super-Slab system cost the owner about $\$ 26 / \mathrm{ft}^{2}$ including fabrication, delivery, and installation that was much higher than a conventional cast-in-place method, it can be a viable alternative because it is able to significantly reduce the user costs.

\subsection{Advantages and Concerns of the Super-Slab System}

Advantages can be addressed as follows:

- Fast: Once precast concrete slabs are prepared, the other steps, including removal of existing slabs and placement of new slabs can be performed in a single day.

- Overnight, weekend, or off-peak construction has little impact or no impact to the traveling public. 
- Better concrete quality and its performance can be achieved.

- Lower user cost can be achieved through the use of the Super-Slab system.

Several concerns can be listed as follows:

- The Super-Slab system is restricted by patents.

- The surveying and its program may fail to generate reliable profile data.

- The pace of supergrading process is slow which may reduce productivity rate.

- There is $15 \%$ stonedust (fine aggregate) pass \#200 size sieve

- The stone dust bed may cause a drainage problem.

- The overall long-term performance of the Super-Slab system remained to be seen. 


\section{URETEK METHOD}

The Uretek method can be categorized into three segments as follows.

\subsection{Uretek Method $(21,22)$}

The Uretek method uses special high-density polymers to lift, realign, undersea, and fill void of concrete slabs that are placed directly on the ground. Polymer resin components are injected through small-drilled holes at the concrete slab. As the Uretek method employs small drilled holes to inject resin mixture and does not depend on the hydraulic forces to lift a slab, it is not likely to crack or break slabs. As the resin mixture expands, void spaces are filled, the subbases are strengthened, and the section is stabilized. The composite mixture quickly cures into a strong, stable, and long lasting replacement base material. The Uretek process can be employed to repair differential settlement and void conditions on a wide variety of concrete and asphalt slab configurations, including highways, roads, airport runways, and more. Figure 6.1 shows the application of the Uretek method.
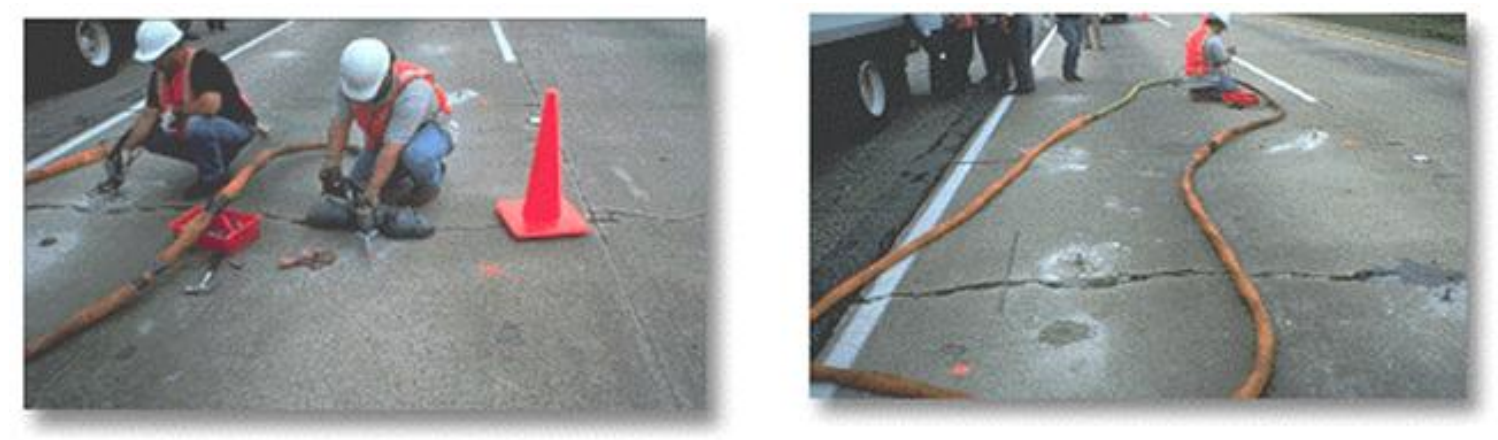

Figure 6.1 Uretek Method $(21,22)$

\subsection{Stitch-in-Time Technology $(21,22)$}

Stitch-in-Time technology is a repair system for restoring load transfer to jointed, cracked, spalled, or otherwise damaged concrete pavement. The Stitch-in-Time system employs a series of deep, half-inch saw-cut slots to insert $1 / 4$ inch thick composite reinforced resin blades. 
Once the blades are positioned, the remaining space in the slots is filled with dry sand and the whole materials are wetted out and bonded into place with a high-density polymer resin $(21,22)$. Since the material is cured rapidly, the traffic can be restored almost immediately. The system for damaged concrete pavement can provide stronger, faster, less expensive solutions compared to the existing dowel-bar retrofitting technology. Figure 6.2 shows the Stitch-in-Time technology.
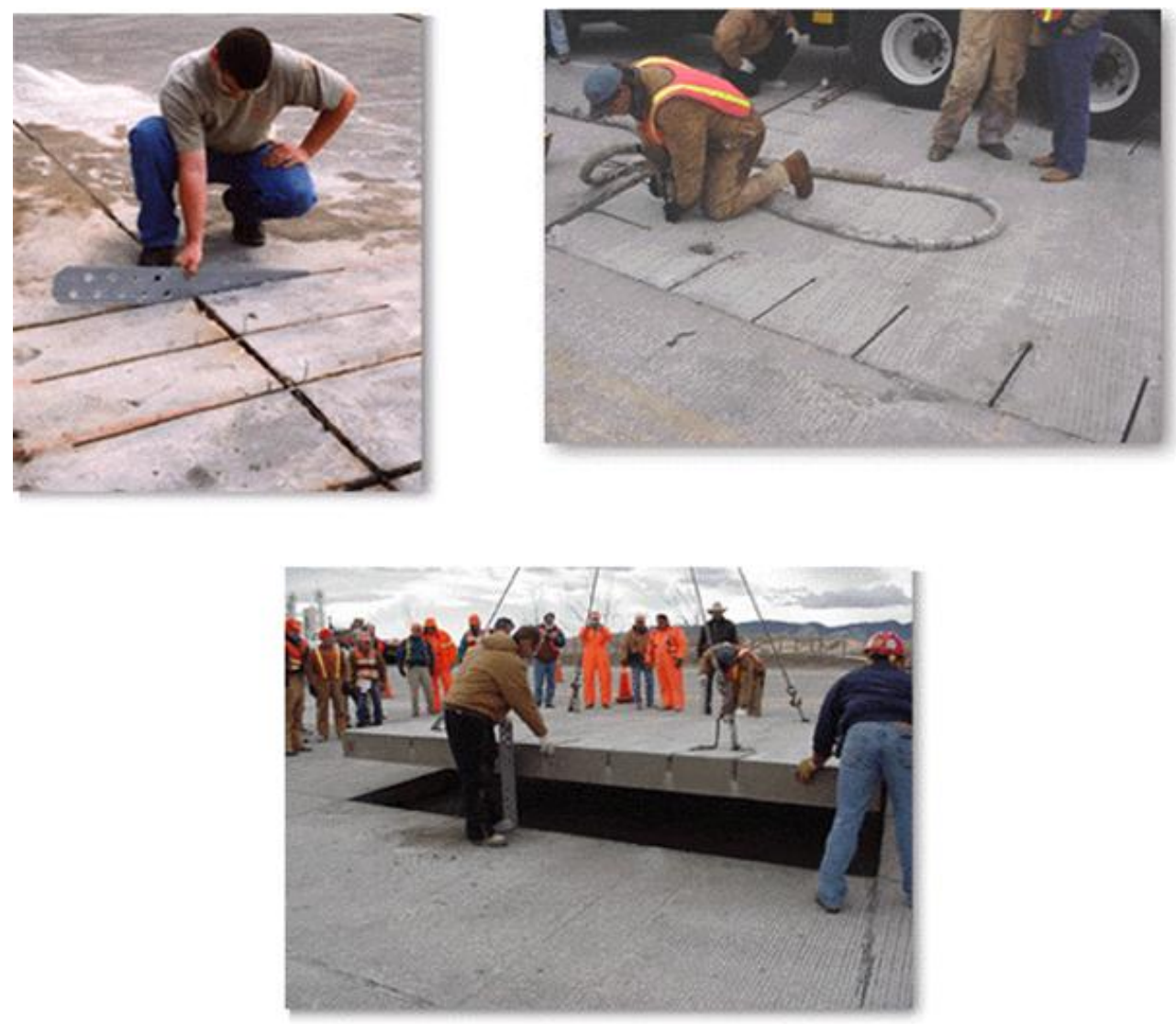

Figure 6.2 Stitch-in-Time Technology $(21,22)$

\subsection{Deep Injection Process $(21,22)$}

The deep injection process uses high-density expanding resins to fill, densify, and stabilize low-density compressible soils to a depth of 30 feet and beyond. Uretek's expanding 
polymer is a specially designed hydrophobic material that can be inserted to various damaged strata levels through small-drilled holes. The process can be applied to highways, bridge approach/exit slabs, and any slab with settlement problems and base soil compaction. Figure 6.3 shows the deep injection method.
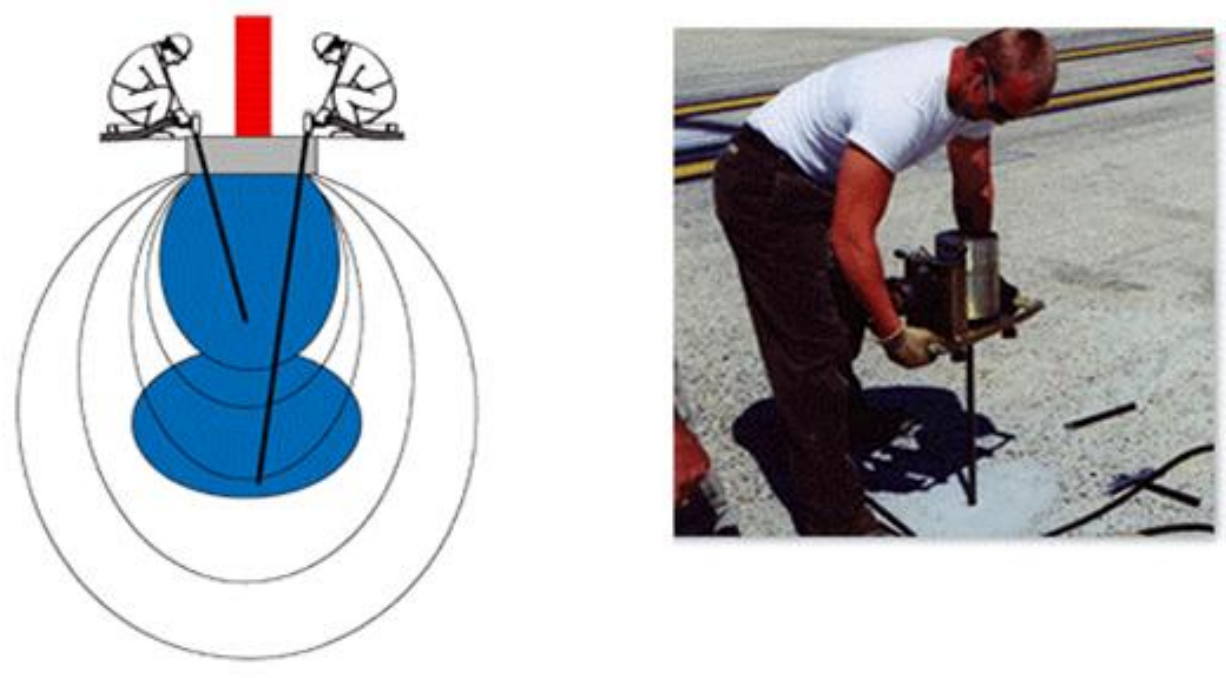

Figure 6.3 Deep Injection Method $(21,22)$

\section{$\underline{\text { 6.4 Case Study of Uretek Method - Colorado Pilot Project (23) }}$}

CDOT (Colorado Department of Transportation) decided to use precast concrete slabs to replace deteriorated highway concrete panels. CDOT started to make a plan to apply precast concrete slabs with Uretek USA engineers.

CDOT chose the site of State Highway 287 near Fort Collins for a pilot project where 10,000 to 15,000 vehicles travel daily. Three precast concrete slabs were cast to replace deteriorated panels. Since the job site was located on a curved area, the measurements of every side of the 10 " thick panels differed. The panel sides vary from 6' and 8-3/8" to 16 ' and 8-1/8" 
with no two sides identical. The injection hole patterns vary from 18” to 3' apart with 15 to 17 holes per panel. The slabs weighed up to $25,000 \mathrm{lb}$, and strength exceeded 6000 psi in 28 days curing.

First, CDOT injected URETEK 486 foam into the undersides of adjacent slabs to underseal and stabilize the panels. Second, deteriorated panels were saw-cut and removed. And then, a Colorado precaster brought a prepared new precast concrete panel and placed it into the excavation. Next, URETEK 486 foam was injected through the holes on the surface to raise the panel to the specified elevation on the four sides. The last step was to install URETEK's Stitchin-Time load transfer devices. After CDOT successfully installed the first precast concrete slab on December 5, 2000, it installed the remaining two slabs on December 7, 2000.

The second pilot project was performed between May 29 and June 7, 2001, and it involved the replacement of 8 panels with precast concrete slabs and the asphalt overlay in the approach and departure lanes of the St. Vrain bridge on Interstate 25. Since the highway was in a heavy traffic area, all of the work shifts were scheduled from 9 or $11 \mathrm{pm}$ to 5:30 am with mandatory reopening.

With the experiences from two pilot projects, CDOT planned to find out ways to reduce production costs because the cost of using precast concrete slabs was 10 to $40 \%$ higher than a cast-in-place pavement.

\subsection{Advantages and Concerns of Three Uretek Methods}

Advantages can be addressed as follows:

- Voids under the slab or low-density soils can be easily restored.

- Traffic can be restored almost immediately upon completion. 
- Uretek’s expanding polymer is guaranteed for a period of ten years against any significant shrinkage or deterioration

- Uretek’s expanding polymers are light material.

Uretek methods may have several concerns as follows:

- Uretek methods are restricted by patents.

- Uretek methods may affect adjacent pavement systems or sub-grades

- It is hard to identify whether the expanding polymer completely fills the damaged or low-density areas

- Uretek methods are hard to be employed in long-range roadways.

- Finished appearance is not good.

- Long-term durability has to be monitored. 


\section{FULL DEPTH REPAIRS (FDR) METHOD}

\section{$\underline{7.1 \text { Full depth repairs }}$}

Full depth repairs (FDR) remove distressed slabs and place new precast concrete panels. Since the method uses precast concrete panels, it can provide several benefits, including no time required for curing, durable concrete and minimal variability in slab thickness.

\section{$\underline{7.2 \text { Construction Procedures }}$}

The construction procedures for FDR are as follows.

\subsubsection{Pre-cast Panel Mixture Design and Fabrication}

Three dowel bars are cast into the precast panel in each wheel path to ensure load transfer across the joints. The wire mesh is included at the panel mid depth to resist cracking due to contraction and expansion of the pavement system (24). The fabrication process can be illustrated in Figures 7.1a to 7.1d. 


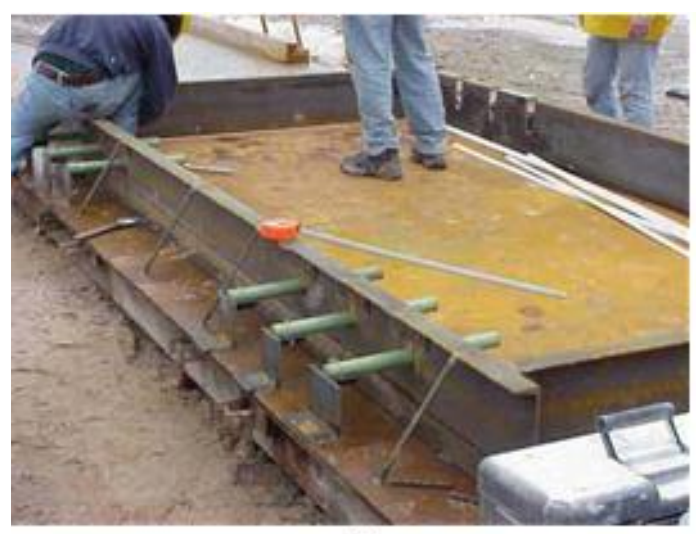

[a] Form Preparation

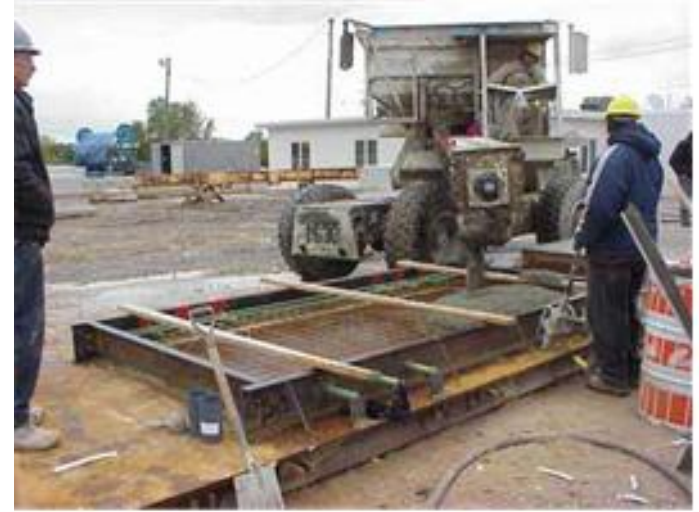

[c] Pouring Concrete

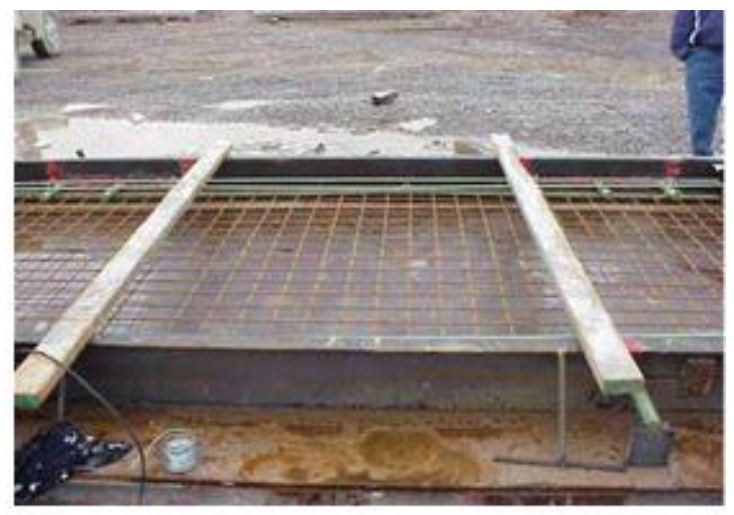

[b] Reinforced Bars

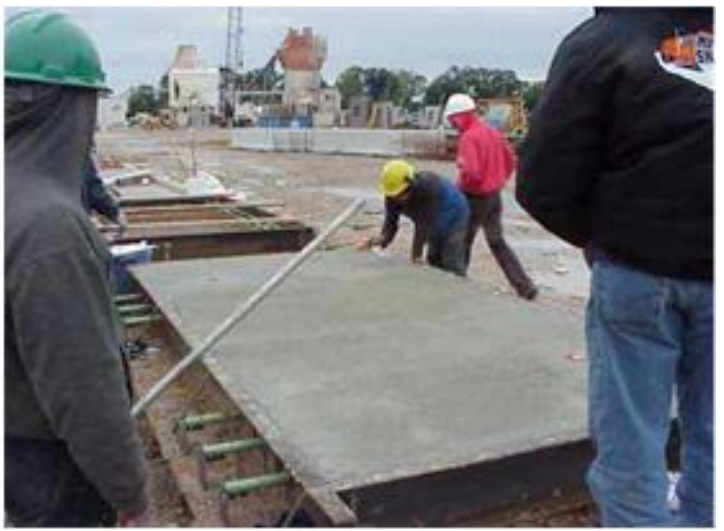

[d] Finishing

Figure 7.1 Pre-cast Concrete Panel Fabrication Process (24)

\subsubsection{Field Installation of Pre-cast Panels}

The field installation of the panels consists of the following steps (24):

- Step1 - Removal of distressed slab: The boundaries of the damaged area are identified and marked. The slab boundaries are saw cut and the lift hooks are inserted on the slab. The damaged panel is removed using a crane or a front-end loader as shown in Figure 7.2. 

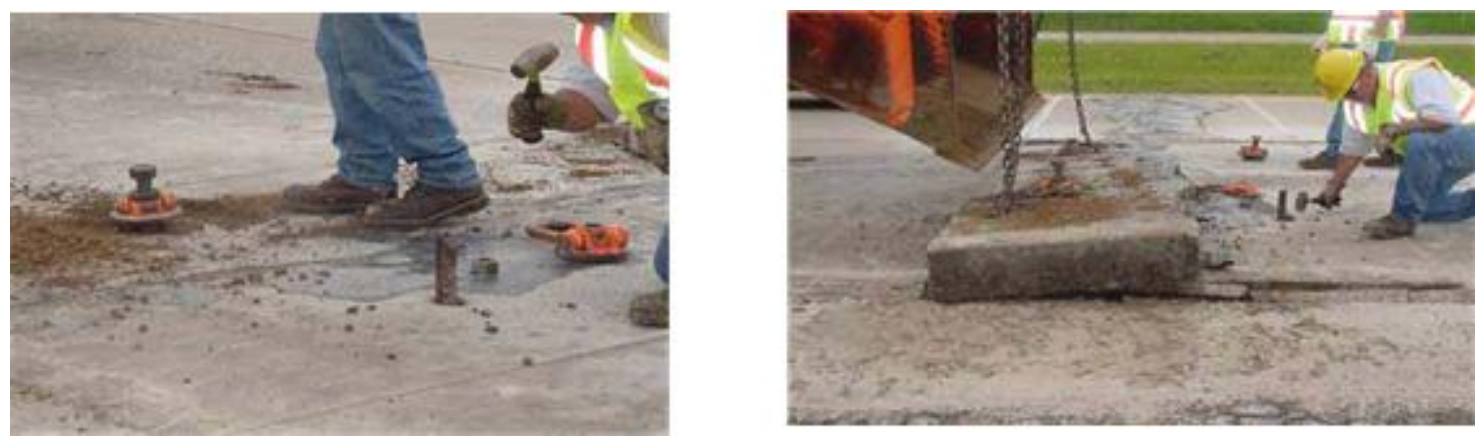

Figure 7.2 Lift Hook Installation and Slab Removal (24)

- Step 2 - Preparation of the base: The excavation of the base course ranged from 2” to 3” below the bottom of the existing slab, while allowing for 1 " to 2 " of flowable fill to be placed. Loose material or additional debris should be cleared. Figure 7.3 shows the base preparation work.
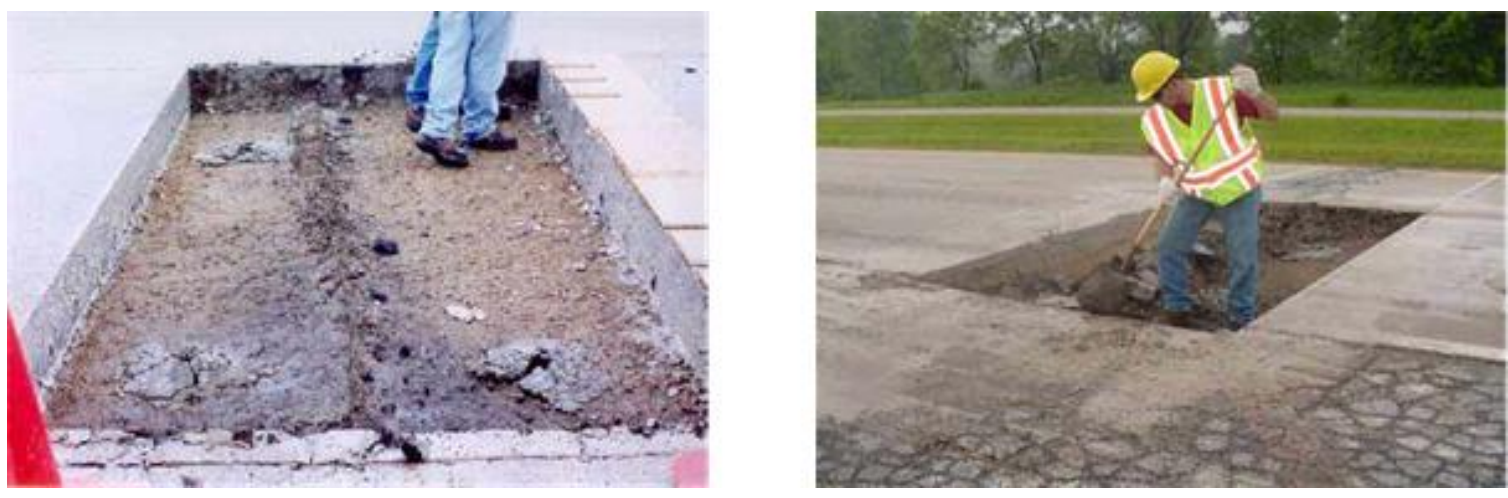

Figure 7.3 Base Preparation (24)

- Step 3 - Cutting of dowel slots: Three dowel slots in each wheel path are prepared through the initial grooving to the required depth and jack hammering to concrete. The cut dowel slots are cleaned and sandblasted. Figure 7.4 shows the dowel slot cutting process.

- Step 4 - Placement of flowable fill: The flowable fill is placed to adjust the elevation of the precast panel and to fill up any low spots in the base as a result of the slab removal process. The base is compacted and graded. Figure 7.5 shows the placement of the flowable fill. 

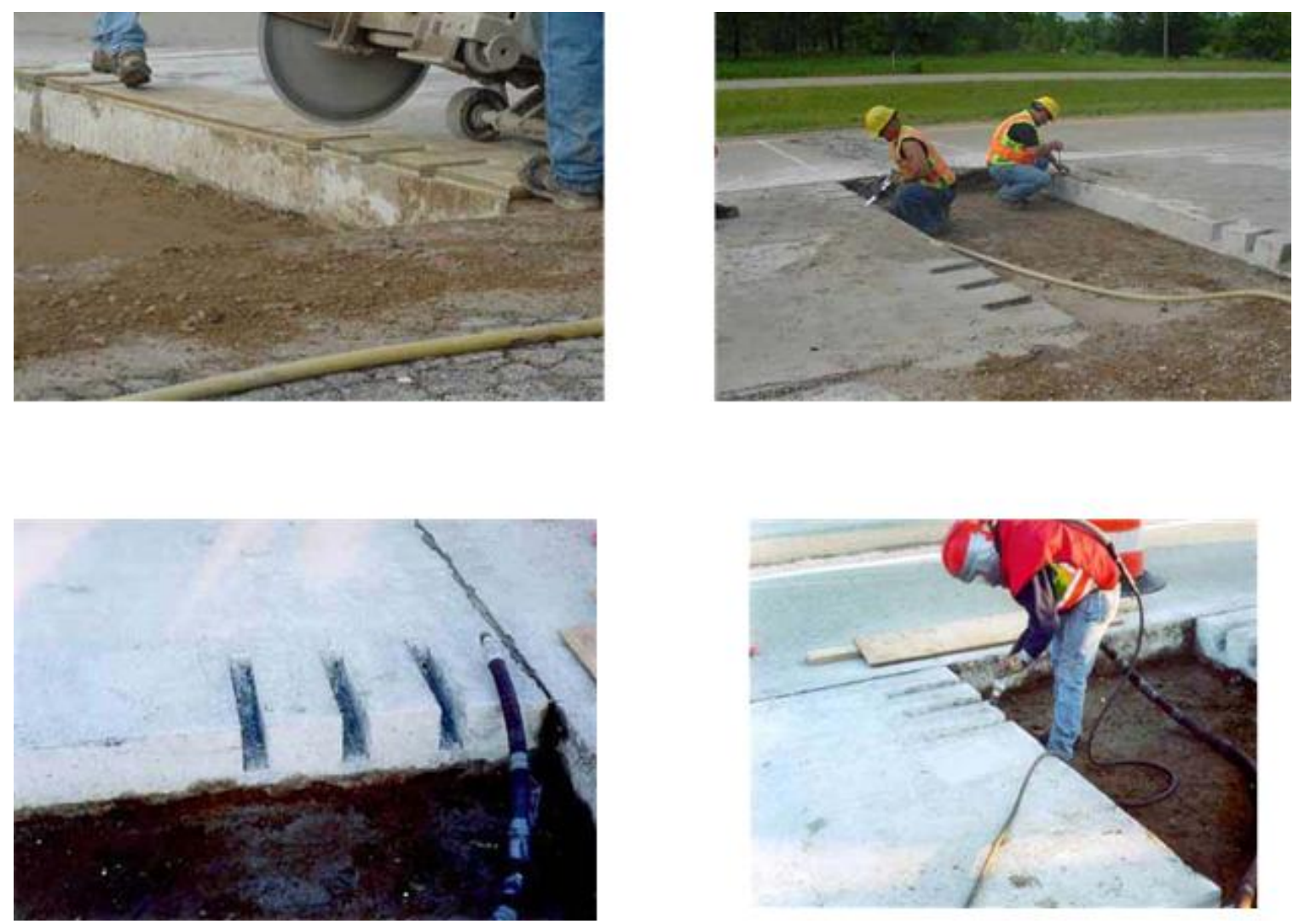

Figure 7.4 Cutting and Sandblasting of Dowel Slots (24)
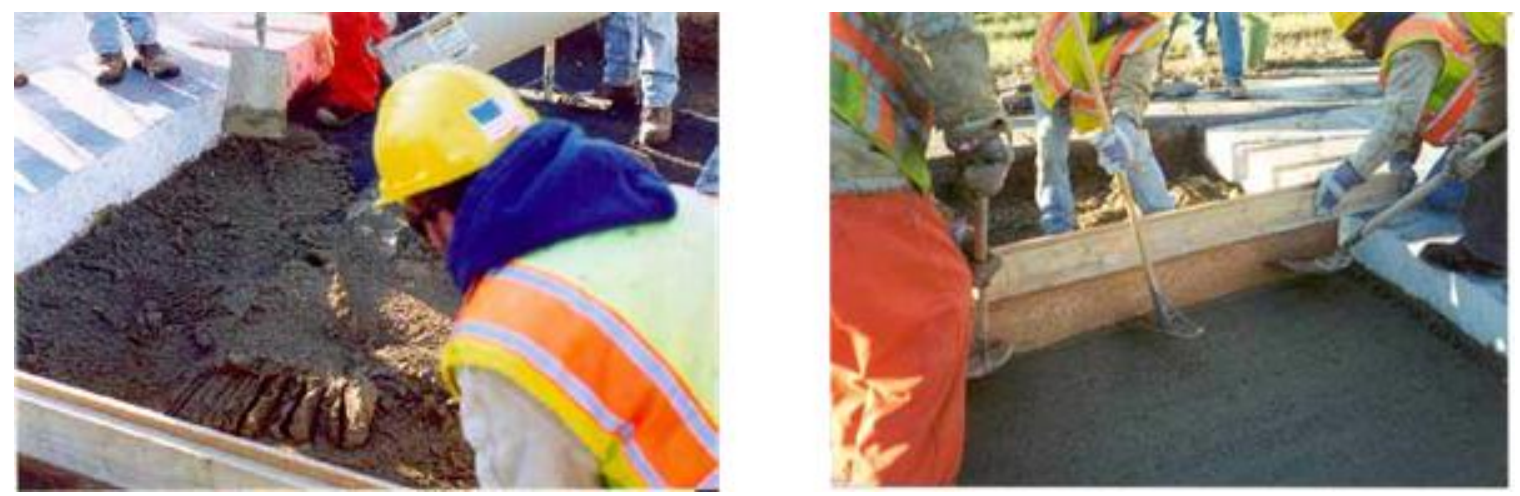

Figure 7.5Flowable Fill (24)

- Step 5 - Placement of pre-cast panel: The pre-cast panel is lifted from the flat bed truck using a crane or a front-end loader and lowered into the place where a bad slab was removed. After the slab elevation is judged as acceptable the dowel slots are grouted and the joints are sealed. Figure 7.6 shows the placement of the panel. 

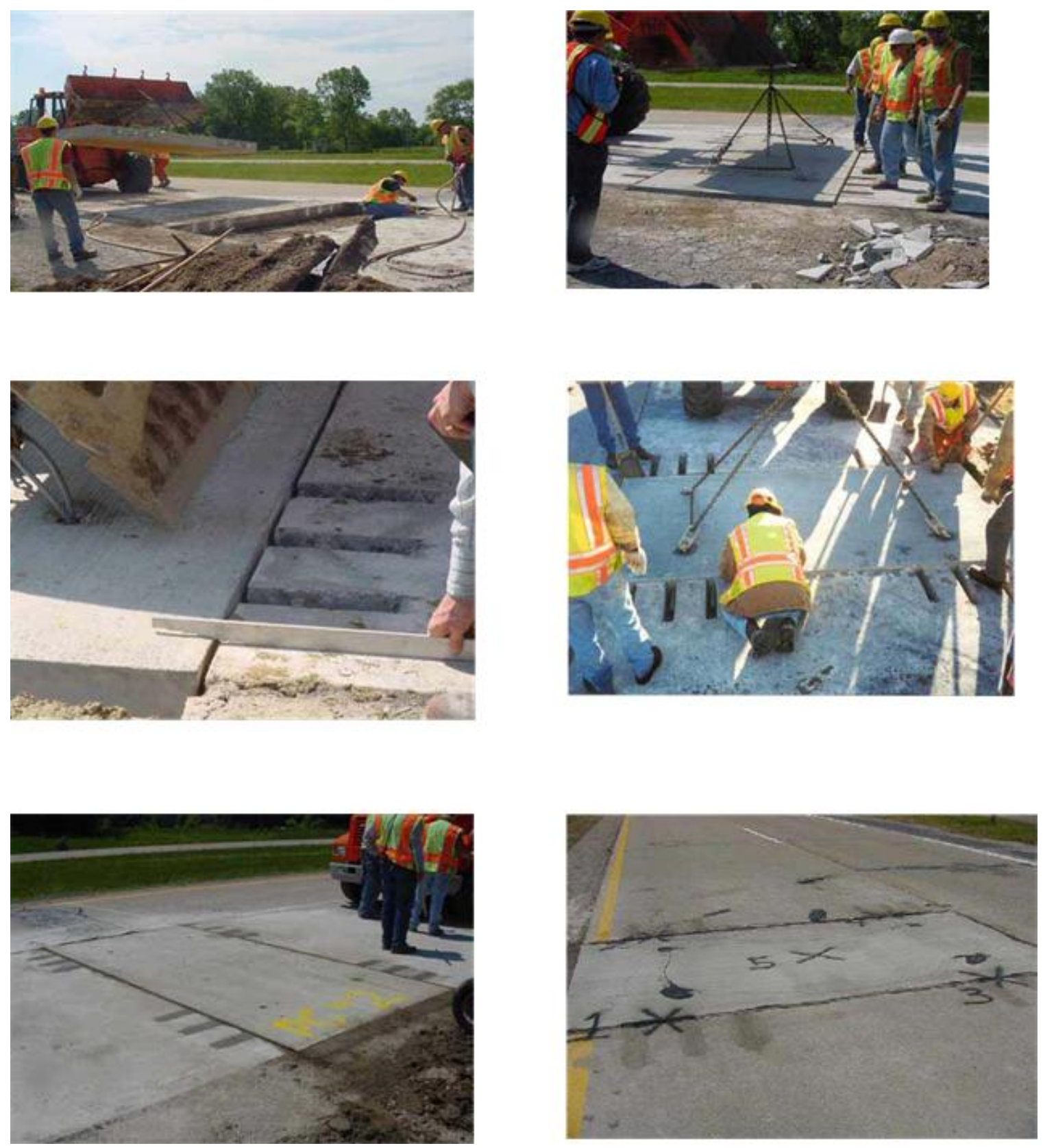

Figure 7.6 Precast Panel Installation (24)

\subsection{Case Study of FDR - Michigan Pilot Project (24)}

The Michigan Department of Transportation (MDOT) installed 10 precast concrete patches along I-94 BL (Business Loop) in October 2001 and summer of 2002 in cooperation 
with MSU (Michigan State University). The applied panels had the size of 6' long, 12' wide, and 10" thick. Each slab had three dowel bars in each wheel path to enhance load transfer and the steel wire mesh at the mid depth. The concrete strength reached 6,800 psi after seven days on average and 8,065 psi on average 28-day strength.

Based on the pilot project, MDOT experienced, the work of cutting dowel bar slots and sand blasting took the most time; four slabs were placed in a day in general. MDOT identified several parameters to monitor and evaluate the effectiveness of the repair method. They include: the degree of distress, ride quality, load transfer efficiency, and life cycle cost analysis due to high initial cost.

\subsection{Advantages and Concerns of FDR}

Advantages can be addressed as follows.

- Good quality concrete and its performance can be achieved.

- No patents are required.

- Lower user cost can be achieved from the MDOT FDR.

Concerns can be listed as follows.

- Difficult to work overnight due to time-consuming dowel slot cutting process

- Impossible to be used in long-range roadways

- Not much data available as of now 


\section{VIII.FOUR-BY-FOUR METHOD}

\section{$\underline{\text { 8.1 Caltrans Slab Replacement Method }}$}

Since most rigid Caltrans’ pavements were constructed between 1950 and 1970 and already exceeded their design life of 20 years, Caltrans has tried to develop efficient repair or rehabilitation strategies to improve pavement conditions to the acceptable level. Most of California’s urban areas, however, require high traffic demand, so most repair work should be done during the limited time, usually nighttime, in a timely way. To meet this demand while having durable pavements, Caltrans has to develop an innovative method for better but faster repair work. Four-by-four stands for achieving 4,000 psi compression strength in 4 hours.

\subsection{Typical Pavement Section and Slab Replacement}

Caltrans’ usual rigid pavements are plain jointed Portland Cement Concrete (PCC). That means that the slabs are not reinforced, with no steel rebar or welded wire mesh and no load transfer devices.

Figure 8.1 shows the typical pavement section. Caltrans applied CTB (Cement-Treated Bases) until 1992, but has moved to LCB (Lean Concrete Bases) since 1992 in the middle layer. PCC slabs are laid on the CTB or LCB bases (25).

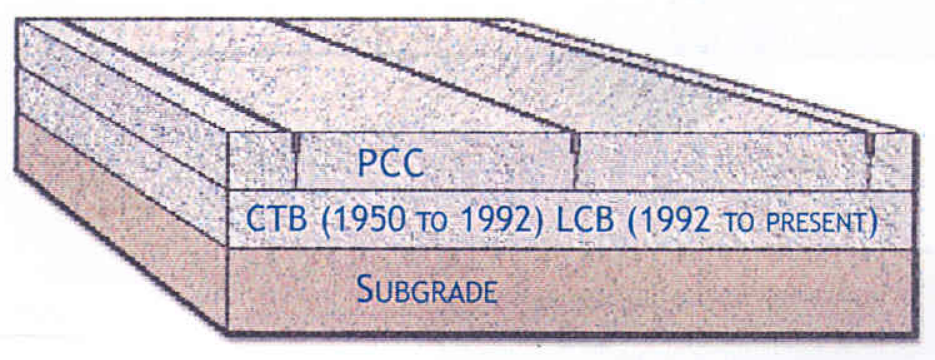

Figure 8.1 Typical Pavement Section (25) 
Slab replacement can be performed in two ways, depending on the given situations: fulldepth and treated base and full-depth repair. Full-depth and treated base repair consists of removing the concrete pavement, including the treated base, and replacing both layers with concrete materials. Full-depth repair is to solely remove and replace the concrete pavement (see Figure 8.2).

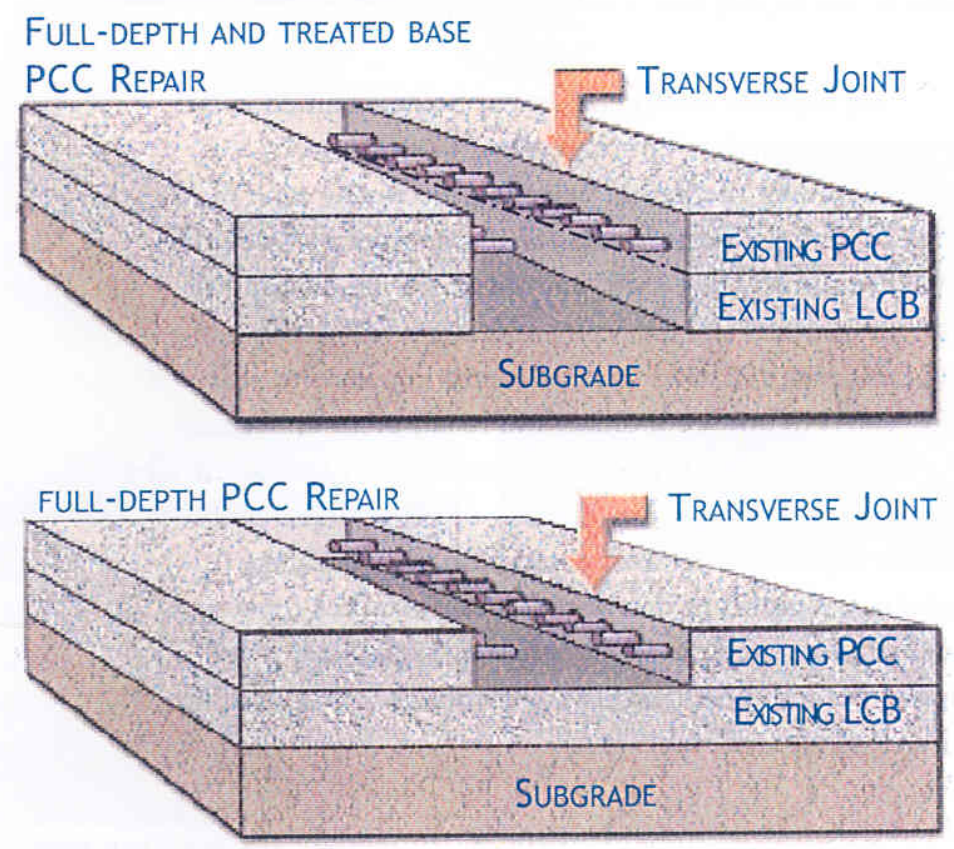

Figure 8.2. Slab Replacement (25)

\subsection{Field Installation of Caltrans Slab Replacement Method}

- Step 1 - Concrete mix design: Caltrans uses three concrete mixes for slab replacement (25).

(1) Proprietary cement mixes: They are applied for a much shorter set time and may be used to meet strength design criteria. 
(2) Accelerated Type III cement mixes with non-chloride accelerators: They are commonly used for a shorter set time and usually meet the opening strength requirements within 4 to 6 hours. The mixes need slightly more mix water than a mix with Type II Portland cement.

(3) Type II cement mixes: The mixes are applied when enough construction time is allowed. They may take 24 hours or more to reach the required opening strength.

To acquire good-quality concrete, it is important for ready-mix truck drivers to have an appropriate level of training and knowledge.

- Step 2 - Concrete slab removal: Deteriorated concrete slab boundaries need to be marked and saw-cut. The slab is removed by lifting it out of place to minimize damage to the adjacent pavement. Figure 8.3 shows the concrete slab removal work.
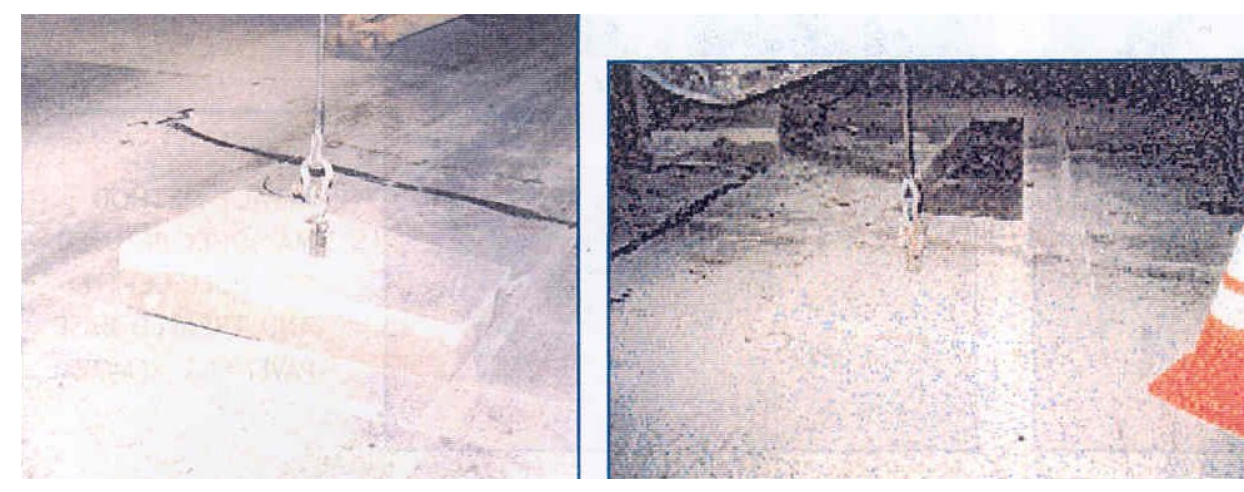

Figure 8.3 Concrete Removal with Lift Pin (25)

- Step 3 - Base preparation: Once the deteriorated slab is removed, the underlying CTB or LCB base should be inspected to identify base conditions. The inspection includes, but not limited to, pockets of loose or missing materials, damaged base areas during slab removal activities, and base deterioration due to traffic loading or environmental conditions (25). 
When the CTB or LCB base is in good to excellent condition, full depth repair is performed with minimal base repair. When the treated base is in poor condition, it may require costly and time-consuming removal and replacement, resulting in full-depth and treated base repair.

On occasion, a plastic sheeting bond breaker can be applied to allow the slab and the base to move independently as shown in Figure 8.4.

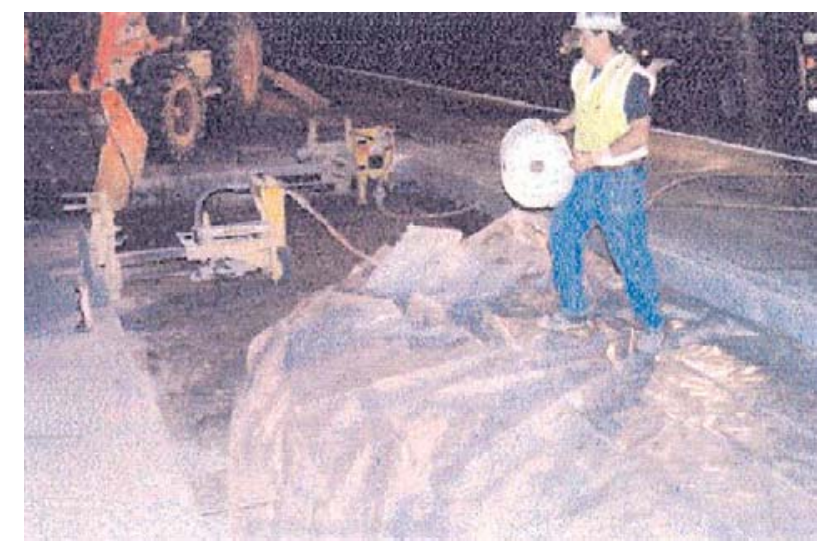

Figure 8.4 Bond Breaker Placement (25)

- Step 4 - Dowel bar installation: After base preparation is completed, dowel bars are installed along the transverse joints using an automatic dowel drilling machine. Regarding the number of dowels, Caltrans requires dowels be placed with $1 \mathrm{ft}$ spacing between dowels. Figure 8.5 shows the dowel drilling work for full-depth repair. After drilling, the dowel holes should be cleaned out by inserting an air nozzle into the holes to drive out all dust and debris. 


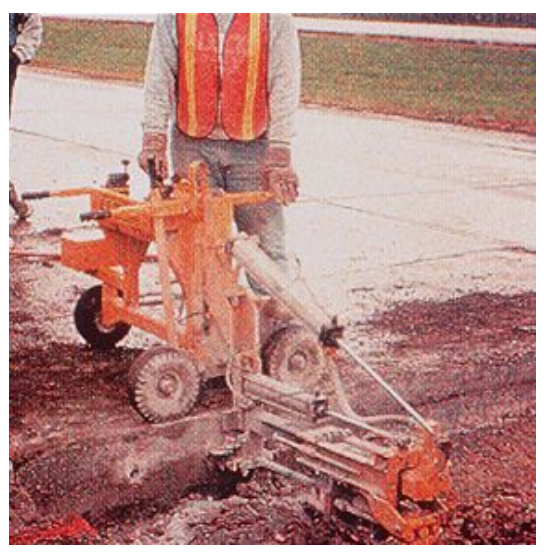

Figure 8.5 Drilling Dowel Slots (26)

For the weakened joints within a slab, type A or U basket dowels should be placed. The J type basket is not allowed for Caltrans construction. Figures 8.6 and 8.7 show the dowel bar basket type A and U, respectively.
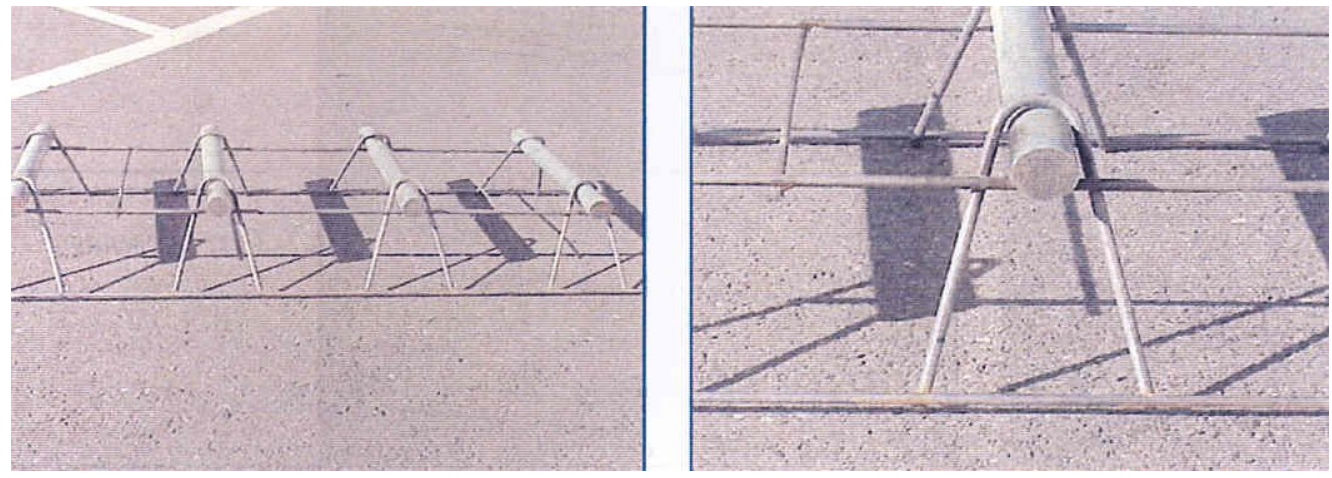

Figure 8.6 Type A Dowel Bar Basket (Caltrans 2002)
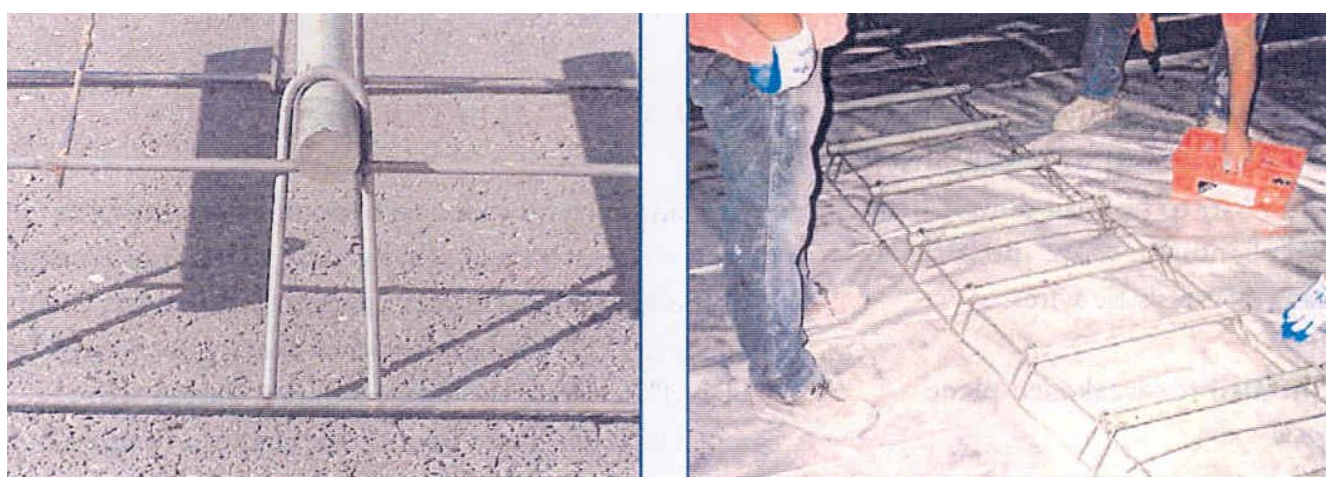

Figure 8.7 Type U Dowel Bar Basket (25) 
- Step 5 - Concrete placement: Prior to concrete placement, the bond breaker and dowel bars have to be inspected to ensure proper placement. As fresh concrete arrives on the job site, the inspector should monitor the concrete temperatures and watch for unmixed cement in the ready-mix truck. The chute operator should distribute the concrete evenly on the prepared base to avoid excessive shoveling work as shown in Figure 8.8. Much care should be taken to acquire good concrete consolidation around dowel bars and along the patch perimeter to achieve long-term pavement performance.

Shortly after the concrete is placed, surface texturing has to begin, during which the concrete surface should have one uniform pattern. Curing of the fresh concrete is critical to attain high-quality concrete pavement and should be performed in a timely manner. The slab must be sprayed with curing compound and covered with plastic sheeting for proper curing (25).

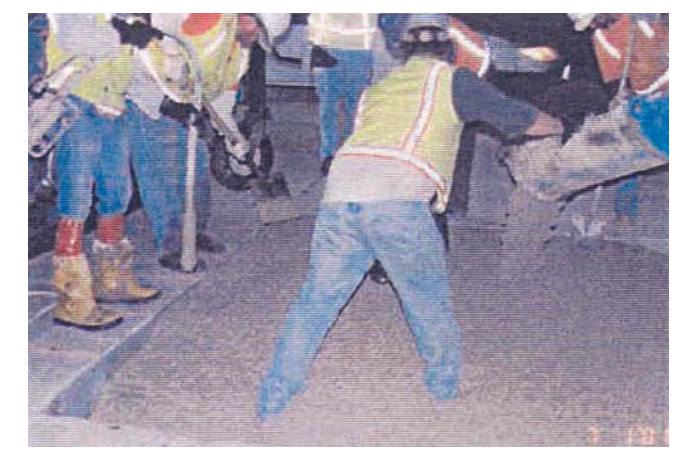

Figure 8.8 Uniform Concrete Placement (25)

- Step 6 - Opening to traffic: After concrete placement, the job site should be cleared for traffic opening and the concrete surface should be cleaned with a sweeper supplied by the contractor. Caltrans requires the concrete strength for traffic opening to reach the minimum flexural strength of $2.8 \mathrm{Mpa}$ or 400 psi. Otherwise, cracks will be developed in the new slab quickly. 


\subsection{Caltrans Demonstration Project}

A Caltrans demonstration project using Texas’ PPCP method is underway as a part of I10 HOV (High Occupancy Vehicle) widening project. The project is to widen the I-10 from eight to ten lanes to provide operational capacity improvements and reduce traffic congestion and the new lanes will extend from Baldwin Avenue in the city of El Monte to the I-605 in the city of Baldwin Park. The length of the project is 3.2 miles (refer to Figure 8.9). The demonstration project is underway near Meeker Road in the eastside of I-10 and the length of project is 248 feet as shown in Figure 8.10. Figure 8.11 is the picture of project site.

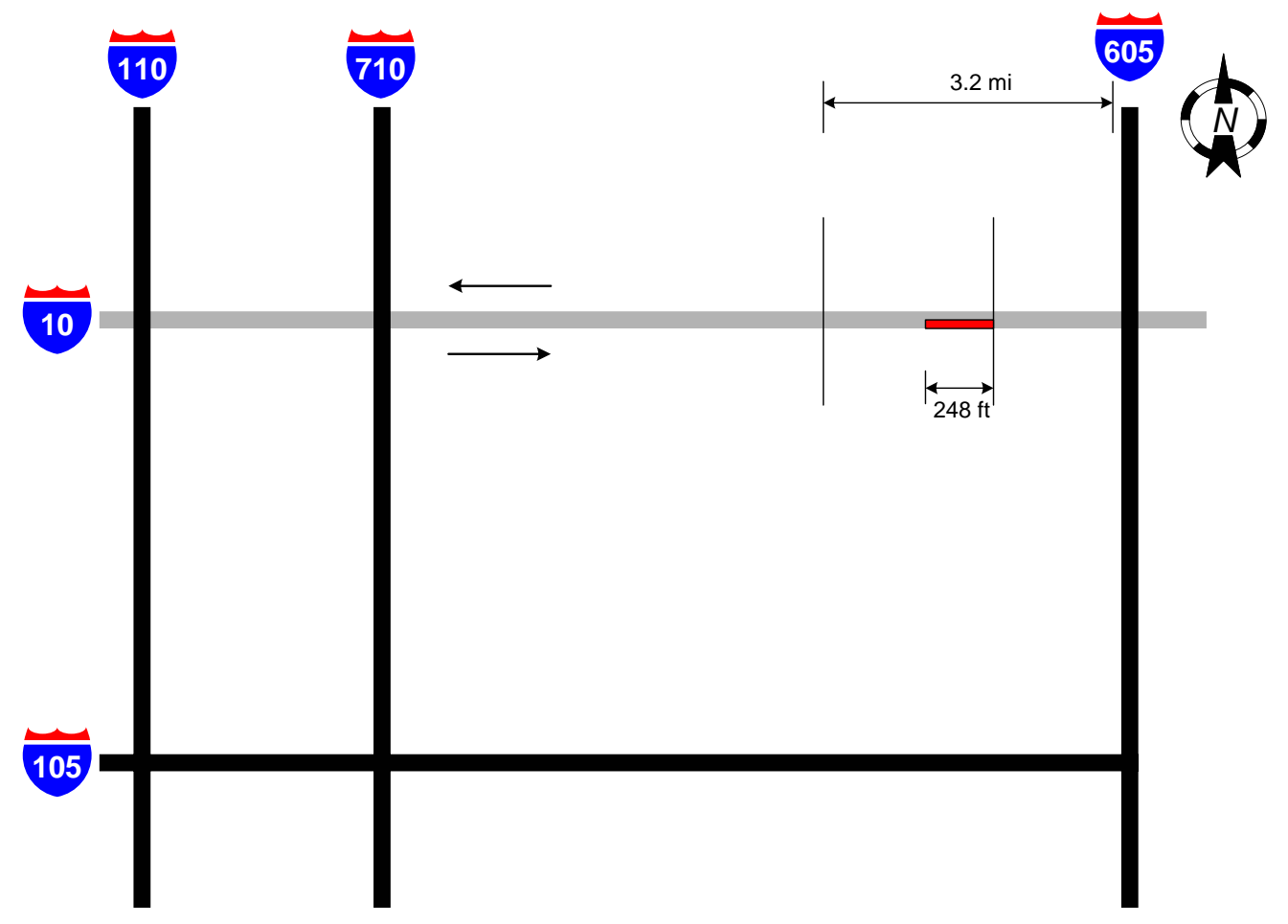

Figure 8.9 I-10 HOV Widening Project 


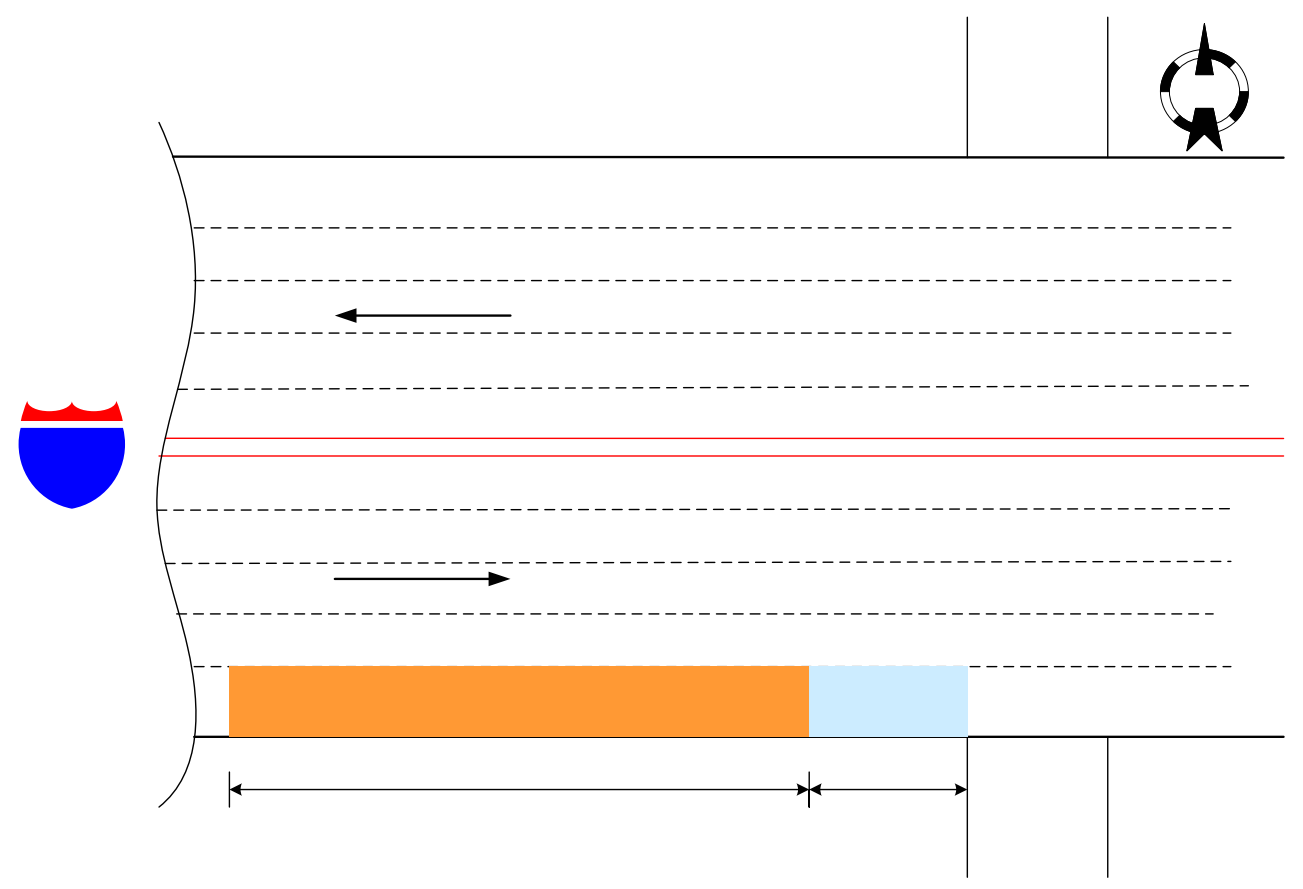

Figure 8.10 Caltrans Demonstration Project

The project can be summarized as follows: (1) designer: Caltrans, (2) contractor: E. L. Yeager Construction Co. Inc., (3) precaster: Permoroy, (4) sponsor: FHWA, and (5) pavement coverage: 248' (L) x 36'-10” (W) x 8” (T) on 6” lean concrete base. FHWA totally funded for the project. Table 8.1 shows cost summary.

Table 8.1. Cost Summary

\begin{tabular}{|c|c|}
\hline Item & Cost (\$) \\
\hline Total cost & $228,023.30$ \\
\hline Saving from less concrete & 28,023 \\
\hline Net cost & 200,000 \\
\hline Funding from FHWA & 200,000 \\
\hline Cost to Caltrans & 0 \\
\hline Unit cost & $24.85\left(\$ 228,023\right.$ 30/ $\mathbf{0} . \mathbf{1 7 6 \mathrm { ft } ^ { 2 } )}$ \\
\hline
\end{tabular}




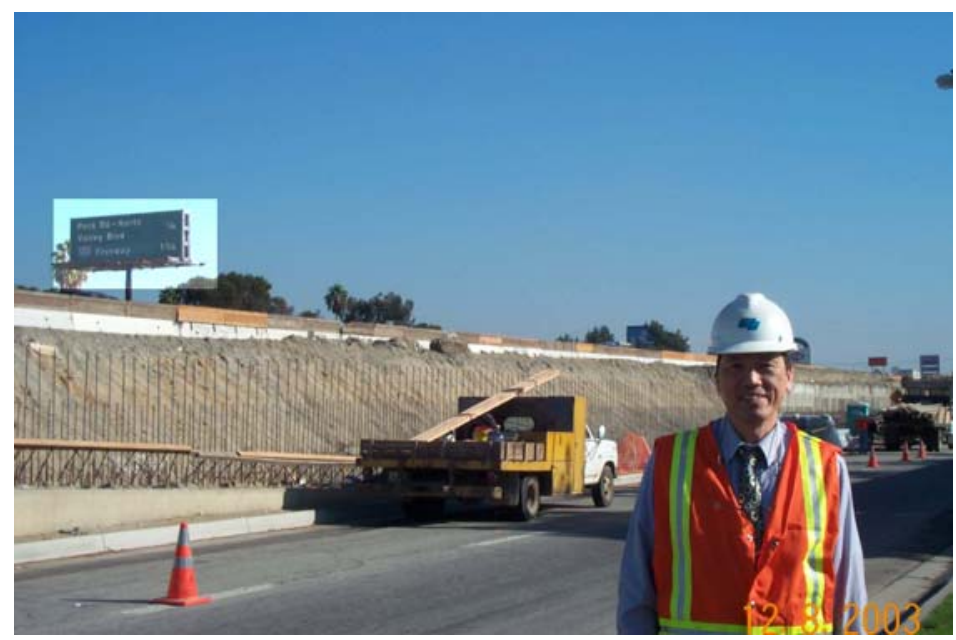

Figure 8.11 Project Site

\subsection{Advantages and Concerns of Four-by-Four Method}

Advantages can be listed as follows.

- Overnight, weekend, or off-peak construction is possible.

- Durable concrete equipped with load transfer devices can be achieved.

Concerns can be addressed as follows.

- Caltrans slab replacement method is not a precast concrete pavement method.

- One of the most common concerns of the quality of the concrete pavement is that it may vary by the contractors owing to the different job site conditions, skill of the workers, climates (temperature and humidity) and etc.

- Since concrete placement is performed outdoors, slab replacement may not be performed, depending on weather conditions.

- Larger field construction crews are required due to concrete work and surface texturing. 
- If the concrete needs more curing time to reach the specified minimum strength, the neighboring traffic flow may be significantly affected.

- Caltrans slab replacement method is nearly impossible to be employed in long-range roadway construction

- There is not much data available up to now 


\section{COMPARISON}

\subsection{Comparing PPCP with PCCP}

Various pavement methods were discussed in the last section. The following Table 9.1 summarizes the comparisons.

Table 9.1. Conventional V.S. Precast Pavments

\begin{tabular}{|c|c|c|}
\hline Parameter & \begin{tabular}{|c|} 
PPCP \\
\end{tabular} & $\begin{array}{r}\text { PCCP } \\
\end{array}$ \\
\hline Speed of Construction & $\begin{array}{l}\text { Possible for Immediate opening } \\
\text { for traffic and } \\
\text { overnight/weekend construction }\end{array}$ & $\begin{array}{l}\text { Requires several days or weeks before } \\
\text { opening for traffic }\end{array}$ \\
\hline Traffic Disruption & Open to traffic during construction & completely closed during construction \\
\hline Ride Quality & 2 & 1 \\
\hline Maintenance & 1 & 2 \\
\hline $\begin{array}{l}\text { Useful Life before the } 1^{\text {st }} \\
\text { Rehab. }\end{array}$ & $\begin{array}{l}30 \text { yrs } \\
\text { (Source:Ref.22) }\end{array}$ & $\begin{array}{l}\text { 20-30 years } \\
\text { (Source: Ref: 13) }\end{array}$ \\
\hline Approximate cost & ${ }^{1} \$ 203 / \mathrm{m}^{2}={ }^{1} \$ 18.86 / \mathrm{ft}^{2}$ & ${ }^{1} \$ 36-\$ 48 / \mathrm{m}^{2}={ }^{1} \$ 3.34-\$ 4.46 / \mathrm{ft}^{2}$ \\
\hline Quality Control & In shop or precast yard & Cast-in-place on-site \\
\hline Slab Thickness & Thinner slab (200mm) & Thicker Slab (355mm) \\
\hline Manpower needed & Comparatively less & Regular \\
\hline New Equipment needed & $\begin{array}{r}\text { Yes } \\
\end{array}$ & No \\
\hline $\begin{array}{l}\text { Familiarity of Engineers and } \\
\text { contractors }\end{array}$ & Unfamiliar & Familiar \\
\hline Notes & $1>2$ (Best->Worst) & \\
\hline
\end{tabular}

Source: ${ }^{1}$ Ref:19, ${ }^{2}$ Mike Byers, Indiana Chapter, ACPA(American Concrete Pavement Association)

Among the comparisons, the costs of the pavements become an important factor in deciding a pavement construction project. In the past, the construction cost often ended up as the key factor for decision making. However, the total cost of the pavement construction is way beyond the costs of design, maintenance, and user. Indiana is currently using HMA and PCCP. The cost of PCCP is about $\$ 3-\$ 5 / \mathrm{ft}^{2}$ as shown in Table 9.2. The installed price for PCCP ranges from $\$ 24.13-\$ 100 / \mathrm{m}^{2}$. 
Table 9.2. Current Cost of Various Pavements in Indiana

\begin{tabular}{|l|l|r|r|r|r|r|}
\hline & \multirow{2}{*}{ Unit } & \multicolumn{2}{|c|}{ Range } & \multirow{2}{*}{ Mean } & \multirow{2}{*}{ Medium } & \multirow{2}{*}{ SD } \\
\cline { 3 - 4 } & & Minimum & maximum & & & \\
\hline QC/QA, PCCP & $\$ / \mathrm{ft}^{2}$ & 2.241759 & 14.49293 & 5.142668 & 3.191232 & 3.387474 \\
\hline PCCP & $\$ / \mathrm{ft}^{2}$ & 0 & 26.94199 & 5.293125 & 4.7613 & 3.879451 \\
\hline
\end{tabular}

Source: Tommy E. Nantung, INDOT 11/17/1998 to 6/11/2002

Since the precast pavement project has not been built in Indiana yet, the precast pavement cost will be calculated using Texas' data for further comparison. It is known that the climate, living standard, skill of labor, and other factors may influence the costs in each state.

This report gives a rough idea of the costs involved in building PCCP pavement and PPCP.

Herein, the total cost of PPCP project at Georgetown is about $\$ 19 / \mathrm{ft}^{2}\left(\$ 203 / \mathrm{m}^{2}\right.$.) For an equivalent $355 \mathrm{~mm}$ PCCP, the total cost is approximately $\$ 3.5 / \mathrm{ft}^{2}$ to $\$ 3.9 / \mathrm{ft}^{2}\left(\$ 36-\$ 48 / \mathrm{m}^{2}\right.$ ). Table 9.3 illustrates the differences among PCCP, and PPCP pavement installed fee in Indiana and

Texas.

Table 9.3. Construction Cost for PCCP, PPCP , HMA pavement and Super-Slab

\begin{tabular}{|c|c|c|c|c|c|c|}
\hline & \multirow[b]{2}{*}{ Unit } & \multicolumn{2}{|c|}{ Range } & \multirow[b]{2}{*}{ Mean } & \multirow[b]{2}{*}{ Medium } & \multirow[b]{2}{*}{ SD } \\
\hline & & $\min$ & $\max$ & & & \\
\hline \multirow[t]{2}{*}{ PCCP in INDOT ${ }^{1}$} & $(\$ / \mathrm{m} 2)$ & 24.13 & 100 & 40.71 & 33.96 & 16.89 \\
\hline & $(\$ / \mathrm{ft} 2)$ & 2.24 & 9.29 & 3.78 & 3.15 & 1.57 \\
\hline \multirow[t]{2}{*}{$350 \mathrm{~mm} \mathrm{PCCP}$ in INDOT } & $(\$ / \mathrm{m} 2)$ & 32.58 & 50.97 & 37.74 & 33.7 & 8.84 \\
\hline & $(\$ / \mathrm{ft} 2)$ & 3.03 & 4.74 & 3.51 & 3.13 & 0.82 \\
\hline \multirow[t]{2}{*}{355 mm PCCP in Texas ${ }^{2}$} & $(\$ / \mathrm{m} 2)$ & 36 & 48 & 42.00 & N/A & N/A \\
\hline & $(\$ / \mathrm{ft} 2)$ & 3.34 & 4.46 & 3.90 & N/A & N/A \\
\hline \multirow[t]{2}{*}{ PPCP in Texas ${ }^{2}$} & $(\$ / \mathrm{m} 2)$ & N/A & $\mathrm{N} / \mathrm{A}$ & 203.00 & N/A & N/A \\
\hline & $(\$ / \mathrm{ft} 2)$ & N/A & $\mathrm{N} / \mathrm{A}$ & 18.86 & N/A & N/A \\
\hline \multirow[t]{2}{*}{ PPCP in Caltran ${ }^{3}$} & $(\$ / \mathrm{m} 2)$ & $\mathrm{N} / \mathrm{A}$ & $\mathrm{N} / \mathrm{A}$ & 236.80 & N/A & N/A \\
\hline & $(\$ / \mathrm{ft} 2)$ & N/A & $\mathrm{N} / \mathrm{A}$ & 24.85 & N/A & N/A \\
\hline \multirow[t]{2}{*}{ HMA Pavement ${ }^{4}$} & $(\$ / \mathrm{m} 2)$ & 32.34 & 53.89 & 43.11 & N/A & N/A \\
\hline & $(\$ / \mathrm{ft} 2)$ & 3 & 5 & 4.00 & N/A & N/A \\
\hline \multirow[t]{2}{*}{ Super Slab ${ }^{5}$} & $(\$ / \mathrm{m} 2)$ & 215.27 & 322.9 & 269.08 & N/A & N/A \\
\hline & $(\$ / \mathrm{ft} 2)$ & 20 & 30 & 25.00 & N/A & N/A \\
\hline
\end{tabular}


Table 9.3 indicates that the cost for precast pavement is much higher than conventional pavements. However, several things should be noticed. First, the Georgetown precast pavement was a relatively small $(0.7 \mathrm{~km})$ project. A longer pavement may result in a lower unit cost. Second, the Georgetown precast pavement project was a demonstration project. Neither the contractor nor the precast supplier had previous experiences in the new precast paving techniques. Therefore, the construction cost was understandably higher. Thirdly, the costs of maintenance, operation, social and economic impact are not taken into consideration. Although all these factors are really hard to be quantified, they have a tremendous effect on the life cycle cost.

Based on the report from CTR, University of Texas-Austin, the significance of the user cost is comprised of four elements in terms of work zone evaluation- delay or travel time costs, vehicle running cost, speed change cycling costs, and accidents. The report is using a 5-mile pavement (possible average work zone length for medium sized projects) with an ADT of 105,000 vehicles per day (the range for urban principle arterial interstates in Texas is 50,000105,000 vpd in both direction) to determine the user delay cost.

The assumptions for both conventional and precast are made as follows: (23)

1. Work zone/project length $=5$ miles

2. Four-lane freeway, median separated, with frontage roads

3. ADT $=5000-105000$ vehicles per day (urban principal arterial-interstate)

4. Vehicle Mix: 25\% trucks

5. One side of freeway reconstructed at a time 
The specific assumptions for precast pavement are:

1. Construction during night only

2. Traffic diverted only from $8 \mathrm{pm}$ to $6 \mathrm{am}$

3. Traffic diversion strategy: Diversion to opposing lanes (one lane open in each direction).

The specific assumptions for conventional pavement are:

1. Traffic diversion: 24 hours/day

2. Actual work time: $10-12$ hours/day

3. Total construction Time: 5 miles/2,000 ft/day $=13$ days. The extra 7 days in the total construction time estimate for JRCP and CRCP mainly account for cure time and placement of reinforcements.

By using QUEWZ (computer program) which was developed by the Texas transportation institute (College Station, Texas) and later modified by TransTec, Inc (Austin, Texas), the daily user delay cost for 5-mile construction is shown in the Table 9.4. (23)

Table 9.4. The User Cost Estimated through QUWEWZ

\begin{tabular}{|l|l|l|l|l|}
\hline $\begin{array}{l}\text { Construction } \\
\text { Method }\end{array}$ & $\begin{array}{l}\text { Placement } \\
\text { Rate } \\
\text { (ft/day) }\end{array}$ & $\begin{array}{l}\text { Daily User } \\
\text { Cost (\$Dollar) }\end{array}$ & $\begin{array}{l}\text { Total } \\
\text { Construction } \\
\text { Time (day) }\end{array}$ & $\begin{array}{l}\text { Total user } \\
\text { Cost } \\
(\$ D o l l a r)\end{array}$ \\
\hline $\begin{array}{l}\text { Conventional } \\
\text { (CRCP, JRCP) }\end{array}$ & 2000 & 680,610 & 20 & $13,612,200$ \\
\hline $\begin{array}{l}\text { Precast Prestressed } \\
\text { Concrete } \\
\text { Pavement (PPCP) }\end{array}$ & 500 & 124,500 & 53 & $6,598,500$ \\
\hline
\end{tabular}

Source: Ref.23

This chart shows the user cost for a 5 mile construction with the previous assumption made. The total user cost for conventional pavements seems to be much higher than precast 
concrete pavement. In order to show impacted user costs on various concrete pavement methods, rough estimate can be made such as those in Table 9.5.

Assumptions for deriving the cost in Table 9.5 are as follows:

1. This is a 4-lane roadway with a 5 mile project length

2. The total 4-lane pavement width for rural roads with shoulders is $10.8 \mathrm{~m}$ including travel lanes and paved shoulders for one direction of travel on a divided road. (According to the design memorandum No. 03-05 Technical advisory. Source: Ref.23)

3. The maintenance fee for each method is the same so it is not taken into account.

4. The total cost only considers user cost and the initial construction cost, which can be shown by the equation below(Unit: $\left.\$ / \mathrm{ft}^{2}\right)$

Total Cost $=$ User Cost + Construction Cost

Table 9.5 Total Cost including the user cost and construction cost

\begin{tabular}{|c|c|c|c|c|c|}
\hline \multirow[b]{2}{*}{ 5-mile Construction } & \multicolumn{3}{|c|}{ User Cost } & $\begin{array}{c}\text { Construction } \\
\text { Cost }^{1}\end{array}$ & $\begin{array}{l}\text { Total } \\
\text { Cost }\end{array}$ \\
\hline & \$ Dollar & \$/mile & $\$ / \mathrm{ft}^{2}$ & $\$ / \mathrm{ft}^{2}$ & $\$ / \mathbf{f t}^{2}$ \\
\hline $\begin{array}{l}\text { Conventional } \\
\text { (CRCP, JRCP) }\end{array}$ & $\$ 31,612,200$ & $\$ 6,322,440$ & $\$ 34$ & $\$ 3.78$ & $\$ 37.57$ \\
\hline $\begin{array}{l}\text { Precast Prestressed } \\
\text { Concrete Pavement } \\
\text { PPCP }^{2}\end{array}$ & $\$ 6,598,500$ & $\$ 1,319,700$ & $\$ 7$ & $\$ 18.86$ & $\$ 25.91$ \\
\hline Super-Slab pavement ${ }^{3}$ & $\$ 6,598,500$ & $\$ 1,319,700$ & $\$ 7$ & $\$ 26.00$ & $\$ 33.05$ \\
\hline
\end{tabular}

Source: Ref.19, 23, and 24

${ }^{1}$. Including base preparation, precast fabrication, transportation and installation

2. Use 2" HMA Leveling Course

3. Use 3/4" Stone Dust and Bedding Grout. 
Although the initial construction cost of conventional CRCP, JRCP is much lower than precast concrete pavement, the estimates in Table 9.5 show that the user cost of CRCP and JRCP are much higher than precast concrete pavement which lead to the higher total cost of Conventional method than PPCP construction.

The estimation in Table 9.4 and Table 9.5 is basically from the data obtained in various sources ( Ref. 19, 23, and 24). Based on the INDOT's data, it is known that JRCP was main type of concrete pavement built by INDOT few years ago. However, JPCP is the type primarily chooses lately. In order to make the estimation more up-to-date, the construction cost and placement rate of the different type of the PCCP are obtained. According to first author of the "The Feasibility of Using Precast Concrete Panels to Expedite Highway Pavement Construction", David Merritt, the report was intended to give the reader some idea of the magnitude of savings in user delay cost. The example was purely theoretical, and was not taken from an actual project. The placement rate $(2,000$ ft/day assumed) in Table 9.4 is a rough estimate for slipform paving which was not directly estimated but extra days was account for cure time or placement of reinforcement. Since JPCP does not require placement of reinforcement, the total construction time may be slightly shorter than JRCP/CRCP, but not significant. (Ref. 43)

As to the construction cost of the three types of the PCCP, it varies with the size of the construction projects. From the average low bid unit price of the TxDOT Expressway in June 1, 2004 , the average cost in the approximately quantity needed for 5 miles, 4 lanes construction varying from the thickness of the pavements (ranging between 6000-16000 square yard) for JPCP, JRCP, CRCP are respectively $\$ 2.345 / \mathrm{ft}^{2}, \$ 4.58 / \mathrm{ft}^{2}, \$ 4.51 / \mathrm{ft}^{2}$. (42) 
Researchers tried to find the similar quantity of the construction in Indiana, the construction cost of JPCP and JRCP are $\$ 4.4 / \mathrm{ft}^{2}$ and $\$ 6.27 / \mathrm{ft}^{2}$ respectively. Since JPCP has rebar operation, the construction cost of JPCP is apparently lower than JRCP and CRCP. Therefore, the total construction cost for JPCP is slightly lower than JRCP \& CRCP, but not really significant in comparison.

Besides, according to the 2003 annual report of INDOT (39), there are many maintenance jobs, including regular cleaning drainage structure and repairing, that are needed for PCCP. The jobs included the sealed 3,300 miles of shoulders, sealed 6,190 miles of cracks, the 8,794,943 feet of ditches that were worked on, replaced 326 pipes, cleaned 73,601 drainage structures, and cleaned/ flushed 8,916 bridges. These require a significant amount of money to maintain the PCCP used by INDOT. In INDOT Quick Facts 1998 of the Highway budget, it is found that maintenance fee is about $10 \%$ of the construction fee from 1996 to 1997. (The average construction fee is $\mathbf{\$ 5 2 0}$ and maintenance fee of \$54 Unit \$MM). (41) Based on Texas’s experience in using the PPCP, the precast panels need less maintenance. Based on Texas report in McLenna County Project, Texas in the mid 1980s (8), less maintenance needed for prestressed concrete panels. Since maintenance cost is about $10 \%$ in INDOT (41), it can be logically estimated that different of total cost between conventional and PPCP may be even higher than the costs shown in Table 9.5. In other words, if maintenance cost is included in the estimated total cost in Table 9.5, the total cost of conventional methods (CRCP, JRCP) will be much higher than PPCP's. 


\subsection{Comparing Paving with Patching}

Various precast/non-precast concrete pavement repair methods have been studied and discussed. All methods have different characteristics and are applied to different situations. Table 9.6 shows the comparison between different repair strategies with respect to eleven parameters.

Table 9.6. Comparison of Different Methods

\begin{tabular}{|c|c|c|c|c|c|c|}
\hline & Parameter & РPCP & $\begin{array}{l}\text { Super- } \\
\text { Slab }\end{array}$ & $\begin{array}{l}\text { Stitch-In- } \\
\text { Time }\end{array}$ & $\begin{array}{c}\text { MDOT } \\
\text { FDR }\end{array}$ & $4 * 4$ \\
\hline 1 & Precast & Yes & Yes & Yes & Yes & No \\
\hline 2 & $\begin{array}{l}\text { Construction } \\
\text { Cost }\left(\$ / f t^{2}\right)\end{array}$ & $\$ 19-\$ 22$ & $\$ 26$ & $\$ 38 *$ & N/A & $\$ 24.85$ \\
\hline 3 & Length & $\begin{array}{l}\text { Long } \\
\text { range } \\
\text { paving }\end{array}$ & $\begin{array}{l}\text { Short } \\
\text { range } \\
\text { paving }\end{array}$ & $\begin{array}{c}\text { Spot } \\
\text { patching }\end{array}$ & $\begin{array}{c}\text { Spot } \\
\text { patching }\end{array}$ & $\begin{array}{c}\text { Spot } \\
\text { patching }\end{array}$ \\
\hline 4 & $\begin{array}{l}\text { Shape of } \\
\text { Panel }\end{array}$ & $\begin{array}{c}\text { Post- } \\
\text { tensioned } \\
\text { panels }\end{array}$ & $\begin{array}{c}\text { Single } \\
\text { and } \\
\text { warped } \\
\text { panels } \\
\text { applied }\end{array}$ & $\begin{array}{l}\text { Single } \\
\text { panels } \\
\text { applied }\end{array}$ & $\begin{array}{l}\text { Single } \\
\text { panels } \\
\text { applied }\end{array}$ & $\begin{array}{l}\text { Cast in } \\
\text { place }\end{array}$ \\
\hline 5 & $\begin{array}{l}\text { Impact to } \\
\text { Traffic }\end{array}$ & Low & Low & Low & Low & Low \\
\hline 6 & $\begin{array}{l}\text { Patents } \\
\text { Restriction }\end{array}$ & No & Yes & Yes & No & No \\
\hline 7 & Durability & Yes & Yes & Yes & Yes & Yes \\
\hline 8 & $\begin{array}{l}\text { Availability } \\
\text { of } \\
\text { Information }\end{array}$ & Many & Many & Some & Few & Few \\
\hline 9 & $\begin{array}{l}\text { Load } \\
\text { Transfer } \\
\text { Device }\end{array}$ & $\begin{array}{l}\text { Dowel } \\
\text { bar and } \\
\text { tie bars }\end{array}$ & $\begin{array}{c}\text { Dowel } \\
\text { bars and } \\
\text { tie bars }\end{array}$ & $\begin{array}{l}\text { Composite } \\
\text { reinforced } \\
\text { resin } \\
\text { blades }\end{array}$ & $\begin{array}{c}\text { Dowel } \\
\text { bars }\end{array}$ & $\begin{array}{c}\text { Dowel } \\
\text { bars }\end{array}$ \\
\hline \multicolumn{7}{|c|}{$\begin{array}{l}\text { *In early 2003, Colorado DOT opened bidding on a project that } \\
\text { included the installation of } 143 \text { precast concrete panels using Stitch- } \\
\text { In-Time method with the total 22,870 } \mathrm{ft}^{2} \text { covered. At that time, the } \\
\text { lowest bid was } \$ 6,064.20 \text { per panel. }\end{array}$} \\
\hline
\end{tabular}




\section{Conclusion and Recommendation}

Overloaded traffic causes the deterioration of pavement on the US highways at a faster rate in recent years. To cope with this increased deterioration, highways are often closed for construction, repair and maintenance. The frequent closed lanes result in greater traffic congestion, delays, and user costs. The severity of the congestion is particularly intensified in urban and densely populated areas. Therefore, Precast Concrete Pavement (PCP) was developed to expedite the pavement construction and to lower the user impact costs.

JTRP undertakes this research is to assess the feasibility of adopting the PCP in Indiana highway construction. A comprehensive literature review was conducted on various state-of-theart methods in precast concrete pavement construction. The review revealed the precast prestressed concrete panels’ method was used in Texas; Super-Slab method in New York. Full Depth Repair method in Michigan; Stitch-in-Time method in Colorado; Four-by-Four Slab Replacement method in California are repairing methods. These methods were evaluated in terms of their design concepts, field installation procedures, merits, pitfalls, and costs.

Texas’ Precast Prestressed Concrete Panels and New York’s Super-Slab are developed for longer and continuous paving and the other three are for shorter and spot repairing. The shorter and spot patching methods practiced in several projects are successful. The further research may be preformed in the future. With SAC's advice, the Precast Concrete Panels and the Super-Slab were selected for further in-depth study. They were compared with conventional cast-in-place concrete pavement methods. Although the precast method has a higher construction cost (First Cost) and the industry is not familiar with this new method, 
precast concrete pavement method possesses many advantages. The speedy pace of the construction results in less traffic congestion and delays, and lowers the user costs significantly. In addition, the precasting is under better controlled environment which could lead to a more durable concrete and requires less maintenance.

Comparing Texas’ Precast Prestressed Concrete Panels method with New York’s Precast Super-Slab method, precast super slab is approximate half size of precast concrete panel. With its precision of Supergrader, the subbase is better prepared for warped slabs. Nevertheless, the Precast Prestressed Concrete Panels method applies pretension and post-tension on concrete which will result in thinner slab. Moreover, because the pretension and post-tension increase the concrete tensile strength and are able to tighten the cracks when they occur, this will lead to more durable concrete in the long run. The Precast Prestressed Concrete Panels method was derived from almost 20 years laboratory and roadway experiments on cast-in-place posttensioned method in Texas. The theories are sound and empirically proved. The detailed information and experimental data are well documented and accessible. This method holds no patents. Based on the data provided by Texas Center of Transportation Research and Fort Miller Company, the unit cost of Precast Concrete Panels is less. It can be reasonably predicted that the unit cost of precast concrete panels will be lowered if the constructed lane length is getting longer and the method can be repeatedly used. Moreover, in recognizing the potential benefits, Caltrans has adopted this method and experiments it at the intersection of I-10 and West 605 in Los Angeles district with the technical support from the Federal Highway Administration.

With all the above advantages and balanced considerations, it is recommended that the precast prestressed concrete panels method be experimented on an INDOT demonstration 
project. To minimize effects of traffic congestion on this stage, the site for demonstration project is suggested to be on a non-priority roadway. 


\section{REFERENCES}

1. HAPI Asphalt Pavement Guide- Hawaii Asphalt Paving industry website http://www.hawaiiasphalt.com/HAPI/modules/04_pavement_types/04_pavement_types.htm

2. Harold N. Atkins, Highway Materials, Soils and Concrete $4^{\text {th }}$ edition, Pretice Hall, 2003

3. Luh M. Chang, “Using precast concrete panel for pavement construction in Indian”, Not published, Project No. C-36-46X, File No. 5-11-24 SPR-2779, August, 2002

4. International Construction Vol. 42 No. 3 ”US\$ 375 billion required for roads” April 2003

5. PCI Handbook $5^{\text {th }}$ Edition, pp.1-3

6. William James Wilde, Steve Waalkes, and Rob Harrison. Life Cycle Cost Analysis of Portland Cement Concrete Pavements, Research Report 1739-1, Center for Transportation Research, The University of Texas at Austin, September 1999, pp. 65-95.

7. T. Y. Lin, and Ned H. Burns. Design of Prestressed Concrete Structures, $3^{\text {rd }}$ ed., John Wiley and Sons, Inc., 1981, pp. 1-30.

8. Neil D. Cable, B. F. McCullough, and N. H. Burns. New Concepts in Prestressed Concrete Pavement, Research Report 401-2, Center for Transportation Research, The University of Texas at Austin, December 1985, pp. 8,11

9. Luh M. Chang, Project PowerPoint Report December 20, 2002

10. David K. Merritt, B. Frank McCullough, and Ned H. Burns, “Texas Tests Precast for Speed and Usability”, US department of Transportation, Federal Highway Administration, July/August 2002, Vol.66, No.1, pp.1, 6, 7,

11. David K. Merritt, B. Frank McCullough, and Ned H. Burns, Paper No. 03-2726 ”Precast prestressed concrete pavement pilot project near Georgetown, Texas”, TRB 2003 Annual Meeting, pp.5, 6

12. David K. Merritt, B. Frank McCullough, and Ned H. Burns and Schindler, Anton K., “The Feasibility of Using Precast Concrete Panels to Expedite Highway Pavement Construction,” Research Report 1517-1, Center for Transportation Research, The University of Texas at Austin, February 2000, Draft Report, Pending for Final Approval. 
13. David K. Merritt, B. Frank McCullough, and Ned H. Burns, “Texas Tests Precast for Speed and Usability”, US department of Transportation, Federal Highway Administration, July/August 2002, Vol.66, No.1

14. Tom Kunnen, "Precast pavement panels prevail”, Concrete Products, May1, 2002

15. The Indiana department of Transportation "Construction and Design Reference Guide”ch52, Sep.2003

16. David K. Merritt, B. Frank McCullough, Ned H. Burns, Anton K. Schindler, Research Report Number 1517-1, “ The Feasibility of Using precast concrete panels to expedite highway pavement construction ”, CTR, University of Texas-Austin, February 2000

17. Design Memorandum No. 03-05 Technical advisory, Indiana Department of Transportation, Inter-department communication standard section -Room N642 Writer’s Direct Line 2326775, May 8, 2003 http://www.in.gov/dot/div/contracts/standards/memos/0305-ta.pdf

18. Fort Miller Co. (2003). “An Overview of the Super-Slab System” Powerpoint Slides Provided by Fort Miller Co., Inc.

19. “Innovative Precast Paving System for NYS Thruway Project.” PCI Journal, Sep/Oct 2002, p135.

20. J. Lepree,“Taking a Toll.” Precast Solutions, 2002, pp10 12.

21. Uretek USA. http://www.uretekusa.com/services/home.html. Accessed July 26, 2003.

22. Uretek. http://www.uretekworldwide.com/services/highwayrepairs4.htm. Accessed September 21, 2003.

23. “Colorado Uses Precast Concrete Panels for Interstate Highway Pavement Repair.” Public Works, August 2001, pp 32-36.

24. N. Buck, V. Barnhart, and R. Kowli “Pre-cast Concrete Slabs as Full Depth Repairs (FDR) - Michigan Experience.” 82nd Annual Meeting of the Transportation Research Board, Washington D. C., 2003

25. Caltrans "Slab Replacement Manual." Beta Version, California Department of Transportation., 2002

26. FHWA. “Full-Depth Repairs.” http://www.fhwa.dot.gov/pavement/full5.htm. Accessed October 20, 2003. 
27. Mohsen A. Issa, Alfred A. Yousif, Mahmoud A. Issa, Iraj I. Kaspar, and Salah Y. Khayyat. “Analysis of Full Depth Precast Concrete Bridge Deck Panels,” PCI Journal, JanuaryFebruary 1998, pp. 74-85.

28. David Merritt, B. Frank McCullough, and Ned H. Burns. Feasibility of Using Precast Concrete Panels to Expedite Construction on Portland Cement Concrete Pavements," Paper No. 01-2904, Transportation Research Board, $80^{\text {th }}$ Annual Meeting, January 7-11, 2001, Washington, D.C, Transportation Research Record 1761, pp. 3-9.

29. P.M. Jones “CBD-38 Bituminous Materials”, Institute for Research in Construction, February 1963 http://irc.nrc-cnrc.gc.ca/cbd/cbd038e.html

30. USEPA(U.S. Environmental Protection Agency), ,'Compilation of Air Pollutant Emission Factors", AP-42, $5^{\text {th }}$ Edition Volume 1: Stationary Point and Area Sources, ch4, January, 1995 http://www.epa.gov/ttn/chief/ap42/ch04/final/c4s05.pdf

31. USEPA(U.S. Environmental Protection Agency), Emission Inventory Improvement Program Document Volume3, ch17,April, 2001 http://www.epa.gov/ttn/chief/eiip/techreport/volume03/

32. NAPA(National Asphalt Pavement Association) "An Asphalt Plant in your community" http://www.hotmix.org/view_article.php?ID=68

33. NAPA(National Asphalt Pavement Association), "Asphalt Industry Update and Overview”, January, 2002 http://www.hotmix.org/view_article.php?ID=10

34. ACE (The asphalt contractor online), “Asphalt Facts” http://www.asphalt.com/facts.html

35. ACPC website http://www.pavement.com/PavTech/Tech/Fundamentals/fundtypes.html

36. FHWA-RD-98-148, "What makes Portland Cement Concrete Pavements rough" http://www.crsi.org/PDF/98-148.pdf

37. US DOT FHWA Public Road July/August 2002 "Paving the Way" http://www.tfhrc.gov/pubrds/02jul/05htm

38. Portland Cement Association, "Pavements" http://www.portcement.org/pv/index.asp

39. INDOT 2003 annual Report http://www.in.gov/dot/div/communications/2003annualreport/Maintenance_and_Winter_O perations.pdf 
40. INDOT January 2002 “Certified Technician program training manula for Concrete Paving” http://www.in.gov/dot/div/training /manuals/concrete, Access: May 27

41. INDOT Quick Facts 1998, http://www.in.gov/dot/pubs/facts.pdf , Access: May 27

42. TXDOT Expressway, Averge low bid unit price-construction-statewide, http://www.dot.state.tx.us/insdtdot/orgchart/cmd/cserve/bidprice/s_0306.htm, Access: June 3, 2004

43. David Merritt, E-mail interview Date:June $1^{\text {st }}, 2004$

44. Tommy E. Nantung, E-mail interview Date: May $17^{\text {th }}, 2004$ 